\title{
Literaturverzeichnis
}

\section{Ungedruckte Quellen}

Badische Landesbibliothek, Karlsruhe.

Sebastian Sailer: Creatio Adami ejusque in paradisum imissio productio Evae penatum et poena [um 1743]., Mus. Hs. 777.

Bundesarchiv (ehem. BDC).

Kartei Reichskulturkammer (RKK), Rommel, Otto, Dr., geb. 12.06.1880.

Zentrum für Populäre Kultur und Musik, Freiburg im Breisgau.

Briefe von Heinz Kindermann an John Meier, Briefe von John Meier an Heinz Kindermann.

Korrespondenz-Ordner 50 und 55.

\section{Gedruckte und digital verfügbare Quellen}

Adam (1996). Wolfgang Adam: Dichtung und Volkstum und erneuerter Euphorion. Überlegungen zur Namensänderung und Programmatik einer germanistischen Fachzeitschrift. In: Wilfried Barner und Christoph König (Hg.): Zeitenwechsel. Germanistische Literaturwissenschaft vor und nach 1945. Frankfurt am Main 1996, S. 60-75.

ADB. Allgemeine Deutsche Biographie. Auf Veranlassung und mit Unterstützung Seiner Majestaet des Königs von Bayern Maximilian Il., hg. durch die historische Commission bei der König[[ichen] Akademie der Wissenschaften. 56 Bände. Leipzig 1875-1912.

Adelung (1793-1801). Johann Christoph Adelung: Grammatisch-kritisches Wörterbuch der Hochdeutschen Mundart, mit beständiger Vergleichung der übrigen Mundarten, besonders aber der Oberdeutschen. Zweyte vermehrte und verbesserte Ausgabe. Leipzig 1793-1801.

Adler (2009). Hans Adler: Herder's Concept of Humanität. In: Hans Adler und Wulf Koepke (Hg.): A Companion to the Works of Johann Gottfried Herder. Rochester, NY 2009 (Studies in German Literature, Linguistics, and Culture), S. 93-116.

Adler und Koepke (2009). Hans Adler und Wulf Koepke (Hg.): A Companion to the Works of Johann Gottfried Herder. Rochester, NY 2009 (Studies in German Literature, Linguistics, and Culture).

Adorno (1996a). Theodor W. Adorno: Gesammelte Schriften. Band 11: Noten zur Literatur. Unter Mitwirkung von Gretel Adorno, Susan Buck-Morss und Klaus Schultz. Hg. von Rolf Tiedemann. 4. Aufl. Frankfurt am Main 1996.

Adorno (1996b). Theodor W. Adorno: Reflexion über das Volksstück [1965]. In: Theodor W. Adorno: Gesammelte Schriften. Band 11: Noten zur Literatur. Unter Mitwirkung von Gretel Adorno, Susan Buck-Morss und Klaus Schultz. Hg. von Rolf Tiedemann. 4. Aufl. Frankfurt am Main 1996, S. 693-694.

Agard, Helmreich und Vinckel-Roisin (2011). Olivier Agard, Christian Helmreich und Hélène VinckelRoisin (Hg.): Das Populäre. Untersuchungen zu Interaktionen und Differenzierungsstrategien in Literatur, Kultur und Sprache. Göttingen 2011.

Ajouri (2013). Philip Ajouri: Probleme der Empirisierung einer Gattung. Zum Erwartungshorizont und der sozialen Funktion des politischen Romans im 18. Jahrhundert. In: Philip Ajouri, Katja Mellmann und Christoph Rauen (Hg.): Empirie in der Literaturwissenschaft. Münster 2013 (Poetogenesis, Bd. 8), S. 283-305.

Albrecht (2005). Andrea Albrecht: Kosmopolitismus. Weltbürgerdiskurse in Literatur, Philosophie und Publizistik um 1800. (Zugl. phil. Diss., Univ. Göttingen 2003). Berlin, New York 2005 (Spectrum Literaturwissenschaft, Bd. 1). 
Alexy, Karasek und Lanz (1984a). J. Eduard Alexy, Alfred Karasek und Josef Lanz: Das deutsche Volksschauspiel in Böhmen, Mähren und der Slowakei. Teil 1: Erbe, Verpflanzung, Erneuerung. Marburg 1984 (Schriftenreihe der Kommission für Ostdeutsche Volkskunde in der Deutschen Gesellschaft für Volkskunde e.V., Bd. 30).

Alexy, Karasek und Lanz (1984b). J. Eduard Alexy, Alfred Karasek und Josef Lanz: Das deutsche Volksschauspiel in Böhmen, Mähren und der Slowakei. Teil 2: Tradition und Wandel. Marburg 1984 (Schriftenreihe der Kommission für Ostdeutsche Volkskunde in der Deutschen Gesellschaft für Volkskunde e.V., Bd. 31).

Alexy, Karasek und Lanz (1986). J. Eduard Alexy, Alfred Karasek und Josef Lanz: Das deutsche Volksschauspiel in Böhmen, Mähren und der Slowakei. Teil 3: Kontakt und Ausstrahlung (Slowakei und Karpatenukraine). Marburg 1986 (Schriftenreihe der Kommission für Ostdeutsche Volkskunde in der Deutschen Gesellschaft für Volkskunde e.V., Bd. 36).

Alxinger, Musäus und Müller von Itzehoe ([1888]). [Johann Baptist von] Alxinger, [Johann Karl August] Musäus und Müller von Itzehoe: Alxinger, Musäus, Müller von Itzehoe. In einer Auswahl aus ihren Werken, im Anschluß an Wielands Werke. Hg. von Heinrich Pröhle. Berlin, Stuttgart [1888] (Deutsche National-Litteratur, historisch kritische Ausgabe, Bd. 57).

Ammann (1898-1900). Johann Josef Ammann: Volksschauspiele aus dem Böhmerwalde. Gesammelt, wissenschaftlich untersucht und herausgegeben. 3 Teile. Prag 1898-1900 (Beiträge zur deutsch-böhmischen Volkskunde, Bd. 2).

Anderson (2006). Benedict Anderson: Imagined Communities. Reflections on the Origin and Spread of Nationalism. London 2006 [1983].

Annuß (2005). Evelyn Annuß: Elfriede Jelinek. Theater des Nachlebens. München 2005.

Annuß (2019). Evelyn Annuß: Volksschule des Theaters. Nationalsozialistische Massenspiele. (Zugl. Habil., Univ. Bochum 2015). Paderborn 2019.

[Anonymus] (1794). [Anonymus]: Tyroler Bauernkomödien. Aus dem Reisejournal eines Hannoveraners, July 1793. In: Neues Hannöverisches Magazin 4 (1794), Sp. 523-534.

[Anonymus] (1826). [Anonymus]: Bemerkungen eines gebornen Oetzthalers über den Aufsatz: „Etwas über das Oetzthal, und besonders über die dortige Mährchen-Poesie“. In: Bothe von und für Tirol und Vorarlberg vom 5.1.1826, S. 8.

[Anonymus] (1854). [Anonymus]: Schuldramen in den Piaristenschulen im 17. und 18. Jahrhundert. In: Programm und Jahres-Bericht des kaiserl. königl. Gymnasiums in Krems (1854), S. 3-12.

[Anonymus] ([1943]). [Anonymus]: Das Volksspiel im Nationalsozialistischen Gemeinschaftsleben. Hg. vom Hauptkulturamt in der Reichspropagandaleitung der NSDAP. München [1943].

[Anonymus] (1948). [Anonymus]: Überprüfung der dörflichen Bühnen und Spielgemeinschaften. In: Bote für Tirol 129 (1948), H. 47, S. 4.

Anzengruber (1890). Ludwig Anzengruber: Gesammelte Werke in zehn Bänden. Hg. von Anton Bettelheim, Vincenz Chiavacci und V[iktor] K. Schembera. Stuttgart 1890.

Anzengruber ([1898]). Ludwig Anzengruber: Gesammelte Werke in zehn Bänden. Hg. von Anton Bettelheim, Vincenz Chiavacci und Karl Gründorf. 3., durchgesehene Aufl. Stuttgart, Berlin [1898].

Anzengruber ([1898a]). Ludwig Anzengruber: 's Jungferngift. Bauernkomödie mit Gesang in fünf Abteilungen. (Februar 1878). In: Ludwig Anzengruber: Gesammelte Werke in zehn Bänden. Achter Band. Hg. von Anton Bettelheim, Vincenz Chiavacci und Karl Gründorf. 3., durchgesehene Aufl. Stuttgart, Berlin [1898], S. 3-116.

Anzengruber ([1898b]). Ludwig Anzengruber: Der G'wissenswurm. Bauernkomödie mit Gesang in drei Akten. (2. bis 16. April 1874). In: Ludwig Anzengruber: Gesammelte Werke in zehn Bänden. Siebenter Band. Hg. von Anton Bettelheim, Vincenz Chiavacci und Karl Gründorf. 3., durchgesehene Aufl. Stuttgart, Berlin [1898], S. 1-88. 
Anzengruber ([1898c]). Ludwig Anzengruber: Die Kreuzelschreiber. Bauernkomödie mit Gesang in drei Akten. (6. April bis 3. Juni 1872). In: Ludwig Anzengruber: Gesammelte Werke in zehn Bänden. Sechster Band. Hg. von Anton Bettelheim, Vincenz Chiavacci und Karl Gründorf. 3. durchgesehene Aufl. Stuttgart, Berlin [1898], S. 203-298.

Anzengruber ([1898d]). Ludwig Anzengruber: Die Trutzige. Bauernkomödie mit Gesang in drei Akten. (Juni bis 3. Juli 1878). In: Ludwig Anzengruber: Gesammelte Werke in zehn Bänden. Achter Band. Hg. von Anton Bettelheim, Vincenz Chiavacci und Karl Gründorf. 3., durchgesehene Aufl. Stuttgart, Berlin [1898], S. 229-335.

Anzengruber ([1898e]). Ludwig Anzengruber: Doppelselbstmord. Bauernposse mit Gesang in drei Akten. (28. November 1874 bis 26. Januar 1875). In: Ludwig Anzengruber: Gesammelte Werke in zehn Bänden. Siebenter Band. Hg. von Anton Bettelheim, Vincenz Chiavacci und Karl Gründorf. 3., durchgesehene Aufl. Stuttgart, Berlin [1898], S. 89-196.

Anzengruber (1920-1928). Ludwig Anzengruber: Sämtliche Werke. Kritisch durchgesehene Gesamtausgabe in 15 Bänden. Unter Mitwirkung von Karl Anzengruber. Hg. von Rudolf Latzke und Otto Rommel. Wien 1920-1928.

Apel (2001). Friedmar Apel: Goethe und die Seinigen. Vom Glück des Sammlers und der Lehre dazu. In: Gisela Ecker, Martina Stange und Ulrike Vedder (Hg.): Sammeln, Ausstellen, Wegwerfen. Königstein/Taunus 2001 (Kulturgeschichtliche Gender Studies, Bd. 2), S. 109-123.

Apel (2006). Friedmar Apel: Gemeinschaft aus dem Elementaren. Hugo von Hofmannsthal und Josef Nadler. In: Wolfgang Braungart und Kai Kauffmann (Hg.): Essayismus um 1900. Heidelberg 2006 (Beihefte zum Euphorion, Bd. 50), S. 213-221.

Arnim (1990). Achim von Arnim: Die Versöhnung in der Sommerfrische. In: Achim von Arnim: Werke in sechs Bänden. Band 3: Sämtliche Erzählungen 1802-1827. Hg. von Renate Moering. Frankfurt am Main 1990, S. 541-609.

Arnim und Brentano (1806). Achim von Arnim und Clemens Brentano: Des Knaben Wunderhorn. Alte deutsche Lieder. Heidelberg, Frankfurt am Main 1806.

Arnim und Brentano (1808a). Achim von Arnim und Clemens Brentano: Des Knaben Wunderhorn. Alte deutsche Lieder. Zweyter Band. Heidelberg 1808.

Arnim und Brentano (1808b). Achim von Arnim und Clemens Brentano: Des Knaben Wunderhorn. Alte deutsche Lieder. Dritter Band. Heidelberg 1808.

Asper (1975). Helmut G. Asper: Spieltexte der Wanderbühne. Ein Verzeichnis der Dramenmanuskripte des 17. und 18. Jahrhunderts in Wiener Bibliotheken. Wien 1975 (Quellen zur Theatergeschichte, Bd. 1).

Asper (1980). Helmut G. Asper: Hanswurst. Studien zum Lustigmacher auf der Berufsschauspielerbühne in Deutschland im 17. und 18. Jahrhundert. Emsdetten 1980.

Assmann (2018). Aleida Assmann: Der europäische Traum. Vier Lehren aus der Geschichte. München 2018.

Auerbach (1846). Berthold Auerbach: Schrift und Volk. Grundzüge der volksthümlichen Literatur, angeschlossen an eine Charakteristik J. P. Hebel's. Leipzig 1846.

Aurnhammer (2003). Achim Aurnhammer: Bolte, Johannes Friedrich Rudolf. In: IGL, S. 228-231.

Aust, Haida und Hein (1989). Hugo Aust, Peter Haida und Jürgen Hein: Volksstück. Vom Hanswurstspiel zum sozialen Drama der Gegenwart. München 1989.

Ayrenhoff (1789). Cornelius von Ayrenhoff: Sämmtliche Werke. Vierter Band. Wien, Leipzig 1789.

[Babo] (1782). [Joseph Marius von Babo]: Otto von Wittelsbach, Pfalzgraf in Bayern. Ein vaterländisches Trauerspiel in fünf Aufzügen. Berlin, Leipzig 1782.

Bachleitner (2010). Norbert Bachleitner: Die Theaterzensur in der Habsburgmonarchie im 19. Jahrhundert. In: Zeitschrift für Literatur- und Theatersoziologie (LiTheS) 5 (2010), S. 71-105. http://lithes.uni-graz.at/lithes/10_05.html (22.6.2019). 
Badenfeld (1825a). Eduard von Badenfeld: Etwas über das Oetzthal in Tyrol, und insbesondere über die dortige Mährchen-Poesie. In: Archiv für Geschichte, Statistik, Literatur und Kunst 16 (1825), H. 107/108, S. 651-657.

Badenfeld (1825b). Eduard von Badenfeld: Etwas über das Oetzthal in Tyrol, und insbesondere über die dortige Mährchen-Poesie (Fortsetzung). In: Archiv für Geschichte, Statistik, Literatur und Kunst 16 (1825), H. 109, S. 662-665.

Badenfeld (1825c). Eduard von Badenfeld: Etwas über das Oetzthal in Tyrol, und insbesondere über die dortige Mährchen-Poesie (Beschluß). In: Archiv für Geschichte, Statistik, Literatur und Kunst 16 (1825), H. 110/111, S. 671-672.

Balme (1985). Christopher B. Balme: The Reformation of Comedy. Genre Critique in the Comedies of Ödön von Horváth. Dunedin 1985 (Otago German studies, Bd. 3).

Balme (2009). Christopher Balme: Relektüre Carl Niessen: Handbuch der Theater-Wissenschaft. In: Forum Modernes Theater 24 (2009), H. 2, S. 183-189.

Barner (2006). Wilfried Barner (Hg.): Geschichte der deutschen Literatur von 1945 bis zur Gegenwart. 2., aktualisierte und erweiterte Aufl. München 2006.

Barner und König (1996). Wilfried Barner und Christoph König (Hg.): Zeitenwechsel. Germanistische Literaturwissenschaft vor und nach 1945. Frankfurt am Main 1996.

Bartsch (1879). Karl Bartsch: Ein Ritterschauspiel in Tirol. In: Die Gegenwart. Wochenschrift für Literatur, Kunst und öffentliches Leben 16 (1879), H. 35, S. 135-137.

Bauer (1977). Roger Bauer: Die Komödientheorie von Jakob Michael Reinhold Lenz, die älteren Plautus-Kommentare und das Problem der „dritten“ Gattung. In: Stanley A. Corngold, Michael Curschmann und Theodore Ziolkowski (Hg.): Aspekte der Goethezeit. Göttingen 1977, S. 11-37. Bauman (2017). Zygmunt Bauman: Retrotopia. Cambridge 2017.

Baur und Gradwohl-Schlacher (2008). Uwe Baur und Karin Gradwohl-Schlacher: Literatur in Österreich 1938-1945. Handbuch eines literarischen Systems. Band I: Steiermark. Wien, Köln, Weimar 2008.

Bausinger (1952). Hermann Bausinger: Lebendiges Erzählen. Studien über das Leben volkstümlichen Erzählgutes auf Grund von Untersuchungen im nordöstlichen Württemberg. Maschinenschriftl. Diss., Universität Tübingen 1952.

Bausinger (1959). Hermann Bausinger (Hg.): Schwäbische Weihnachtsspiele. Mit Beiträgen von Willi Müller, Josef Lanz und Wilhelm Kutter. Stuttgart 1959 (Schwäbische Volkskunde, N.F., Bd. 13).

Bausinger (1968). Hermann Bausinger: Formen der „Volkspoesie“. Berlin 1968 (Grundlagen der Germanistik, Bd. 6).

Bausinger (1980). Hermann Bausinger: Formen der „Volkspoesie“. 2., verbesserte und vermehrte Aufl. Berlin 1980 [1968] (Grundlagen der Germanistik, Bd. 6).

Bausinger (1987). Hermann Bausinger: Bürgerlichkeit und Kultur. In: Jürgen Kocka (Hg.): Bürger und Bürgerlichkeit im 19. Jahrhundert. Göttingen 1987 (Sammlung Vandenhoeck), S. 121-142.

Bausinger (2014). Hermann Bausinger: Volksdichtung. In: Rolf Wilhelm Brednich (Hg.): Enzyklopädie des Märchens. Handwörterbuch zur historischen und vergleichenden Erzählforschung. Begründet von Kurt Ranke. Bd. 14. Berlin, Boston 2014, Sp. 324-328.

Bausinger und Brückner (1969). Hermann Bausinger und Wolfgang Brückner (Hg.): Kontinuität? Geschichtlichkeit und Dauer als volkskundliches Problem. Hans Moser zum 65. Geburtstag gewidmet. Berlin 1969.

Bechstein (1854-1855). Ludwig Bechstein: Mythe, Sage, Märe und Fabel im Leben und Bewußtsein des deutschen Volkes. 3 Theile. Leipzig 1854-1855 (Das deutsche Volk dargestellt in Vergangenheit und Gegenwart zur Begründung der Zukunft, Bd. 14-16).

Becker (1787). Rudolf Zacharias Becker: [Ohne Titel]. In: Siegmund von Bibra (Hg.): Journal von und für Deutschland. Vierter Jahrgang, eilftes Stück 1787, S. 426-430. 
[Becker] (1788). [Rudolf Zacharias Becker]: Noth- und Hülfs-Büchlein für Bauersleute. [0]der lehrreiche Freuden- und Trauer-Geschichte des Dorfs Mildheim. Für Junge und Alte beschrieben. [1. Teil]. Gotha, Leipzig 1788.

Becker (1799a). Rudolf Zacharias Becker: Mildheimisches Lieder-Buch von 518 lustigen und ernsthaften Gesängen über alle Dinge in der Welt und alle Umstände des menschlichen Lebens, die man besingen kann. Gesammelt für Freunde erlaubter Fröhlichkeit und ächter Tugend, die den Kopf nicht hängt. Gotha 1799.

[Becker] (1799b). [Rudolf Zacharias Becker]: Noth- und Hülfsbüchlein oder lehrreiche Freuden- und Trauergeschichte der Einwohner zu Mildheim. Für katholische Leser eingerichtet von Placidus Muth, Obrer des Ordens des heil. Benedict auf dem St. Peterberge zu Erfurt. Mit Churfürstl. Pfalzbaierischer höchster Genehmigung und Freyheit. Anderer Theil. Gotha, Amberg, Sulzbach 1799.

Beer (1994). Johann Beer: Teutsche Winter-Nächte [1682]. Hg. von Ferdinand van Ingen und HansGert Roloff. Bern 1994 (Mittlere deutsche Literatur in Neu- und Nachdrucken, Bd. 7).

Beer (2000). Johann Beer: Die kurtzweiligen Sommer-Täge [1683]. Hg. von Ferdinand van Ingen und Hans-Gert Roloff. Bern 2000 (Mittlere deutsche Literatur in Neu- und Nachdrucken, Bd. 8).

Bein (2000). Thomas Bein: Die mediävistische Edition und ihre Methoden. In: Rüdiger Nutt-Kofoth, Bodo Plachta, H.T.M. van Vliet und Hermann Zwerschina (Hg.): Text und Edition. Positionen und Perspektiven. Berlin 2000, S. 81-98.

Bein (2011). Thomas Bein: Karl Lachmann. Ethos und Ideologie der frühen Editionswissenschaft. In: Roland S. Kamzelak, Rüdiger Nutt-Kofoth und Bodo Plachta (Hg.): Neugermanistische Editoren im Wissenschaftskontext. Biografische, institutionelle, intellektuelle Rahmen in der Geschichte wissenschaftlicher Ausgaben neuerer deutschsprachiger Autoren. Berlin, Boston 2011 (Bausteine zur Geschichte der Edition, Bd. 3), S. 1-15.

Beise (2010). Arnd Beise: Geschichte, Politik und das Volk im Drama des 16. bis 18. Jahrhunderts. (Zugl. Habil., Univ. Marburg 2007). Berlin, New York 2010 (Hallesche Beiträge zur Europäischen Aufklärung, Bd. 40).

Benjamin (1974). Walter Benjamin: Ursprung des deutschen Trauerspiels. In: Walter Benjamin: Gesammelte Schriften I, 1. Hg. von Rolf Tiedemann und Hermann Schweppenhäuser. Frankfurt am Main 1974, S. 203-430.

Benyovszky (1934). Karl Benyovszky: Die Oberuferer Weihnachtsspiele. Mit einer Kostümtafel und einem Anhang der Singweisen, gesammelt und aufgezeichnet von Ludwig Rajter jun. Preßburg 1934.

Berger, Döhl und Morsch (2015). Hanno Berger, Frédéric Döhl und Thomas Morsch (Hg.): Prekäre Genres. Zur Ästhetik peripherer, apokrypher und liminaler Gattungen. Bielefeld 2015 (Edition Kulturwissenschaft, Bd. 56).

Bernhard (2010a). Thomas Bernhard: Der deutsche Mittagstisch. Dramolette. In: Thomas Bernhard: Werke. Band 17: Dramen III. Hg. von Martin Huber und Bernhard Judex. Berlin 2010, S. 265355.

Bernhard (2010b). Thomas Bernhard: Werke. Band 17: Dramen III. Hg. von Martin Huber und Bernhard Judex. Berlin 2010.

Bernhart (2007a). Toni Bernhart: Adolf Pichler und Alexander von Humboldt. Drei Briefe. In: Georg Mühlberger und Mercedes Blaas (Hg.): Grafschaft Tirol - Terra Venusta. Studien zur Geschichte Tirols, insbesondere des Vinschgaus. In Würdigung der Kulturarbeit von Marjan Cescutti. Innsbruck 2007 (Schlern-Schriften, Bd. 337), S. 383-391.

Bernhart (2007b). Toni Bernhart: Die neuere Forschung zu Goethes Ästhetik und Kunsttheorie. In: Bernd Hamacher und Rüdiger Nutt-Kofoth (Hg.): Johann Wolfgang Goethe. Neue Wege der Forschung. Band 2: Romane und theoretische Schriften. Darmstadt 2007, S. 164-189. 
Bernhart (2012). Toni Bernhart: Das implizite Publikum im Laaser Spiel vom Eigenen Gericht (vor 1805). In: Hermann Korte und Hans-Joachim Jakob (Hg.): „Das Theater glich einem Irrenhause“. Das Publikum im Theater des 18. und 19. Jahrhunderts. Heidelberg 2012 (Proszenium, Bd. 1), S. 179-191.

Bernhart (2017a). Toni Bernhart: Griseldis (1713). Ein Neufund aus dem Stiftsarchiv Marienberg und die Geschichte des Schultheaters am Benediktinergymnasium Meran. In: Nestroyana 37 (2017), H. 3/4, S. 175-187.

Bernhart (2017b). Toni Bernhart: Imagining the Audience in Eighteenth-Century Folk Theatre in Tyrol. In: Katja Gvozdeva, Tatiana Korneeva und Kirill Ospovat (Hg.): Dramatic Experience. The Poetics of Drama and the Early Modern Public Sphere(s). Leiden, Boston 2017 (Drama and Theatre in Early Modern Europe, Bd. 6), S. 269-288.

Bernhart (2019). Toni Bernhart: Volksstück und fünfziger Jahre. Eine vorläufige Exploration. In: treibhaus 14/15 (2019), S. 179-205.

Bernhart, Drnovšek, Kilian, Küpper und Mosch (2018). Toni Bernhart, Jaša Drnovšek, Sven Thorsten Kilian, Joachim Küpper und Jan Mosch (Hg.): Poetics and Politics. Net Structures and Agencies in Early Modern Drama. Berlin 2018.

Bernhart und Janke (2019). Toni Bernhart und Janina Janke: The Crystallization of Early Modern European Drama in the Folk-Theater Tradition in Tyrol. The Marienberg Griseldis from 1713, Staged in 2016. In: Joachim Küpper, Jan Mosch und Elena Penskaya (Hg.): History and Drama. The Pan-European Tradition. Berlin 2019, S. 147-159.

Bernstengel und Rebehn (2007). Olaf Bernstengel und Lars Rebehn (Hg.): Volkstheater an Fäden. Vom Massenmedium zum musealen Objekt - sächsisches Marionettentheater im 20. Jahrhundert. Halle (Saale) 2007 (Reihe Weiß-Grün, Sächsische Geschichte und Volkskultur, Bd. 36).

Bertsch und Grave (2005). Markus Bertsch und Johannes Grave (Hg.): Räume der Kunst. Blicke auf Goethes Sammlungen. In Verbindung mit der Stiftung Weimarer Klassik und Kunstsammlungen. Göttingen 2005 (Ästhetik um 1800, Bd. 3).

Bettelheim (1892). Anton Bettelheim: Die Zukunft unseres Volkstheaters. Zehn Aufsätze aus den Jahren 1882-1892. Berlin 1892.

Bettelheim ([1926]). Anton Bettelheim: Karl Schönherr und das österreichische Volksstück. Wien, Leipzig [1926] (Österreichische Bücherei, Bd. 24).

Beutner (2012). Eduard Beutner: Von Wien nach München. Volksstück und Volkstheater in Österreich und Bayern in der zweiten Hälfte des 19. Jahrhunderts. In: Österreich in Geschichte und Literatur 56 (2012), H. 4, S. 402-411.

Biccari (2001). Gaetano Biccari: „Zuflucht des Geistes“? Konservativ-revolutionäre, faschistische und nationalsozialistische Theaterdiskurse in Deutschland und Italien 1900-1944. Tübingen 2001 (Forum Modernes Theater, Bd. 28).

Bidmon (2014). Lothar Bidmon: Sebastian Sailer. Ein bibliographischer Versuch. Weißenhorn 2014.

Bies, Gamper und Kleeberg (2013a). Michael Bies, Michael Gamper und Ingrid Kleeberg: Einleitung. In: Michael Bies, Michael Gamper und Ingrid Kleeberg (Hg.): Gattungs-Wissen. Wissenspoetologie und literarische Form. Göttingen 2013, S. 7-18.

Bies, Gamper und Kleeberg (2013b). Michael Bies, Michael Gamper und Ingrid Kleeberg (Hg.): Gattungs-Wissen. Wissenspoetologie und literarische Form. Göttingen 2013.

Blitz (2000). Hans-Martin Blitz: Aus Liebe zum Vaterland. Die deutsche Nation im 18. Jahrhundert. (Zugl. phil. Diss., Univ. Freiburg im Breisgau 2000, u.d.T.: Konstruktionen des Nationalen). Hamburg 2000.

Blum, Herloßsohn und Marggraff (1841). R[obert] Blum, K[arl] Herloßsohn und H[ermann] Marggraff: Allgemeines Theater-Lexikon oder Encyklopädie alles Wissenswerthen für Bühnenkünstler, Dilettanten und Theaterfreunde unter Mitwirkung der sachkundigsten Schriftsteller Deutschlands. Fünfter Band. Mit 1 lithographirten Zeichnung. Altenburg, Leipzig 1841. 
Blum, Herloßsohn und Marggraff (1842). R[obert] Blum, K[arl] Herloßsohn und H[ermann] Marggraff: Allgemeines Theater-Lexikon oder Encyklopädie alles Wissenswerthen für Bühnenkünstler, Dilettanten und Theaterfreunde unter Mitwirkung der sachkundigsten Schriftsteller Deutschlands. Siebenter Band. Mit 1 lithographirten Zeichnung. Altenburg, Leipzig 1842.

Blum, Herloßsohn und Marggraff (1846a). R[obert] Blum, K[arl] Herloßsohn und H[ermann] Marggraff: Allgemeines Theater-Lexikon oder Encyklopädie alles Wissenswerthen für Bühnenkünstler, Dilettanten und Theaterfreunde unter Mitwirkung der sachkundigsten Schriftsteller Deutschlands. Fünfter Band. Mit 1 lithographirten Zeichnung. Neue Ausgabe. Altenburg, Leipzig 1846.

Blum, Herloßsohn und Marggraff (1846b). R[obert] Blum, K[arl] Herloßsohn und H[ermann] Marggraff: Allgemeines Theater-Lexikon oder Encyklopädie alles Wissenswerthen für Bühnenkünstler, Dilettanten und Theaterfreunde unter Mitwirkung der sachkundigsten Schriftsteller Deutschlands. Siebenter Band. Mit 1 lithographirten Zeichnung. Neue Ausgabe. Altenburg, Leipzig 1846.

Blumenbach (1779). Johann Friedrich Blumenbach: Handbuch der Naturgeschichte. Mit Kupfern. Göttingen 1779.

Blumenbach (1791). Johann Friedrich Blumenbach: Handbuch der Naturgeschichte. Mit Kupfern. 4., sehr verbesserte Aufl. Göttingen 1791.

Blumenbach (1797). Johann Friedrich Blumenbach: Handbuch der Naturgeschichte. Nebst zwey Kupfertafeln. 5. Aufl. Göttingen 1797.

Blümml und Gugitz (1925). Emil Karl Blümml und Gustav Gugitz: Alt-Wiener Thespiskarren. Die Frühzeit der Wiener Vorstadtbühnen. Wien 1925.

Boden (2003). Petra Boden: Stamm - Geist - Gesellschaft. Deutsche Literaturwissenschaft auf der Suche nach einer integrativen Theorie. In: Holger Dainat und Lutz Danneberg (Hg.): Literaturwissenschaft und Nationalsozialismus. Tübingen 2003 (Studien und Texte zur Sozialgeschichte der Literatur, Bd. 99), S. 215-261.

Bohnenkamp, Kaluga und Krabiel (2011a). Klaus E. Bohnenkamp, Katja Kaluga und Klaus-Dieter Krabiel: Varianten und Erläuterungen [zu „Deutsche Festspiele in Salzburg“]. In: Hugo von Hofmannsthal: Sämtliche Werke XXXIV. Reden und Aufsätze, Band 3. Hg. von Klaus E. Bohnenkamp, Katja Kaluga und Klaus-Dieter Krabiel. Frankfurt am Main 2011, S. 1036-1047.

Bohnenkamp, Kaluga und Krabiel (2011b). Klaus E. Bohnenkamp, Katja Kaluga und Klaus-Dieter Krabiel: Varianten und Erläuterungen [zu „Die Salzburger Festspiele“]. In: Hugo von Hofmannsthal: Sämtliche Werke XXXIV. Reden und Aufsätze, Band 3. Hg. von Klaus E. Bohnenkamp, Katja Kaluga und Klaus-Dieter Krabiel. Frankfurt am Main 2011, S. 1048-1052.

Bohnenkamp, Kaluga und Krabiel (2011c). Klaus E. Bohnenkamp, Katja Kaluga und Klaus-Dieter Krabiel: Varianten und Erläuterungen [zu „Jedermann. Vorwort“]. In: Hugo von Hofmannsthal: Sämtliche Werke XXXIV. Reden und Aufsätze, Band 3. Hg. von Klaus E. Bohnenkamp, Katja Kaluga und Klaus-Dieter Krabiel. Frankfurt am Main 2011, S. 395-398.

Bolte (1884). Johannes Bolte: Ein Spandauer Weihnachtspiel. 1549. In: Märkische Forschungen 18 (1884), S. 109-222.

Bolte (1926). Johannes Bolte (Hg.): Drei märkische Weihnachtsspiele des 16. Jahrhunderts. 1. Heinrich Knaust 1541, 2. Christoph Lasius 1549, 3. Berliner Anonymus 1589 nebst einem süddeutschen Spiel von 1693. Berlin 1926.

Boock (2007). Barbara Boock: Kinderliederbücher 1770-2000. Eine annotierte, illustrierte Bibliografie der deutschsprachigen Kinderliederbücher im Deutschen Volksliedarchiv. Mit einem Essay von Günther Noll. Münster u.a. 2007 (Volksliedstudien, Bd. 8).

Braumüller (1935). Wolf Braumüller: Freilicht- und Thingspiel. Rückschau und Forderungen. Berlin 1935 (Schriften zum deutschen Volksspiel, Bd. 1). 
Brauneck und Noe (1970-2007). Manfred Brauneck und Alfred Noe (Hg.): Spieltexte der Wanderbühne. 6 Bände. Berlin, New York 1970-2007 (Ausgaben deutscher Literatur des XV. bis XVIII. Jahrhunderts).

Brecht (1951). Bertolt Brecht: Herr Puntila und sein Knecht Matti. In: Bertolt Brecht: Versuche 22/23/24. Heft 10. Berlin 1951, S. 5-114.

Brecht (1965). Bertolt Brecht: Gedichte VIII: Nachträge zu den Gedichten 1913-1956. [Frankfurt am Main] 1965.

Brecht (1989a). Bertolt Brecht: Herr Puntila und sein Knecht Matti. In: Bertolt Brecht: Stücke 6. Bearbeitet von Klaus-Detlef Müller. Berlin, Weimar, Frankfurt am Main 1989 (Werke, Bd. 6), S. 283-374.

Brecht (1989b). Bertolt Brecht: Stücke 6. Bearbeitet von Klaus-Detlef Müller. Berlin, Weimar, Frankfurt am Main 1989 (Werke, Bd. 6).

Brecht (1991a). Bertolt Brecht: Anmerkungen zum Volksstück. In: Bertolt Brecht: Schriften 4: Texte zu Stücken. Bearbeitet von Peter Kraft unter Mitarbeit von Marianne Conrad, Sigmar Gerund und Benno Slupianek. Berlin, Weimar, Frankfurt am Main 1991 (Werke, Bd. 24), S. 293-299.

Brecht (1991b). Bertolt Brecht: Schriften 4: Texte zu Stücken. Bearbeitet von Peter Kraft unter Mitarbeit von Marianne Conrad, Sigmar Gerund und Benno Slupianek. Berlin, Weimar, Frankfurt am Main 1991 (Werke, Bd. 24).

Brecht (1993). Bertolt Brecht: Schriften 2, Teil 1. Bearbeitet von Inge Gellert und Werner Hecht unter Mitarbeit von Marianne Conrad, Sigmar Gerund und Benno Slupianek. Berlin, Weimar, Frankfurt am Main 1993 (Werke, Bd. 22).

Brecht (1993a). Bertolt Brecht: Das Volkstümliche. In: Bertolt Brecht: Schriften 2, Teil 1. Bearbeitet von Inge Gellert und Werner Hecht unter Mitarbeit von Marianne Conrad, Sigmar Gerund und Benno Slupianek. Berlin, Weimar, Frankfurt am Main 1993 (Werke, Bd. 22), S. 417.

Brecht (1993b). Bertolt Brecht: Volkstümliche Literatur. In: Bertolt Brecht: Schriften 2, Teil 1. Bearbeitet von Inge Gellert und Werner Hecht unter Mitarbeit von Marianne Conrad, Sigmar Gerund und Benno Slupianek. Berlin, Weimar, Frankfurt am Main 1993 (Werke, Bd. 22), S. 415-416.

Brecht (1993c). Bertolt Brecht: Volkstümlichkeit und Realismus [1]. In: Bertolt Brecht: Schriften 2, Teil 1. Bearbeitet von Inge Gellert und Werner Hecht unter Mitarbeit von Marianne Conrad, Sigmar Gerund und Benno Slupianek. Berlin, Weimar, Frankfurt am Main 1993 (Werke, Bd. 22), S. 405-413.

Brecht (1993d). Bertolt Brecht: Volkstümlichkeit und Realismus [2]. In: Bertolt Brecht: Schriften 2, Teil 1. Bearbeitet von Inge Gellert und Werner Hecht unter Mitarbeit von Marianne Conrad, Sigmar Gerund und Benno Slupianek. Berlin, Weimar, Frankfurt am Main 1993 (Werke, Bd. 22), S. 413-415.

Brecht (1997). Bertolt Brecht: Der Salzburger Totentanz. In: Bertolt Brecht: Stücke 10: Stückfragmente und Stückprojekte, Teil 2. Bearbeitet von Günter Glaeser. Berlin, Weimar, Frankfurt am Main 1997 (Werke, Bd. 10), S. 958-970.

Brednich (1976). Rolf Wilh[elm] Brednich (Hg.): Deutsche Volkslieder. Balladen. Sechster Teil. Gemeinsam mit Heinke Binder, Jürgen Dittmar, Monika Hasse, Otto Holzapfel, Lutz Röhrich, Wiegand Stief und Wolfgang Suppan. Freiburg im Breisgau 1976 (Deutsche Volkslieder mit ihren Melodien, Bd. 6).

Brednich (2014). Rolf Wilhelm Brednich (Hg.): Enzyklopädie des Märchens. Handwörterbuch zur historischen und vergleichenden Erzählforschung. Begründet von Kurt Ranke. Bd. 14. Berlin, Boston 2014.

Brentano (1978). Clemens Brentano: Sämtliche Werke und Briefe. Frankfurter Brentano-Ausgabe, Band 9,3: Des Knaben Wunderhorn, Lesarten und Erläuterungen. Hg. von Heinz Rölleke. Stuttgart u.a. 1978. 
Brentano (1991). Clemens Brentano: Zirkularbrief zur Volksliedersammlung, Heidelberg, um den 20. Mai 1806. In: Clemens Brentano: Sämtliche Werke und Briefe. Frankfurter BrentanoAusgabe, Band 31: Briefe III (1803-1807). Hg. von Lieselotte Kinskofer. Stuttgart, Berlin, Köln 1991, S. 530-532.

Breuer (1979). Dieter Breuer: Oberdeutsche Literatur 1565-1650. Deutsche Literaturgeschichte und Territorialgeschichte in frühabsolutistischer Zeit. (Zugl. Habil., RWTH Aachen). München 1979 (Zeitschrift für bayerische Landesgeschichte, Beihefte, Reihe B, Bd. 11).

Breuer (1989). Dieter Breuer: Deutsche Nationalliteratur und katholischer Kulturkreis. In: Klaus Garber (Hg.): Nation und Literatur im Europa der Frühen Neuzeit. Akten des I. Internationalen Osnabrücker Kongresses zur Kulturgeschichte der Frühen Neuzeit. Tübingen 1989 (Frühe Neuzeit, Bd. 1), S. 701-715.

Breuer (2003). Dieter Breuer: Johann Beers einstürzende Theater. In: Ferdinand van Ingen und HansGert Roloff (Hg.): Johann Beer. Schriftsteller, Komponist und Hofbeamter 1655-1700. Beiträge zum Internationalen Beer-Symposion in Weißenfels, Oktober 2000. Bern u.a. 2003 (Jahrbuch für Internationale Germanistik, Reihe A, Bd. 70), S. 597-613.

Briefe der Brüder Grimm (1923). Briefe der Brüder Grimm. Gesammelt von Hans Gürtler, nach dessen Tode hg. und erläutert von Albert Leitzmann. Mit 2 Abbildungen und 2 Faksimiles. Jena 1923.

Brown (2010). Wendy Brown: Walled States, Waning Sovereignty. New York 2010.

Brückner (1997). Wolfgang Brückner: Moser, Hans. In: NDB. Bd. 18 (1997), S. 184.

Bruinier (1894). Johannes W. Bruinier: Faust vor Goethe. Band 1: Das Engelsche Volksschauspiel Doctor Johann Faust als Fälschung erwiesen. Halle (Saale) 1894.

Brümmer ([1913]). Franz Brümmer: Lexikon der deutschen Dichter und Prosaisten vom Beginn des 19. Jahrhunderts bis zur Gegenwart. 8 Bände. 6., völlig neu bearbeitete und stark vermehrte Aufl. Leipzig [1913].

Brunner (2003). Horst Brunner: Lexer, Matthias von. In: IGL, S. 1080-1082.

Bühler (1900). M[ichael] Bühler: Die Nationalfeste. In: Paul Seippel (Hg.): Die Schweiz im neunzehnten Jahrhundert. Mit zahlreichen Illustrationen. Dritter Band. Bern, Lausanne 1900, S. 349387.

Bürger (1987a). Gottfried August Bürger: Sämtliche Werke. Hg. von Günter und Hiltrud Häntzschel. München, Wien 1987.

Bürger (1987b). Gottfried August Bürger: Aus Daniel Wunderlichs Buch. In: Gottfried August Bürger: Sämtliche Werke. Hg. von Günter und Hiltrud Häntzschel. München, Wien 1987, S. 685-697.

Bürger (1987c). Gottfried August Bürger: Von der Popularität der Poesie. In: Gottfried August Bürger: Sämtliche Werke. Hg. von Günter und Hiltrud Häntzschel. München, Wien 1987, S. 725730.

Bürger (1987d). Gottfried August Bürger: Vorrede [zu der Ausgabe der „Gedichte“] 1778. In: Gottfried August Bürger: Sämtliche Werke. Hg. von Günter und Hiltrud Häntzschel. München, Wien 1987, S. 716-724.

Büsching (1812). Johann Gustav Büsching: Volks-Sagen, Märchen und Legenden. Gesammelt von Johann Gustav Büsching. Leipzig 1812.

Büsching und von der Hagen (1807). [Johann Gustav Gottlieb] Büsching und [Friedrich Heinrich] von der Hagen: Sammlung Deutscher Volkslieder, mit einem Anhange Flammländischer und Französischer, nebst Melodien. Berlin 1807.

Buselmeier (2003). Karin Buselmeier: Stumpfl, Robert Heinrich Viktor. In: IGL, S. 1840-1841.

Carriere (1859). Moriz Carriere: Festrede bei der Feier von Schiller's hundertstem Geburtstag. München 1859.

Carriere (1863-1873). Moriz Carriere: Die Kunst im Zusammenhang der Culturentwickelung und die Ideale der Menschheit. 5 Bände. Leipzig 1863-1873. 
Carriere (1871). Moriz Carriere: Wilhelm Tell. Schauspiel von Friedrich Schiller. Mit Einleitung, dem alten Volksschauspiel von Uri, und Erläuterungen herausgegeben. Leipzig 1871.

Carriere (1884). Moriz Carriere: Die Poesie. Ihr Wesen und ihre Formen mit Grundzügen der vergleichenden Literaturgeschichte. 2. umgearb. Aufl. Leipzig 1884 [1854].

Carriere (1892). Moriz Carriere: Materialismus und Ästhetik. Eine Streitschrift zur Verständigung. Stuttgart 1892.

Castle (1928). Eduard Castle: Vom Pradltheater und anderen Tiroler Bauerntheatern. Zur Aufführung am Sonntag, den 19. Februar. In: Radio Wien vom 10.2.1928, S. 727-728.

Catalano (2007). Gabriella Catalano: Musei invisibili. Idea e forma della collezione nell'opera di Goethe. Rom 2007 (Proteo, Bd. 32).

Chemnitz (1805). Carl Wilhelm Chemnitz: Ueber den nachtheiligen Einfluß der jetzt gewöhnlichen Marionettenspiele auf den religiösen und sittlichen Zustand der unteren Volksklassen. Ein Wort an alle edel denkende Männer, denen die irdische und ewige Wohlfahrth der niedern Stände am Herzen liegt. Zerbst 1805.

Clark (1946). Robert T. Clark: Herder, Percy, and the Song of Songs. In: PMLA 61 (1946), H. 4, S. $1087-1100$.

Cotticelli und Schindler (2005). Francesco Cotticelli und Otto G. Schindler (Hg.): Commedia dell'arte. [Themenheft der Zeitschrift „Maske und Kothurn“]. Wien 2005.

Creizenach (1878). Wilhelm Creizenach: Versuch einer Geschichte des Volksschauspiels vom Doctor Faust. Halle (Saale) 1878.

Creizenach (1881). Wilhelm Creizenach: Die Bühnengeschichte des Goethe'schen Faust. Frankfurt am Main 1881.

Creizenach ([1889]). Wilhelm Creizenach (Hg.): Die Schauspiele der englischen Komödianten. Berlin, Stuttgart [1889] (Deutsche National-Litteratur, historisch kritische Ausgabe, Bd. 23).

Creizenach (1893-1916). Wilhelm Creizenach: Geschichte des neueren Dramas. 5 Bände. Band 1: Mittelalter und Frührenaissance; Band 2: Renaissance und Reformation, Teil 1; Band 3: Renaissance und Reformation, Teil 2; Band 4: Das englische Drama im Zeitalter Shakespeares, Teil 1; Band 5: Das englische Drama im Zeitalter Shakespeares, Teil 2. Halle (Saale) 1893-1916.

Creizenach (1896). Wilhelm Creizenach: Zur Geschichte der Weihnachtsspiele und des Weihnachtsfestes. Nach Handschriften der Krakauer Universitätsbibliothek. In: Wilhelm Creizenach, Paul Drechsler, Siegmund Fraenkel, Alfred Hillebrandt, Otto L. Jiriczek, E. Mogk, Karl Olbrich, Paul Regell, Franz Schroller, Theodor Siebs, Friedrich Vogt und Otto Warnatsch: Beiträge zur Volkskunde. Festschrift. Karl Weinhold zum 50jährigen Doktorjubiläum am 14. Januar 1896 dargebracht im Namen der Schlesischen Gesellschaft für Volkskunde. Breslau 1896, S. 1-10.

Czeike (1992). Felix Czeike: Historisches Lexikon Wien, 1. Band. Wien 1992.

Czeike (1994). Felix Czeike: Historisches Lexikon Wien, 3. Band. Wien 1994.

Dacrema (1995). Nicoletta Dacrema: Josef Nadler und Hugo von Hofmannsthal. In: Zeitschrift für Germanistik 5 (1995), H. 3, S. 535-543.

Dainat und Danneberg (2003). Holger Dainat und Lutz Danneberg (Hg.): Literaturwissenschaft und Nationalsozialismus. Tübingen 2003 (Studien und Texte zur Sozialgeschichte der Literatur, Bd. 99).

[Dalberg] (1787). [Wolfgang Heribert von Dalberg]: Vorrede. In: [Wolfgang Heribert von Dalberg]: Montesquieu, oder die unbekannte Wohlthat. Ein Schauspiel in drey Handlungen; für die Mannheimer National-Schaubühne. Mannheim 1787, S. III-XII.

Dammer und Jeßing (2007). Raphael Dammer und Benedikt Jeßing: Der Jedermann im 16. Jahrhundert. Die Hecastus-Dramen von Georgius Macropedius und Hans Sachs. Berlin, New York 2007 (Quellen und Forschungen zur Literatur- und Kulturgeschichte, Bd. 42).

Dann (2015). Otto Dann: Nation. In: Heinz Thoma (Hg.): Handbuch europäische Aufklärung. Begriffe, Konzepte, Wirkung. Stuttgart, Weimar 2015, S. 353-361. 
Danneberg (1989). Lutz Danneberg: Zwischen Innovation und Tradition. Begriffsbildung und Begriffsentwicklung als Explikation. In: Christian Wagenknecht (Hg.): Zur Terminologie der Literaturwissenschaft. Akten des IX. Germanistischen Symposions der Deutschen Forschungsgemeinschaft Würzburg 1986. Stuttgart 1989 (Germanistische Symposien, Berichtsbände, Bd. 9), S. 50-68.

Danneberg (2000). Lutz Danneberg: Schleiermacher und das Ende des Akkomodationsgedankens in der hermeneutica sacra des 17. und 18. Jahrhunderts. In: Ulrich Barth und Claus-Dieter Osthövener (Hg.): 200 Jahre „Reden über die Religion“. Akten des 1. Internationalen Kongresses der Schleiermacher-Gesellschaft, Halle, 14.-17. März 1999. Berlin, New York 2000 (Schleiermacher-Archiv, Bd. 19), S. 194-246.

Danneberg (2006). Lutz Danneberg: Von der Heiligen Schrift als Quelle des Wissens zur Ästhetik der Literatur (Jes 6,3 und Jos 10,12/13). In: Steffen Martus und Andrea Polaschegg (Hg.): Das Buch der Bücher - gelesen. Lesarten der Bibel in den Wissenschaften und Künsten. Bern u.a. 2006 (Publikationen zur Zeitschrift für Germanistik, Bd. 13), S. 219-262.

Das Paradeisspiel von Oberufer (1935). Das Paradeisspiel von Oberufer. Mit einer geschichtlichen Einleitung über die Oberuferer Weihnachtsspiele, Erläuterungen und Noten. Hg. von Helmut Amanshauser. Berlin 1935 (Volksspieldienst, Bd. 70).

Deiters (2002). Franz-Josef Deiters: Das Volk als Autor? Der Ursprung einer kulturgeschichtlichen Fiktion im Werk Johann Gottfried Herders. In: Heinrich Detering (Hg.): Autorschaft. Positionen und Revisionen. DFG-Symposium 2001. Stuttgart, Weimar 2002 (Germanistische Symposien, Berichtsbände, Bd. 24), S. 181-201.

Deutsch-Schreiner (2013). Evelyn Deutsch-Schreiner: Burgtheater; Erlkönigin; Präsident Abendwind; Ich liebe Österreich; Das Lebewohl. In: Pia Janke (Hg.): Jelinek-Handbuch. Unter Mitarbeit von Christian Schenkermayr und Agnes Zenker. Stuttgart, Weimar 2013, S. 137-147.

Deutsch-Schreiner (2016). Evelyn Deutsch-Schreiner: Joseph Schreyvogel, ein Dramaturg im Kampf mit Zensur und Obrigkeit. In: Evelyn Deutsch-Schreiner: Theaterdramaturgien von der Aufklärung bis zur Gegenwart. Köln, Weimar, Wien 2016, S. 86-108.

Devrient (1848). Eduard Devrient: Geschichte der deutschen Schauspielkunst. Erster Band: Geschichte der mittelalterlichen Schauspielkunst. Leipzig 1848.

Devrient (1851). Eduard Devrient: Das Passionsschauspiel in Oberammergau und seine Bedeutung für die neue Zeit. Mit Illustrationen von F[riedrich] Pecht. Leipzig 1851.

Diederichsen (1988). Diedrich Diederichsen: Zwischen Kunst und Kommerz. Organisationsformen der Barock-Oper. In: Hans Joachim Marx (Hg.): Händel auf dem Theater. Bericht über die Symposien der Internationalen Händel-Akademie Karlsruhe 1986 und 1987. Laaber 1988 (Veröffentlichungen der Internationalen Händel-Akademie Karlsruhe, Bd. 1), S. 115-132.

Dietl (2002). Cora Dietl: Wolfgang Schmeltzl und die Anfänge des katholischen Schultheaters in deutscher Sprache am Wiener Schottenstift. In: Österreich in Geschichte und Literatur 46 (2002), H. 4/5, S. 287-294.

Dittmann (2003). Ulrich Dittmann: Brecht, Karl Walther. In: IGL, S. 266-268.

Dittmar und Holzapfel (1982). Jürgen Dittmar und Otto Holzapfel (Hg.): Deutsche Volkslieder. Balladen. Siebenter Teil. Gemeinsam mit Michael Belgrader, Hartmut Braun, Rolf Wilh[elm] Brednich, David G. Engle, Lutz Röhrich und Wiegand Stief. Freiburg im Breisgau 1982 (Deutsche Volkslieder mit ihren Melodien, Bd. 7).

Dittmar und Stief (1992). Jürgen Dittmar und Wiegand Stief (Hg.): Deutsche Volkslieder mit ihren Melodien. Balladen. Band 9. Freiburg im Breisgau 1992 (Deutsche Volkslieder mit ihren Melodien, Bd. 9).

Doering (1830). Heinrich Doering: Die deutschen Kanzelredner des achtzehnten und neunzehnten Jahrhunderts. Nach ihrem Leben und Wirken dargestellt. Neustadt an der Orla 1830. 
Döring (2009). Jörg Döring: Zur Geschichte der Literaturkarte (1907-2008). In: Jörg Döring und Tristan Thielmann (Hg.): Mediengeographie. Theorie - Analyse - Diskussion. Bielefeld 2009, S. 247-289.

Dörrer (1929). Anton Dörrer: Die Volksschauspiele in Tirol. Mittel und Beiträge zur Erforschung ihrer Vergangenheit und Gegenwart. In: Tiroler Heimat N.F. 2 (1929), H. 2/3, S. 69-126.

Dörrer (1936). Anton Dörrer: Volksschauspiel. Ursprung und heutige Gestalt des tirolischen Bergbauernspiels. In: Monatsschrift für Kultur und Politik 1 (1936), S. 271-273.

Doppler (1971). Alfred Doppler: Vorwort. In: Institut für Österreichkunde (Hg.): Das österreichische Volksstück. Wien 1971 (Schriften des Institutes für Österreichkunde), S. 4.

Dow (2014). James R. Dow: Hans Naumann's gesunkenes Kulturgut and primitive Gemeinschaftskultur. In: Journal of Folklore Research 51 (2014), H. 1, S. 49-100.

Dressler (2003). Stephanie Dressler: Bartsch, Karl Friedrich Adolf Konrad. In: IGL, S. 88-90.

Drnovšek (2016). Jaša Drnovšek: Frühneuzeitliche Passionsprozessionsspiele als Projekt der katholischen Erneuerung. In: Svorad Zavarský, Lucy R. Nicholas und Andrea Riedl (Hg.): Themes of Polemical Theology Across Early Modern Literary Genres. Newcastle upon Tyne 2016, S. 321333.

Drnovšek (2018). Jaša Drnovšek: Early Modern Religious Processions. The Rise and Fall of a Political Genre. In: Toni Bernhart, Jaša Drnovšek, Sven Thorsten Kilian, Joachim Küpper und Jan Mosch (Hg.): Poetics and Politics. Net Structures and Agencies in Early Modern Drama. Berlin 2018, S. 215-224.

Dyer (2010). Elizabeth Anne Dyer: The Emergence of the Independent Prologue and Chorus in Jesuit School Theatre c. 1550-c. 1700. Derived from a Comparative Analysis of Benedictine, Augustinian and Jesuit School Theatre, Lay Youth Confraternity Theatre and the Oratorio Vespertina of the Congregation of the Oratory. (PhD thesis, York, UK, University of York 2010). http://etheses.whiterose.ac.uk/1517/ (14.3.2019).

Eberl (2008). Elfriede Eberl: August Hartmanns Sammeltätigkeit im Salzburger Land. In: Thomas Hochradner (Hg.): Volksmusik in Salzburg. Lieder und Schnaderhüpfl um 1900 aus dem Sammelgut des „Arbeitsausschusses für das Volkslied in Salzburg“. Wien, Köln, Weimar 2008 (Corpus Musicae Popularis Austriacae, Bd. 19), S. 25-36.

Eichberg, Dultz, Gadberry und Rühle (1977). Henning Eichberg, Michael Dultz, Glen Gadberry und Günther Rühle: Massenspiele. NS-Thingspiel, Arbeiterweihespiel und olympisches Zeremoniell. Stuttgart-Bad Cannstatt 1977 (Problemata, Bd. 58).

Elm (2004). Theo Elm: Das soziale Drama. Von Lenz bis Kroetz. Stuttgart 2004.

Elsie (2012). Robert Elsie: A Biographical Dictionary of Albanian History. London, New York 2012.

Emmerich (1971). Wolfgang Emmerich: Zur Kritik der Volkstumsideologie. (Zugl. tw. phil. Diss., Univ. Tübingen 1968, u.d.T.: Germanistische Volkstumsideologie. Genese und Kritik der Volksforschung im Dritten Reich). Frankfurt am Main 1971 (Edition Suhrkamp, Bd. 502).

Engel (1874). Carl Engel: Das Volksschauspiel Doctor Johann Faust. Mit geschichtlicher Einleitung und einem Verzeichniß der Literatur der Faustsage von 1510 bis Mitte 1873. Oldenburg 1874 (Deutsche Puppenkomödien, Bd. 1).

Engel (1885). Karl Engel: Zusammenstellung der Faust-Schriften vom 16. Jahrhundert bis Mitte 1884. 2. Aufl. Oldenburg 1885 (Bibliotheca Faustiana).

Engel (1887a). Karl Engel: Das 300jährige erste Faust-Buch vom Jahre 1587. Ein Buch-Jubiläum. Oldenburg, Leipzig 1887.

Engel (1887b). Karl Engel: Die Don Juan-Sage auf der Bühne. Zur 100jährigen Feier der ersten Aufführung von Mozart's Don Juan am 29. October 1787. Mit einem Anhang. Dresden, Leipzig 1887.

Engel (1890). Karl Engel: Die beiden alten deutschen Volksschauspiele vom Doctor Johann Faust und Christoph Wagner, Faust's Famulus. Vervollständigter Text mit vielfachen Ergänzungen 
bisher ungedruckter Scenen, Varianten etc. Oldenburg, Leipzig 1890 (Deutsche Puppenkomödien, Bd. 9).

Engels (2001). Hans-Werner Engels: Schütze, Johann Friedrich. In: Franklin Kopitzsch und Dirk Brietzke (Hg.): Hamburgische Biografie. Personenlexikon. Band 1. Hamburg 2001, S. 281.

Engels und Sucher (2012). Kilian Engels und C. Bernd Sucher (Hg.): Occupy Identity. Regisseure von morgen. Leipzig 2012.

Erk und Irmer (1838-1845). Ludwig Erk und Wilhelm Irmer: Die deutschen Volkslieder mit ihren Singweisen, gesammelt und herausgegeben. 13 Hefte. Berlin 1838-1845.

Ernyey und Kurzweil (1932). József Ernyey und Géza Kurzweil: Deutsche Volksschauspiele aus den oberungarischen Bergstädten. Hg. vom Ungarischen Nationalmuseum. 1. Band. Budapest 1932.

Ernyey, Kurzweil und Schmidt (1938). József Ernyey, Géza Kurzweil und Leopold Schmidt: Deutsche Volksschauspiele aus den oberungarischen Bergstädten. Hg. vom Ungarischen Nationalmuseum. 2. Band. Budapest 1938.

Estermann (1995). Alfred Estermann: Inhaltsanalytische Bibliographien deutscher Kulturzeitschriften des 19. Jahrhunderts (IBDK). Band 1: Deutsches Museum (1851-1867), Teil 1. München u.a. 1995.

Euringer (1933). Richard Euringer: Deutsche Passion 1933. Hörwerk in Sechs Sätzen. Oldenburg, Berlin 1933.

Eybl (1996). Franz M. Eybl: Österreichische Komik. Konstruktion und Brauchbarkeit einer literaturgeschichtlichen Leitkategorie. In: Wendelin Schmidt-Dengler, Johann Sonnleitner und Klaus Zeyringer (Hg.): Komik in der österreichischen Literatur. Berlin 1996 (Philologische Studien und Quellen, Bd. 142), S. 20-32.

Falk und Košenina (2008). Rainer Falk und Alexander Košenina (Hg.): Friedrich Nicolai und die Berliner Aufklärung. Hannover 2008.

Favretto und Itçaina (2017). Ilaria Favretto und Xabier Itçaina (Hg.): Protest, Popular Culture and Tradition in Modern and Contemporary Western Europe. London 2017.

Federspiel (1999). Johannes Ulrich von Federspiel: Hirlanda. Durch falschheit zu feir verdamte unschuld. Edition des Legendenspiels nach der Laaser Handschrift von 1791. Hg. von Toni Bernhart. Wien, Bozen 1999.

Feifalik (1858). Julius Feifalik: Über König Wenzel von Böhmen als deutschen Liederdichter und über die Unechtheit der altböhmischen Píseň Milostná Krále Václava I. Zwei literar-historische Studien. Wien 1858.

Feifalik (1859-1860). Julius Feifalik: Zwei böhmische Volksbücher zur Sage von Reinfrit von Braunschweig. 2 Bände. Wien 1859-1860.

Feifalik (1860). Julius Feifalik: Über die Königinhofer Handschrift. Wien 1860.

Feifalik (1862). Julius Feifalik: Altčechische Leiche, Lieder und Sprüche des XIV. und XV. Jahrhunderts mit einer Einleitung und Anmerkungen. Wien 1862.

Feifalik (1864). Julius Feifalik: Volksschauspiele aus Mähren. Mit Anhängen: I. Sterndreherlieder, II. Weihnachtslieder, III. De sancta Dorothea; Passional, 1495, und einem Nachtrage. Gesammelt und herausgegeben. Olmüz 1864.

Fischer (1918). Eugen K[urt] Fischer: Das deutsche Volksschauspiel. München 1918 (Flugschrift zur Ausdruckskultur, Bd. 177).

Fischer (2002). Gerhard Fischer: GRIPS. Geschichte eines populären Theaters (1966-2000). München 2002.

Fischer, Cornelia (2009). Cornelia Fischer: Jeitteles, Ignaz. In: Wilhelm Kühlmann (Hg.): Killy Literaturlexikon. Autoren und Werke des deutschsprachigen Kulturraumes. In Verbindung mit Achim Aurnhammer, Jürgen Egyptien, Karina Kellermann, Steffen Martus, Reimund B. Sdzuj. 6. Bd. 2. Aufl. Berlin, New York 2009, S. 125. 
Fischer, Michael (2009). Michael Fischer: Rekonstruktion und Dekonstruktion. Die Edition Deutsche Volkslieder mit ihren Melodien (1935-1996) und die Online-Publikation Populäre und traditionelle Lieder. Historisch-kritisches Liederlexikon (2005ff.). In: Lied und populäre Kultur / Song and Popular Culture 54 (2009), S. 33-61.

Fischer (2014). Michael Fischer (Hg.): Die Salzburger Festspiele. Ihre Bedeutung für die europäische Festspielkultur und ihr Publikum. Salzburg 2014.

Fischer-Lichte (2004). Erika Fischer-Lichte: Theater oder/und Ritual? Anmerkungen zu den geistlichen Spielen des Mittelalters. In: Edda Fuhrich und Hilde Haider (Hg.): Theater, Kunst, Wissenschaft. Festschrift für Wolfgang Greisenegger zum 66. Geburtstag. Zusammengestellt vom Institut für Theater-, Film- und Medienwissenschaft [der] Universität Wien. Wien, Köln, Weimar 2004, S. 143-154.

Fischer-Lichte (2007). Erika Fischer-Lichte: Theater und Fest. Anmerkungen zum Verhältnis von Theatralität und Ritualität in den geistlichen Spielen des Mittelalters. In: Ingrid Kasten und Erika Fischer-Lichte (Hg.): Transformationen des Religiösen. Performativität und Textualität im geistlichen Spiel. Berlin, New York 2007, S. 3-17.

Fleißer (1977). Marieluise Fleißer: Ingolstädter Stücke. Frankfurt am Main 1977.

Fleißer (1989). Marieluise Fleißer: Alle meine Söhne. Über Martin Sperr, Rainer Werner Fassbinder und Franz Xaver Kroetz [1972]. In: Marieluise Fleißer: Gesammelte Werke. Vierter Band: Aus dem Nachlaß. Hg. von Günther Rühle und Eva Pfister. Frankfurt am Main 1989, S. 508-513.

Flemming (1958). Willi Flemming: Haupt- und Staatsaktion. In: Reallexikon der deutschen Literaturgeschichte. Begründet von Paul Merker und Wolfgang Stammler. Band 1, hg. von Werner Kohlschmidt und Wolfgang Mohr. 2. Aufl. Berlin 1958, S. 619-621.

Fohrmann (1989). Jürgen Fohrmann: Das Projekt der deutschen Literaturgeschichte. Entstehung und Scheitern einer nationalen Poesiegeschichtsschreibung zwischen Humanismus und Deutschem Kaiserreich. (Zugl. Habil., Univ. Bielefeld 1988). Stuttgart 1989.

Foitzik (1997). Doris Foitzik: Rote Sterne, braune Runen. Politische Weihnachten zwischen 1870 und 1970. (Zugl. Diss., Univ. Bremen 1994). Münster u.a. 1997 (Internationale Hochschulschriften, Bd. 253).

Forssman (1999). Erik Forssman: Goethezeit. Über die Entstehung des bürgerlichen Kunstverständnisses. München 1999.

Frank (1989). Manfred Frank: Vom „Bühnenweihefestspiel“ zum „Thingspiel“. Zur Wirkungsgeschichte der ,Neuen Mythologie‘ bei Nietzsche, Wagner und Johst. In: Walter Haug und Rainer Warning (Hg.): Das Fest. München 1989 (Poetik und Hermeneutik), S. 610-638.

Fricke (1981). Harald Fricke: Norm und Abweichung. Eine Philosophie der Literatur. München 1981.

Friedrich und Niefanger (2017). Sabine Friedrich und Dirk Niefanger (Hg.): Populärkultur. Würzburg 2017 (Focus Gegenwart, Bd. 3).

Frischbier (1867). H[ermann] Frischbier: Preußische Volksreime und Volksspiele. Gesammelt und herausgegeben. Berlin 1867.

Frischbier (1882-1883). H[ermann] Frischbier: Preussisches Wörterbuch. Ost- und westpreussische Provinzialismen in alphabetischer Folge. 2 Bände. Berlin 1882-1883.

Frischbier (1892a). H[ermann] Frischbier: Preussische Volksreime und Volksspiele. In: Altpreussische Monatsschrift 28 (1892), H. 7/8, S. 577-631.

Frischbier (1892b). H[ermann] Frischbier: Preußische Volksreime und Volksspiele (Schluß). In: Altpreussische Monatsschrift 29 (1892), H. 5/6, S. 332-363.

Frischbier (1972). Hermann Frischbier: Preußische Volksreime und Volksspiele. Walluf bei Wiesbaden 1972 [1867].

[Fülleborn] (1798). [Georg Gustav Fülleborn]: Volksmährchen der Deutschen. Nicht von Musäus. Sechster Theil. Prag 1798. 
Füllenbach (2004). Elias H. Füllenbach: Ein Außenseiter als Sündenbock? Der Fall Josef Nadler. In: Kritische Ausgabe (2004), H. 2, S. 25-30.

Gaier (1990). Ulrich Gaier: Kommentar. In: Johann Gottfried Herder: Werke in zehn Bänden. Band 3: Volkslieder, Übertragungen, Dichtungen. Hg. von Ulrich Gaier. Frankfurt am Main 1990, S. 8411496.

Garber (1989). Klaus Garber (Hg.): Nation und Literatur im Europa der Frühen Neuzeit. Akten des I. Internationalen Osnabrücker Kongresses zur Kulturgeschichte der Frühen Neuzeit. Tübingen 1989 (Frühe Neuzeit, Bd. 1).

Gaskill (2008). Howard Gaskill (Hg.): The Reception of Ossian in Europe. London, New York 2008 (The Athlone critical traditions series, Bd. 5).

Gebhardt und Siller (2004). Michael Gebhardt und Max Siller (Hg.): Vigil Raber. Zur 450. Wiederkehr seines Todesjahres. Akten des 4. Symposiums der Sterzinger Osterspiele (25.-27.3.2002). Innsbruck 2004 (Schlern-Schriften, Bd. 326).

Geertz (1973). Clifford Geertz: Deep Play. Notes on the Balinese Cockfight. In: Clifford Geertz: The Interpretation of Cultures. Selected Essays. New York 1973, S. 412-453.

Geramb (1924). Viktor von Geramb: Die Volkskunde als Wissenschaft. In: Zeitschrift für Deutschkunde 38 (1924), S. 323-341.

Giebisch und Gugitz (1964). Hans Giebisch und Gustav Gugitz (Hg.): Bio-bibliographisches Literaturlexikon Österreichs. Von den Anfängen bis zur Gegenwart. Wien 1964.

Gläser (2009). Franz Gläser: [Autobiographie]. In: Klaus Martin Kopitz und Rainer Cadenbach (Hg.): Beethoven aus der Sicht seiner Zeitgenossen in Tagebüchern, Briefen, Gedichten und Erinnerungen. Unter Mitarbeit von Oliver Korte und Nancy Tanneberger. Band 1: Adamberger-Kuffner. München 2009, S. 348-350.

Glei und Seidel (2008). Reinhold F. Glei und Robert Seidel (Hg.): Das lateinische Drama der Frühen Neuzeit. Exemplarische Einsichten in Praxis und Theorie. Tübingen 2008 (Frühe Neuzeit, Bd. 129).

Goethe (1964). Johann Wolfgang Goethe: Hanswursts Hochzeit oder der Lauf der Welt. Ein mikrokosmisches Drama. In: Johann Wolfgang Goethe: Berliner Ausgabe. Band 5: Kleine Dramen (1767-1788). Dramatische Fragmente (1765-1787), bearbeitet von Annemarie Noelle. Berlin, Weimar 1964, S. 488-496.

Görres (1807). J[oseph] Görres: Die teutschen Volksbücher. Nähere Würdigung der schönen Historien-, Wetter- und Arzneybüchlein, welche theils innerer Werth, theils Zufall, Jahrhunderte hindurch bis auf unsere Zeit erhalten hat. Heidelberg 1807.

Gottschalck (1814). Friedrich Gottschalck: Die Sagen und Volksmährchen der Deutschen. Erstes Bändchen [mehr nicht erschienen]. Halle 1814.

Gottsched (1973). Johann Christoph Gottsched: Versuch einer Critischen Dichtkunst. Erster allgemeiner Theil [1730 / hier 3. Aufl. 1742]. In: Johann Christoph Gottsched: Ausgewählte Werke, VI/1. Hg. von Joachim Birke und Brigitte Birke. Berlin, New York 1973, S. 113-493.

Grabbe, Köhler und Wagner-Egelhaaf (2012). Katharina Grabbe, Sigrid G. Köhler und Martina Wagner-Egelhaaf (Hg.): Das Imaginäre der Nation. Zur Persistenz einer politischen Kategorie in Literatur und Film. Bielefeld 2012.

Graff und Wilhelmi (2017). Max Graff und Thomas Wilhelmi (Hg.): Heüt woellen wir werden vol. Trinklieder von Oswald bis Goethe. Sandersdorf-Brehna 2017.

Gratl (2016). Franz Gratl: Musik zu Innsbrucker und Meraner Schulspielen. Quellen aus dem Benediktinerstift Marienberg (Südtirol) in Konkordanz zu den gedruckten Periochen. In: Roland Sila (Hg.): Der frühe Buchdruck in der Region. Neue Kommunikationswege in Tirol und seinen Nachbarländern. Innsbruck 2016 (Schlern-Schriften, Bd. 366), S. 283-302.

Gratl (2018). Franz Gratl: The Role of Music in Folk Drama. An Investigation Based on Tyrolean Sources. In: Toni Bernhart, Jaša Drnovšek, Sven Thorsten Kilian, Joachim Küpper und Jan 
Mosch (Hg.): Poetics and Politics. Net Structures and Agencies in Early Modern Drama. Berlin 2018, S. 185-198.

Grave (2006). Johannes Grave: Der „ideale Kunstkörper“. Johann Wolfgang Goethe als Sammler von Druckgraphiken und Zeichnungen. (Zugl. phil. Diss., Univ. Jena 2004). Göttingen 2006 (Ästhetik um 1800, Bd. 4).

Greif (2008). Stefan Greif: Komplementäre Fremdheit. Das Reflexivwerden des Eigenen und das transkulturelle Subjekt bei Johann Gottfried Herder und Thomas Meinecke. In: Achim Barsch, Helmut Scheuer und Georg-Michael Schulz (Hg.): Literatur - Kunst - Medien. Festschrift für Peter Seibert zum 60. Geburtstag. München 2008 (Kontext, Bd. 8), S. 31-45.

Greif (2016). Stefan Greif: Volkslieder (1778f.). In: Stefan Greif, Marion Heinz und Heinrich Clairmont (Hg.): Herder Handbuch. Unter Mitwirkung von Violetta Stolz, Tobias Bender, Anna Meywirth und Nils Lehnert. Paderborn 2016, S. 495-504.

Gretz und Pethes (2016). Daniela Gretz und Nicolas Pethes (Hg.): Archiv / Fiktionen. Verfahren des Archivierens in Literatur und Kultur des langen 19. Jahrhunderts. Freiburg im Breisgau, Berlin, Wien 2016 (Rombach Wissenschaft, Reihe Litterae, Bd. 217).

Grig (2017). Lucy Grig (Hg.): Popular culture in the ancient world. Cambridge 2017.

Grimm (1854a). Jacob Grimm: Deutsche Mythologie. Dritte Ausgabe. Erster Band. Göttingen 1854.

Grimm (1854b). Jacob Grimm: Deutsche Mythologie. Dritte Ausgabe. Zweiter Band. Göttingen 1854.

Grimm (1968). Jacob Grimm: Circular wegen Aufsammlung der Volkspoesie. Wien 1815, Facsimile. Mit einem Nachwort von Kurt Ranke. Hg. von Ludwig Denecke. Kassel 1968.

[Grimm] (1985). [Jacob Grimm]: Aufforderung an die gesammten Freunde deutscher Poesie und Geschichte erlassen [1811]. In: Heinz Rölleke: Die Märchen der Brüder Grimm. Eine Einführung. München, Zürich 1985 (Artemis Einführungen, Bd. 18), S. 63-69.

Grimm (1993). Gunter E. Grimm: Kommentar. In: Johann Gottfried Herder: Werke in zehn Bänden. Band 2: Schriften zur Ästhetik und Literatur 1767-1781. Hg. von Gunter E. Grimm. Frankfurt am Main 1993, S. 793-1439.

Grimm (2004). Gunter E. Grimm: „Lieber ein unerträgliches Original als ein glücklicher Nachahmer“. Bürgers Volkspoesie-Konzept und seine Vorbilder. In: Reinhard Breymayer (Hg.): In dem milden und glücklichen Schwaben und in der Neuen Welt. Beiträge zur Goethezeit. Festschrift für Hartmut Fröschle. Stuttgart 2004 (Suevica, Bd. 9), S. 55-74.

Grimm (2015). Gunter E. Grimm: Zwischentöne. Stationen der deutschen Lyrik. Vom Barock bis zur Gegenwart. Marburg 2015.

Grimm und Grimm (1812). [Jacob] Grimm und [Wilhelm] Grimm: Kinder- und Haus-Märchen. Gesammelt durch die Brüder Grimm. Berlin 1812.

Grimm und Grimm (1815). [Jacob] Grimm und [Wilhelm] Grimm: Kinder- und Haus-Märchen. Gesammelt durch die Brüder Grimm. Zweiter Band. Berlin 1815.

Grimm und Grimm (1816). [Jacob] Grimm und [Wilhelm] Grimm: Deutsche Sagen. Herausgegeben von den Brüdern Grimm. Berlin 1816.

Grimm und Grimm (1818). [Jacob] Grimm und [Wilhelm] Grimm: Deutsche Sagen. Herausgegeben von den Brüdern Grimm. Zweiter Theil. Berlin 1818.

DWB. Jacob Grimm und Wilhelm Grimm: Deutsches Wörterbuch. [16 Bände in 32 Teilbänden]. Leipzig 1854-1961.

Gröf (2003). Siegfried Gröf: Flemming, Karl Willi Max. In: IGL, S. 498-500.

Grosse (1929). Walther Grosse: Heinrich Christoph Ferdinand Pröhle. In: Historische Kommission für die Provinz Sachsen und für Anhalt (Hg.): Lebensbilder des 18. und 19. Jahrhunderts. Magdeburg 1929 (Mitteldeutsche Lebensbilder, Bd. 4), S. 342-353.

Grubmüller und Hess (1986). Klaus Grubmüller und Günter Hess (Hg.): Bildungsexklusivität und volkssprachliche Literatur. Literatur vor Lessing - nur für Experten? Tübingen 1986 (Kontroversen, alte und neue, Bd. 7). 
Grunert und Stiening (2011). Frank Grunert und Gideon Stiening (Hg.): Johann Georg Sulzer (17201779). Aufklärung zwischen Christian Wolff und David Hume. Berlin 2011 (Werkprofile, Bd. 1).

Grünwald (1872a). Conrad Grünwald [d.i. Carl Gareis]: Die Bauerntheater im bayerischen Hochgebirg (Einleitung). In: Mnemosyne. Beiblatt zur Neuen Würzburger Zeitung mit Würzburger Anzeiger vom 30.10.1872, S. 351-352.

Grünwald (1872b). Conrad Grünwald [d.i. Carl Gareis]: Die Bauerntheater im bayerischen Hochgebirg (Schluß). In: Mnemosyne. Beiblatt zur Neuen Würzburger Zeitung mit Würzburger Anzeiger vom 2.11.1872, S. 354-356.

Gumbrecht (2012). Hans Ulrich Gumbrecht: Nach 1945. Latenz als Ursprung der Gegenwart. Aus dem amerikanischen Englisch von Frank Born. Berlin 2012.

Gumppenberg (1889). Carl Freiherr von Gumppenberg: Das Bauerntheater in Südbayern und Tirol. In: Zeitschrift des Deutschen und Oesterreichischen Alpenvereins 20 (1889), S. 136-159.

Gundolf (1911). Friedrich Gundolf: Shakespeare und der deutsche Geist. Berlin 1911.

Günther (1926). Hans F.K. Günther: Rasse und Stil. Gedanken über ihre Beziehungen im Leben und in der Geistesgeschichte der europäischen Völker, insbesondere des deutschen Volkes. Mit 80 Abbildungen. 2. Aufl. München 1926.

Gymnich, Neumann und Nünning (2007). Marion Gymnich, Birgit Neumann und Ansgar Nünning (Hg.): Gattungstheorie und Gattungsgeschichte. Unter Mitarbeit von Martin Butler, Ronja Tripp und Alexandre Segão Costa. Trier 2007 (Studies in English Literary and Cultural History, Bd. 28).

Hadamowsky (1979). Franz Hadamowsky: Ein Jahrhundert Literatur- und Theaterzensur in Österreich (1751-1848). In: Herbert Zeman (Hg.): Die österreichische Literatur. Eine Dokumentation ihrer literarhistorischen Entwicklung. Ihr Profil an der Wende vom 18. zum 19. Jahrhundert (17501830). Teil 1. Graz 1979, S. 289-305.

Haekel (2000). Ralf Haekel: Zum Verhältnis von Theaterpraxis und Drama in der Frühen Neuzeit: Heinrich Julius’ „Susanna“ und die englischen Komödianten. In: Zeitsprünge. Forschungen zur Frühen Neuzeit 4 (2000), H. 3, S. 163-180.

Haekel (2004). Ralf Haekel: Die englischen Komödianten in Deutschland. Eine Einführung in die Ursprünge des deutschen Berufsschauspiels. Heidelberg 2004 (Beiträge zur neueren Literaturgeschichte, Bd. 212).

Hagemann (1793a). [Friedrich] Gustav Hagemann: Die glückliche Werbung, oder Liebe zum König. Volkslustspiel in einem Aufzuge. [Wien] 1793.

Hagemann (1793b). [Friedrich] Gustav Hagemann: Die glückliche Werbung, oder: Liebe zum König. Volkslustspiel in einem Aufzuge. Hannover 1793.

Hagemann (1794). [Friedrich] Gustav Hagemann: Die glückliche Werbung, oder: Liebe zum König. Volkslustspiel in einem Aufzuge. In: Deutsche Schaubühne 6 (1794), H. 7, S. 1-30.

Hammacher (2010). Wilfried Hammacher: Die Uraufführung der Mysteriendramen von und durch Rudolf Steiner. München 1910-1913. Dornach 2010.

Häntzschel (1988). Günter Häntzschel: Gottfried August Bürger. München 1988.

Häntzschel (2014). Günter Häntzschel: Sammel(l)ei(denschaft). Literarisches Sammeln im 19. Jahrhundert. Würzburg 2014.

Happé und Hüsken (2016). Peter Happé und Wim Hüsken (Hg.): Staging Scripture. Biblical Drama, 1350-1600. Leiden, Boston 2016 (Ludus, Bd. 14).

Hartmann (1875). August Hartmann: Weihnachtlied und Weihnachtspiel in Oberbayern. SeparatAbdruck aus dem XXXIV. Bande des Oberbayerischen Archivs. München 1875.

Hartmann (1880). August Hartmann (Hg.): Das Oberammergauer Passionsspiel in seiner ältesten Gestalt. Zum ersten Male herausgegeben. Leipzig 1880. 
Hartmann (1974). Rudolf Hartmann: Das deutsche Volksschauspiel in der Schwäbischen Türkei (Ungarn). Marburg 1974 (Schriftenreihe der Kommission für Ostdeutsche Volkskunde in der Deutschen Gesellschaft für Volkskunde, Bd. 12).

Hartmann und Abele (1880). August Hartmann und Hyacinth Abele: Volksschauspiele. In Bayern und Österreich-Ungarn gesammelt. Mit vielen Melodien, nach dem Volksmund aufgezeichnet. Leipzig 1880.

Hartmann und Abele (1884). August Hartmann und Hyacinth Abele: Volkslieder. In Bayern, Tirol und Land Salzburg gesammelt. Mit vielen Melodien nach dem Volksmund aufgezeichnet. Band 1: Volksthümliche Weihnachtlieder [mehr nicht erschienen]. Leipzig 1884.

Hartmann und Abele (1907-1913). August Hartmann und Hyacinth Abele: Historische Volkslieder und Zeitgedichte vom sechzehnten bis neunzehnten Jahrhundert. Gesammelt und erläutert. Band 1: Bis zum Ende des dreißigjährigen Krieges; Band 2: Von Mitte des siebzehnten bis zu der des achtzehnten Jahrhunderts; Band 3: Von 1756 bis 1879. München 1907-1913.

Hassel und Herzmann (1992). Ursula Hassel und Herbert Herzmann (Hg.): Das zeitgenössische deutschsprachige Volksstück. Akten des internationalen Symposions, University College Dublin, 28. Februar-2. März 1991. Tübingen 1992 (Stauffenburg Colloquium, Bd. 23).

Hastaba (1990). Ellen Hastaba: Das Passionsspiel zur Zeit der Gegenreformation. Das Passionsspiel als gegenreformatorisches Spiel? - Spiele der Gegenreformation. In: Michael Henker, Eberhard Dünninger und Evamaria Brockhoff (Hg.): Hört, sehet, weint und liebt. Passionsspiele im alpenländischen Raum. München 1990, S. 67-74.

Hastaba (1995/1996). Ellen Hastaba: Theater in Tirol. Spielbelege in der Bibliothek des Tiroler Landesmuseums Ferdinandeum. In: Veröffentlichungen des Tiroler Landesmuseums Ferdinandeum 75/76 (1995/1996), S. 233-343.

Hauffen (1895). Adolf Hauffen: Die deutsche Sprachinsel Gottschee. Geschichte und Mundart, Lebensverhältnisse, Sitten und Gebräuche, Sagen, Märchen und Lieder. Mit vier Abbildungen und einer Sprachkarte. Graz 1895 (Quellen und Forschungen zur Geschichte, Litteratur und Sprache Österreichs und seiner Kronländer, Bd. 3).

Hein (1973). Jürgen Hein: Das Volksstück. Entwicklung und Tendenzen. In: Jürgen Hein (Hg.): Theater und Gesellschaft. Das Volksstück im 19. und 20. Jahrhundert. Düsseldorf 1973 (Literatur in der Gesellschaft, Bd. 12), S. 9-28.

Hein (1997). Jürgen Hein: Das Wiener Volkstheater. Raimund und Nestroy. 3. Aufl. Darmstadt 1997 [1978] (Erträge der Forschung, Bd. 100).

Heinemann (1972). Gerd Heinemann: Horn, Franz. In: NDB. Bd. 9 (1972), S. 627-628.

Heintze (1989). Horst Heintze: Das 15. und 16. Jahrhundert in Italien. Von der Dualität Latein-Volgare zur sprachlichen und literarischen Kodifizierung. In: Klaus Garber (Hg.): Nation und Literatur im Europa der Frühen Neuzeit. Akten des I. Internationalen Osnabrücker Kongresses zur Kulturgeschichte der Frühen Neuzeit. Tübingen 1989 (Frühe Neuzeit, Bd. 1), S. 262-286.

Heiske (1967). Wilhelm Heiske (Hg.): Deutsche Volkslieder. Balladen. Fünfter Teil. Unter Mithilfe von Erich Seemann gemeinsam mit Rolf Wilh. Brednich und Wolfgang Suppan. Freiburg im Breisgau 1967 (Deutsche Volkslieder mit ihren Melodien, Bd. 5).

Heitz (2006). Raymond Heitz: Das Ritterdrama und die Shakespeare-Rezeption in Deutschland im 18. Jahrhundert. In: Konrad Feilchenfeldt, Ursula Hudson, York-Gothart Mix und Nicholas Saul (Hg.): Zwischen Aufklärung und Romantik. Neue Perspektiven der Forschung. Festschrift für Roger Paulin. Würzburg 2006 (Publications of the Institute of Germanic Studies, Bd. 89), S. 106-137.

Hempfer (1973). Klaus W. Hempfer: Gattungstheorie. Information und Synthese. München 1973 (UTB, Bd. 133). 
Hempfer (2010). Klaus W. Hempfer: Zum begrifflichen Status der Gattungsbegriffe. Von ,Klassen`zu ,Familienähnlichkeiten‘ und ,Prototypen‘. In: Zeitschrift für französische Sprache und Literatur 120 (2010), H. 1, S. 14-32.

Hensler (1795). Karl Friedrich Hensler: Alles in Uniform für unsern König! Ein Volkslustspiel in drey Aufzügen. Zum Erstenmal aufgeführt auf der kaiserl. königl. privil. Marinellischen Schaubühne in Wien. Wien 1795.

Hensler (1797a). Karl Friedrich Hensler: Die getreuen Oesterreicher oder das Aufgeboth. Ein Volksstück mit Gesang in drey Aufzügen, für die k.k. priv. Marinellische Schaubühne bearbeitet. Nebst einem mit dem Stück verbundenen militärischen Kontratanz von Johann Sartory. Die Musik ist von Wenzel Müller, Kapellmeister. Wien 1797.

Hensler (1797b). Karl Friedrich Hensler: Es ist Friede. Ein Zeitstück mit Gesang in drey Aufzügen, als Gegenstück von dem Volkslustspiel: Alles in Uniform für unsern König! für die k. k. privil. Marinellische Schaubühne bearbeitet. Nebst einem mit dem Stück verbundenen militärischen Kontratanz von Johann Sartori. Die Musik ist von Wenzel Müller, Kapellmeister. Wien 1797.

Hensler (1798). Karl Friedrich Hensler: Das Donauweibchen. Erster Theil. Ein romantisch-komisches Volksmährchen mit Gesang in drey Aufzügen, nach einer Sage der Vorzeit für die k. k. priv. Marinellische Schaubühne. Die Musik ist von Ferdinand Kauer, Musikdirektor. Wien 1798.

Hensler (1799). Karl Friedrich Hensler: Die Teufelsmühle am Wienerberg. Ein österreichisches Volksmährchen mit Gesang in vier Aufzügen, nach einer Sage der Vorzeit von Herrn Leopold Huber. Für die k. k. priv. Marinellische Schaubühne bearbeitet. Die Musik ist von Herrn Wenzel Müller, Kapellmeister. Wien 1799.

Hensler (1800). Karl Friedrich Hensler: Das Waldweibchen. Erster Theil. Ein romantisch-komisches Volksmärchen mit Gesang in drey Aufzügen, als Seitenstück vom Donauweibchen. Nach einer Sage der österreichischen Vorzeit für die k. k. priv. Marinellische Schaubühne. Die Musik ist von Herrn Ferdinand Kauer, Musik-Director. Wien 1800.

Hensler (1801). Karl Friedrich Hensler: Der Teufelsstein in Mödlingen. Ein romantisch-komisches Volksmärchen mit Gesang in drey Aufzügen, nach einer österreichischen Sage der Vorzeit für die Marinellische Schaubühne. Die Musik ist von Herrn Wenzel Müller, Kapellmeister. Wien 1801.

Hensler (1803). Karl Friedrich Hensler: Die Nymphe der Donau. Erster Theil. Fortsetzung des Donauweibchens. Ein romantisch-komisches Volksmährchen mit Gesang in drey Aufzügen nach Berling bearbeitet. Die Musik ist von Herrn Ferdinand Kauer, Musik-Direktor. Wien 1803.

Herbst (2010). Johann Herbst: Das Laaser Spiel vom Eigenen Gericht. Edition der Abschrift von Oswald von Zingerle und Kommentar. Hg. von Toni Bernhart. Wien, Bozen 2010 (Transfer, Bd. 103).

[Herder] (1778). [Johann Gottfried Herder]: Volkslieder. Erster Theil. Leipzig 1778.

[Herder] (1779). [Johann Gottfried Herder]: Volkslieder. Nebst untermischten andern Stücken. Zweiter Theil. Leipzig 1779.

Herder (1807). Johann Gottfried von Herder: Sämmtliche Werke. Band 8: Stimmen der Völker in Liedern. Gesammelt, geordnet, zum Theil übersezt durch Johann Gottfried von Herder. Neu herausgegeben durch Johann von Müller. Tübingen 1807.

Herder (1884). Johann Gottfried Herder: Sämmtliche Werke, Band 28. Poetische Werke, Band 4: Dramatische und epische Dichtungen. Hg. von Carl Redlich. Berlin 1884.

Herder (1977). Johann Gottfried Herder: Brief an Christoph Friedrich Nicolai, Bückeburg, 11. März 1773. In: Johann Gottfried Herder: Briefe. Zweiter Band: Mai 1771-April 1773. Bearbeitet von Wilhelm Dobbek und Günter Arnold. Weimar 1977, S. 323-324.

Herder (1985). Johann Gottfried Herder: Abhandlung über den Ursprung der Sprache. In: Johann Gottfried Herder: Werke in zehn Bänden. Band 1: Frühe Schriften 1764-1772. Hg. von Ulrich Gaier. Frankfurt am Main 1985, S. 695-810. 
Herder (1990). Johann Gottfried Herder: Werke in zehn Bänden. Band 3: Volkslieder, Übertragungen, Dichtungen. Hg. von Ulrich Gaier. Frankfurt am Main 1990.

Herder (1990a). Johann Gottfried Herder: Ausweg zu Liedern fremder Völker. In: Johann Gottfried Herder: Werke in zehn Bänden. Band 3: Volkslieder, Übertragungen, Dichtungen. Hg. von Ulrich Gaier. Frankfurt am Main 1990, S. 59-68.

Herder (1990b). Johann Gottfried Herder: Volkslieder. Nebst untermischten andern Stücken. Zweiter Teil. In: Johann Gottfried Herder: Werke in zehn Bänden. Band 3: Volkslieder, Übertragungen, Dichtungen. Hg. von Ulrich Gaier. Frankfurt am Main 1990, S. 229-428.

Herder (1990c). Johann Gottfried Herder: Von Ähnlichkeit der mittleren englischen und deutschen Dichtkunst. In: Johann Gottfried Herder: Werke in zehn Bänden. Band 3: Volkslieder, Übertragungen, Dichtungen. Hg. von Ulrich Gaier. Frankfurt am Main 1990, S. 47-58.

Herder (1990d). Johann Gottfried Herder: Vorrede. In: Johann Gottfried Herder: Werke in zehn Bänden. Band 3: Volkslieder, Übertragungen, Dichtungen. Hg. von Ulrich Gaier. Frankfurt am Main 1990, S. 15-25.

Herder (1990e). Johann Gottfried Herder: Wäre Shakespear unübersetzbar? In: Johann Gottfried Herder: Werke in zehn Bänden. Band 3: Volkslieder, Übertragungen, Dichtungen. Hg. von Ulrich Gaier. Frankfurt am Main 1990, S. 26-46.

Herder (1993). Johann Gottfried Herder: Werke in zehn Bänden. Band 2: Schriften zur Ästhetik und Literatur 1767-1781. Hg. von Gunter E. Grimm. Frankfurt am Main 1993.

Herder (1993). Johann Gottfried Herder: Von deutscher Art und Kunst. Einige fliegende Blätter. In: Johann Gottfried Herder: Werke in zehn Bänden. Band 2: Schriften zur Ästhetik und Literatur 1767-1781. Hg. von Gunter E. Grimm. Frankfurt am Main 1993, S. 443-562.

Herder (2000). Johann Gottfried Herder: Volksgesang. In: Johann Gottfried Herder: Werke in zehn Bänden. Band 10: Adrastea (Auswahl). Hg. von Günter Arnold. Frankfurt am Main 2000, S. 800-808.

Herder (2002). Johann Gottfried Herder: Werke. Band III/1: Ideen zur Philosophie der Geschichte der Menschheit. [1784]. Hg. von Wolfgang Proß. München, Wien 2002.

Herder und Nicolai (1887). Johann Gottfried Herder und Friedrich Nicolai: Herder’s Briefwechsel mit Nicolai, im Originaltext hg. von Otto Hoffmann. Berlin 1887.

Herrmann (1996). Ulrich Herrmann (Hg.): Volk - Nation - Vaterland. Hamburg 1996 (Studien zum achtzehnten Jahrhundert, Bd. 18).

Herrmann (1999). Wilhelm Herrmann: Hoftheater - Volkstheater - Nationaltheater. Die Wanderbühnen im Mannheim des 18. Jahrhunderts und ihr Beitrag zur Gründung des Nationaltheaters. Frankfurt am Main u.a. 1999 (Quellen und Studien zur Geschichte der Mannheimer Hofkapelle, Bd. 5).

Herzmann (1994). Herbert Herzmann: Das epische Theater und das Volksstück. In: Modern Austrian Literature (MAL) 28 (1994), H. 1, S. 95-111.

Herzmann (1997). Herbert Herzmann: Tradition und Subversion. Das Volksstück und das epische Theater. Tübingen 1997 (Stauffenburg Colloquium, Bd. 41).

Heynicke (1934). Kurt Heynicke: Neurode. Ein Spiel von deutscher Arbeit. Berlin-Schöneberg 1934. Hochradner (2008). Thomas Hochradner (Hg.): Volksmusik in Salzburg. Lieder und Schnaderhüpfl um 1900 aus dem Sammelgut des „Arbeitsausschusses für das Volkslied in Salzburg“. Wien, Köln, Weimar 2008 (Corpus Musicae Popularis Austriacae, Bd. 19).

Hochwälder (1958). Fritz Hochwälder: Das heilige Experiment. Schauspiel in fünf Aufzügen. Mit einem Nachwort von Otto Rommel. Stuttgart 1958.

Hochwälder (1965). Fritz Hochwälder: Der Himbeerpflücker. Komödie in drei Akten. München, Wien 1965 (Theater-Texte, Bd. 5).

Hochwälder (1975a). Fritz Hochwälder: Der Himbeerpflücker. Komödie in drei Akten [1965]. In: Fritz Hochwälder: Dramen II. Graz 1975, S. 211-276. 
Hochwälder (1975b). Fritz Hochwälder: Esther. Ein altes Märchen, neu in dramatische Form gebracht. In: Fritz Hochwälder: Dramen I. Graz 1975, S. 7-82.

[Hoffmann] (1792). [Leopold Alois Hoffmann]: [Ohne Titel]. In: Wiener Zeitschrift 1 (1792), H. 8, S. 154-157.

Hoffmann (1991). Lutz Hoffmann: Das ,Volk‘. Zur ideologischen Struktur eines unvermeidbaren Begriffs. In: Zeitschrift für Soziologie 20 (1991), H. 3, S. 191-208.

Hoffmann von Fallersleben und Richter (1842). Hoffmann von Fallersleben und Ernst Richter: Schlesische Volkslieder mit Melodien. Aus dem Munde des Volks gesammelt und herausgegeben. Leipzig 1842.

Hofmann (1919). Emil Hofmann: Alt-Wien. Geschichten und Sagen. Wien 1919.

Hofmannsthal (2011a). Hugo von Hofmannsthal: Deutsche Festspiele zu Salzburg [1919]. In: Hugo von Hofmannsthal: Sämtliche Werke XXXIV. Reden und Aufsätze, Band 3. Hg. von Klaus E. Bohnenkamp, Katja Kaluga und Klaus-Dieter Krabiel. Frankfurt am Main 2011, S. 229-230. Hofmannsthal (2011b). Hugo von Hofmannsthal: Die Salzburger Festspiele [1919]. In: Hugo von Hofmannsthal: Sämtliche Werke XXXIV. Reden und Aufsätze, Band 3. Hg. von Klaus E. Bohnenkamp, Katja Kaluga und Klaus-Dieter Krabiel. Frankfurt am Main 2011, S. 231-235.

Hofmannsthal (2011c). Hugo von Hofmannsthal: Jedermann. Vorwort [1911]. In: Hugo von Hofmannsthal: Sämtliche Werke XXXIV. Reden und Aufsätze, Band 3. Hg. von Klaus E. Bohnenkamp, Katja Kaluga und Klaus-Dieter Krabiel. Frankfurt am Main 2011, S. 24.

Hofmannsthal (2011). Hugo von Hofmannsthal: Sämtliche Werke XXXIV. Reden und Aufsätze, Band 3. Hg. von Klaus E. Bohnenkamp, Katja Kaluga und Klaus-Dieter Krabiel. Frankfurt am Main 2011.

Hogarty (2017). Jean Hogarty: Popular Music and Retro Culture in the Digital Era. New York, Abingdon 2017 (Routledge Advances in Sociology, Bd. 186).

Holzapfel (1988). Otto Holzapfel (Hg.): Deutsche Volkslieder. Balladen. Achter Teil. Freiburg im Breisgau 1988 (Deutsche Volkslieder mit ihren Melodien, Bd. 8).

Holzapfel und Stief (1996). Otto Holzapfel und Wiegand Stief (Hg.): Deutsche Volkslieder mit ihren Melodien. Balladen. Band 10. Bern u.a. 1996 (Deutsche Volkslieder mit ihren Melodien, Bd. 10).

Holzner und Oberkofler (1983). Johann Holzner und Gerhard Oberkofler (Hg.): Ausbruch aus der Provinz. Adolf Pichler - Alois Brandl. Briefwechsel 1876-1900. Innsbruck 1983 (Innsbrucker Beiträge zur Kulturwissenschaft, Germanistische Reihe, Bd. 16).

Homering (2012). Liselotte Homering: Wolfgang Heribert von Dalberg als Theaterleiter und Autor. In: Volker Gallé und Werner Nell (Hg.): Zwischenwelten. Das Rheinland um 1800. Tagung vom 28. bis 30. Oktober 2011 in Schloss Herrnsheim, Worms. Worms 2012, S. 69-94.

[Hommel] (1791). [Rudolph Hommel]: Briefe über die Kaiserwahl, während derselben aus Frankfurt geschrieben. Leipzig 1791.

Horak (1940). Karl Horak: Burgenländische Volksschauspiele. Wien, Leipzig 1940 (Volkstum im Südosten).

Horak (1975). Karl Horak: Das deutsche Volksschauspiel im Banat. Marburg 1975 (Schriftenreihe der Kommission für Ostdeutsche Volkskunde in der Deutschen Gesellschaft für Volkskunde e.V., Bd. 14).

Horak (1977). Karl Horak: Das deutsche Volksschauspiel in Mittelungarn. Marburg 1977 (Schriftenreihe der Kommission für Ostdeutsche Volkskunde in der Deutschen Gesellschaft für Volkskunde e.V., Bd. 17).

Hörmann (1874). L[udwig] von Hörmann: Im Bauerntheater. In: Die Presse vom 17.7.1874, S.1-4. Horn (1823). Franz Horn: Die Poesie und Beredsamkeit der Deutschen, von Luthers Zeit bis zur Gegenwart. Zweiter Band. Berlin 1823. 
Horváth (1970). Ödön von Horváth: Interview [1932]. In: Ödön von Horváth: Gesammelte Werke. Band I: Volksstücke, Schauspiele. Hg. von Dieter Hildebrandt, Walter Huder und Traugott Krischke. Frankfurt am Main 1970, S. 5-16.

Horváth (1978a). Ödön von Horváth: Gebrauchsanweisung. In: Ödön von Horváth: Gesammelte Werke. Band IV: Fragmente und Varianten, Exposés, Theoretisches, Briefe, Verse. Hg. von Traugott Krischke und Dieter Hildebrandt. 3., verbesserte Aufl. Frankfurt am Main 1978, S. 659-665.

Horváth (1978b). Ödön von Horváth: Gesammelte Werke. Band IV: Fragmente und Varianten, Exposés, Theoretisches, Briefe, Verse. Hg. von Traugott Krischke und Dieter Hildebrandt. 3., verbesserte Aufl. Frankfurt am Main 1978.

Hosp-Schmidt (1978). Inga Hosp-Schmidt: Das Schlierseer Bauerntheater. In: Markt Schliersee (Hg.): Schliersee 779-1979. Eine Chronik zum Jubiläum. Schliersee 1978, S. 294-297.

Howard (1999). Jean E. Howard: Shakespeare and Genre. In: David Scott Kastan (Hg.): A Companion to Shakespeare. Oxford, Malden, MA 1999, S. 297-310.

Huber (2016). Florian Huber: Grenzkatholizismen. Religion, Raum und Nation in Tirol 1830-1848. Göttingen 2016 (Schriften zur politischen Kommunikation, Bd. 23).

Huemer (1958). Helmuth Huemer: Studien zur Volksbuchliteratur Österreichs. Mit besonderer Berücksichtigung des Landes ob der Enns. In: Oberösterreichische Heimatblätter 12 (1958), H. 1/2, S. 1-20.

Hufer (2018). Klaus-Peter Hufer: Neue Rechte, altes Denken. Ideologie, Kernbegriffe und Vordenker. Weinheim 2018.

Hugelmann (1889). Karl Hugelmann: Rohrer, Joseph. In: ADB. Bd. 29 (1889), S. 64-68.

Huter (1983). F[ranz] Huter: Pichler von Rautenkar Adolf. In: ÖBL. Bd. 8 (1983), S. 59.

Hüttner (1980). Johann Hüttner: Theatre Censorship in Metternich's Vienna. In: Theatre Quarterly 10 (1980), H. 37, S. 61-69.

Hüttner (1986). Johann Hüttner: Volkstheater als Geschäft. Theaterbetrieb und Publikum im 19. Jahrhundert. In: Jean-Marie Valentin (Hg.): Volk - Volksstück - Volkstheater im deutschen Sprachraum des 18.-20. Jahrhunderts. Akten des mit Unterstützung des Centre National de la Recherche Scientifique veranstalteten Kolloquiums, Nancy, 12.-13. November 1982. Bern, Frankfurt am Main, New York 1986 (Jahrbuch für Internationale Germanistik, Reihe A, Bd. 15), S. 127-149.

Huyssen (1872). G[otthelf] Huyssen: Bilder aus dem Kriegsleben eines Militär-Geistlichen. Ein Beitrag zur Culturgeschichte des deutsch-französischen Krieges von 1870 und 71 . Kreuznach 1872.

Huyssen (1881). Gotthelf Huyssen: Christi Leiden im deutschen Volksschauspiel, namentlich im Oberammergauer Passionsspiel. Barmen 1881.

Huyssen (1883). Gotthelf Huyssen: Die Poesie des Krieges und die Kriegs-Poesie. Berlin 1883.

IGL. Internationales Germanistenlexikon 1800-1950. Hg. von Christoph König. Bearbeitet von Birgit Wägenbaur zusammen mit Andrea Frindt, Hanne Knickmann, Volker Michel, Angela Reinthal und Karla Rommel. 3 Bände. Berlin, New York 2003.

Immermann (1828). Karl Immermann: Das Trauerspiel in Tyrol. Ein dramatisches Gedicht in fünf Aufzügen. Hamburg 1828.

Immermann (1835). Karl Immermann: Blick in’s Tyrol. In: Karl Immermann: Karl Immermann's Schriften. Zweiter Band. Düsseldorf 1835, S. 509-557.

Inbar (1982). Eva Maria Inbar: Shakespeare in Deutschland. Der Fall Lenz. Tübingen 1982 (Studien zur deutschen Literatur, Bd. 67).

Infirmus (1822). Johannes Infirmus [d.i. Johannes Schuler]: Über die Bauernspiele in Tyrol. In: Wiener Zeitschrift für Kunst, Literatur, Theater und Mode (1822), H. 86 vom 18.7.1822, S. 693-695.

Institut für Österreichkunde (1971). Institut für Österreichkunde (Hg.): Das österreichische Volksstück. Wien 1971 (Schriften des Institutes für Österreichkunde). 
Jäger (2001). Georg Jäger: Das Kleinhäuslertum in Südtirol - Aktueller Forschungsstand. Ein historisch-geographischer Beitrag zur neuzeitlichen Siedlungsgenese und Sozialstruktur des Landes an Etsch, Eisack und Rienz. In: Tiroler Heimat 65 (2001), S. 25-110.

Jakli (2016). Timon Jakli: „Volkspoesie“ und „Volk“ als Zentralbegriffe deutscher Identitätsbildung im 18. Jahrhundert. In: Heidrun Kämper, Ingo H. Warnke und Daniel Schmidt-Brücken (Hg.): Textuelle Historizität. Interdisziplinäre Perspektiven auf das historische Apriori. Berlin, Boston 2016 (Diskursmuster, Bd. 12), S. 163-175.

Janke (2002). Pia Janke (Hg.): Die Nestbeschmutzerin. Jelinek \& Österreich. Salzburg, Wien 2002. Janke (2004/2005/2006). Pia Janke: Die Wiener Haupt- und Staatsaktionen des frühen 18. Jahrhunderts. In: Jahrbuch der Österreichischen Goethe-Gesellschaft 108/109/110 (2004/2005/2006), S. 259-271.

Janke (2010). Pia Janke: Politische Massenfestspiele in Österreich zwischen 1918 und 1938. (Zugl. Habil., Univ. Wien 2006). Wien, Köln, Weimar 2010.

Janke (2013). Pia Janke (Hg.): Jelinek-Handbuch. Unter Mitarbeit von Christian Schenkermayr und Agnes Zenker. Stuttgart, Weimar 2013.

Janke (2014). Pia Janke: Elfriede Jelinek. Werk und Rezeption. Unter Mitarbeit von Verena Humer, Teresa Kovacs, Christian Schenkermayr. 2 Teile. Wien 2014 (Diskurse, Kontexte, Impulse, Bd. 10).

Janke, Kovacs und Schenkermayr (2018). Pia Janke, Teresa Kovacs und Christian Schenkermayr (Hg.): Elfriede Jelineks Burgtheater. Eine Herausforderung. Unter Mitarbeit von Bettina Chybiorz. Wien 2018 (Diskurse, Kontexte, Impulse, Bd. 18).

Jazo (2017). Jelena Jazo: Postnazismus und Populärkultur. Das Nachleben faschistoider Ästhetik in Bildern der Gegenwart. (Zugl. Diss., Univ. Frankfurt am Main 2017). Bielefeld 2017 (Image, Bd. 109).

Jeitteles (1978). Ignaz Jeitteles: Aesthetisches Lexikon enthaltend Kunstphilosophie, Poesie, Poetik, Rhetorik, Musik, Plastik, Graphik, Architektur, Malerei, Theater. [Nachdr. d. Ausg. Wien 1839]. Hildesheim, New York 1978.

Jelinek (1984). Elfriede Jelinek: Burgtheater. Posse mit Gesang. In: Elfriede Jelinek: Theaterstücke. Clara S., Was geschah, nachdem Nora ihren Mann verlassen hatte, Burgtheater. Hg. und mit einem Nachwort von Ute Nyssen. Köln 1984, S. 102-150.

Jelinek (1984). Elfriede Jelinek: Theaterstücke. Clara S., Was geschah, nachdem Nora ihren Mann verlassen hatte, Burgtheater. Hg. und mit einem Nachwort von Ute Nyssen. Köln 1984.

Jelinek (1988). Elfriede Jelinek: Präsident Abendwind. Ein Dramolett. In: Herbert Wiesner (Hg.): Anthropophagen im Abendwind. Vier Theatertexte nach Johann Nepomuk Nestroys „Häuptling Abendwind“. Helmut Eisendle, Elfriede Jelinek, Libuše Moníková, Oskar Pastior nebst Johann Nepomuk Nestroy. Berlin 1988 (Texte aus dem Literaturhaus Berlin, Bd. 2), S. 19-35.

Jelinek (2000a). Elfriede Jelinek: Ich liebe Österreich. In: Matthias Lilienthal und Claus Philipp: Schlingensiefs Ausländer raus. Bitte liebt Österreich. Dokumentation. Frankfurt am Main 2000, S. 151-152.

Jelinek (2000b). Elfriede Jelinek: Ich liebe Österreich. Montiert aus Texten der Asylanten von „Bitte liebt Österreich!“ mit Hilfe von Mario Rauter. http://www.elfriedejelinek.com/fkasperl.htm (3.5.2019).

Jeßing (2008). Benedikt Jeßing: Zur Rezeption des morall play vom „Everyman“ in der neulateinischen und frühneuhochdeutschen Komödie. Georg Macropedius, Hans Sachs. In: Reinhold F. Glei und Robert Seidel (Hg.): Das lateinische Drama der Frühen Neuzeit. Exemplarische Einsichten in Praxis und Theorie. Tübingen 2008 (Frühe Neuzeit, Bd. 129), S. 87-99.

John und Widmaier (2005-). Eckhard John und Tobias Widmaier (Hg.): Populäre und traditionelle Lieder. Historisch-kritisches Liederlexikon. http://www.liederlexikon.de/ (25.3.2019). Freiburg im Breisgau 2005-. 
Karasek und Horak (1972). Alfred Karasek und Karl Horak: Das deutsche Volksschauspiel in der Batschka, in Syrmien und Slawonien. Marburg 1972 (Schriftenreihe der Kommission für Ostdeutsche Volkskunde in der Deutschen Gesellschaft für Volkskunde e.V., Bd. 11).

Karasek und Lanz (1960). Alfred Karasek und Josef Lanz: Das deutsche Volksschauspiel in Galizien. Eine Spiellandschaft zwischen Polen, Slowaken und Ukrainern. Freilassing, Salzburg 1960 (Schriftenreihe der Kommission für Volkskunde der Heimatvertriebenen im Verband der Vereine für Volkskunde, Bd. 3).

Karasek und Lanz (1971). Alfred Karasek und Josef Lanz: Das deutsche Volksschauspiel in der Bukowina. Marburg 1971 (Schriftenreihe der Kommission für Ostdeutsche Volkskunde in der Deutschen Gesellschaft für Volkskunde, Bd. 9).

Karasek-Langer (1932). Alfred Karasek-Langer: Die Erforschung des deutschen Volksschauspiels in Galizien. In: Schaffen und Schauen. Mitteilungsblatt für Kunst und Bildungspflege in der Wojewodschaft Schlesien 8 (1932), H. 5/6, S. 1-9.

Karstens (2011). Simon Karstens: Lehrer, Schriftsteller, Staatsreformer. Die Karriere des Joseph von Sonnenfels (1733-1817). Wien, Köln, Weimar 2011 (Veröffentlichungen der Kommission für Neuere Geschichte Österreichs, Bd. 106).

Kasten und Fischer-Lichte (2007). Ingrid Kasten und Erika Fischer-Lichte (Hg.): Transformationen des Religiösen. Performativität und Textualität im geistlichen Spiel. Berlin, New York 2007.

Ketelsen (2004). Uwe-K. Ketelsen: Völkische Nationenbildung. Das Thingspiel. In: Kritische Ausgabe 12 (2004), H. 2, S. 31-33.

Ketelsen (2009). Uwe-K. Ketelsen: Nationalistische und rassistische Germanistik. In: Jost Schneider (Hg.): Methodengeschichte der Germanistik. Unter redaktioneller Mitarbeit von Regina Grundmann. Berlin 2009, S. 529-548.

Kiesel (2017). Helmut Kiesel: Geschichte der deutschen Literatur von den Anfängen bis zur Gegenwart, Band X: Geschichte der deutschsprachigen Literatur 1918 bis 1933. München 2017.

Kieseritzky (1893). G[angolf von] Kieseritzky: Storch, Heinrich Friedrich von. In: ADB. Bd. 36 (1893), S. 437-439.

Kießhauer (2009). Inge Kießhauer: Emil Ottocar Weller (1823-1886). In: Günter Benser und Michael Schneider (Hg.): „Bewahren - Verbreiten - Aufklären“. Archivare, Bibliothekare und Sammler der Quellen der deutschsprachigen Arbeiterbewegung. Berlin, Bonn 2009, S. 345-351.

Kimmich (2003). Dorothee Kimmich: Lugowski, Clemens. In: IGL, S. 1124-1126.

Kindermann (1928). Heinz Kindermann (Hg.): Volks- und Schwankbücher. Band 1: Volksbücher vom sterbenden Rittertum. Weimar, Leipzig, Wien 1928 (Deutsche Literatur. Sammlung literarischer Kunst- und Kulturdenkmäler in Entwicklungsreihen, Reihe Volks- und Schwankbücher, Bd. 1).

Kindermann (1933-1936). Heinz Kindermann (Hg.): Volks- und Schwankbücher. Band 2: Volksbücher von Weltweite und Abenteuerlust. Band 7: Anfänge des bürgerlichen Prosaromans in Deutschland. Bearbeitet von Franz Podleiszek. Leipzig 1933-1936 (Deutsche Literatur. Sammlung literarischer Kunst- und Kulturdenkmäler in Entwicklungsreihen, Reihe Volks- und Schwankbücher, Bd. 2 und 7).

Kindermann (1937/1938). Heinz Kindermann: Ferdinand Raimund, ein deutscher Volksdramatiker. In: Der getreue Eckart. Schriftenfolge für politische und wirtschaftliche Fragen 15 (1937/1938).

Kindermann (1938). Heinz Kindermann: Die Commedia dell'arte und das deutsche Volkstheater. Leipzig 1938 (Kaiser Wilhelm-Institut für Kunst- und Kulturwissenschaft Bibliotheca Hertziana in Rom, Erste Reihe: Vorträge, Bd. 12).

Kindermann (1939). Heinz Kindermann (Hg.): Danziger Barockdichtung. Leipzig 1939 (Deutsche Literatur. Sammlung literarischer Kunst- und Kulturdenkmäler in Entwicklungsreihen, Reihe Barock, Ergänzungsband).

Kindermann (1943). Heinz Kindermann: Ferdinand Raimund. Lebenswerk und Wirkungsraum eines deutschen Volksdramatikers. 2. Aufl. Wien 1943 [1940]. 
Kindermann (1967). Heinz Kindermann: Theatergeschichte Europas, Band 3: Das Theater der Barockzeit. 2. verbesserte und ergänzte Aufl. Salzburg 1967.

Klausing und Wiczlinski (2017). Caroline Klausing und Verena von Wiczlinski (Hg.): Die Napoleonischen Kriege in der europäischen Erinnerung. Bielefeld 2017 (Mainzer Historische Kulturwissenschaften).

Klausnitzer (1999). Ralf Klausnitzer: Blaue Blume unterm Hakenkreuz. Die Rezeption der deutschen literarischen Romantik im Dritten Reich. (Zugl. Diss., Humboldt-Univ. zu Berlin 1998). Paderborn u.a. 1999.

Kleihues, Naumann und Pankow (2010). Alexandra Kleihues, Barbara Naumann und Edgar Pankow (Hg.): Intermedien. Zur kulturellen und artistischen Übertragung. Zürich 2010 (Medienwandel, Medienwechsel, Medienwissen, Bd. 14).

Klein (1929). Hans Klein: Die Oberuferer Volksschauspiele. In: Die Singgemeinde 5 (1929), H. 3, S. 81-87.

Kleiner und Wilke (2018). Marcus S. Kleiner und Thomas Wilke (Hg.): Populäre Wissenschaftskulissen. Über Wissenschaftsformate in Populären Medienkulturen. Bielefeld 2018 (Popkulturen, Bd. 2).

Klotz (1998). Volker Klotz: Dramaturgie des Publikums. Wie Bühne und Publikum aufeinander eingehen: insbesondere bei Raimund, Büchner, Wedekind, Horváth, Gatti und im politischen Agitationstheater. 2. Aufl. Würzburg 1998 [1976].

Kluckhohn (1934). Paul Kluckhohn (Hg.): Die Idee des Volkes im Schrifttum der deutschen Bewegung von Möser und Herder bis Grimm. Berlin 1934 (Literarhistorische Bibliothek, Bd. 13).

[Knaffl] (1928). [Johann Felix Knaffl]: Die Knaffl-Handschrift. Eine obersteirische Volkskunde aus dem Jahre 1813. Mit 4 einfarbigen und 4 mehrfarbigen Tafeln. Hg. von Viktor von Geramb. Berlin, Leipzig 1928 (Quellen zur deutschen Volkskunde, Bd. 2).

Knopf (2001). Jan Knopf (Hg.): Brecht Handbuch in fünf Bänden. Band 1: Stücke. Stuttgart, Weimar 2001.

Knudsen (1957). Hans Knudsen: Dalberg, Wolfgang Heribert. In: NDB. Bd. 3 (1957), S. 490-491.

Kobald (1919). Karl Kobald: Alt-Wiener Musikstätten. Zürich, Leipzig, Wien 1919 (AmaltheaBücherei, Bd. 6).

Koch (1922). Georg Koch: Volkskunde, Romantik und l'Houet's Bauernpsychologie. Beitrag zu einer Methodenlehre der Volkskunde. In: Hessische Blätter für Volkskunde 21 (1922), S. 22-50.

Koch (2011). Hans-Albrecht Koch: Sailer, Sebastian. In: Wilhelm Kühlmann (Hg.): Killy Literaturlexikon. Autoren und Werke des deutschsprachigen Kulturraumes. In Verbindung mit Achim Aurnhammer, Jürgen Egyptien, Karina Kellermann, Steffen Martus, Reimund B. Sdzuj. 10. Band. 2. Aufl. Berlin, Boston 2011, S. 167.

Koepke (2009). Wulf Koepke: Herder's Views on the Germans and Their Future Literature. In: Hans Adler und Wulf Koepke (Hg.): A Companion to the Works of Johann Gottfried Herder. Rochester, NY 2009 (Studies in German Literature, Linguistics, and Culture), S. 215-232.

Köhler-Zülch (1993). Ines Köhler-Zülch: Heinrich Pröhle. A Successor to the Brothers Grimm. In: Donald Haase (Hg.): The Reception of Grimms' Fairy Tales. Responses, Reactions, Revisions. Detroit Mich. 1993, S. 41-58.

Kohns (2008). Oliver Kohns: Was war nationale Literatur? Herders Literaturtheorie zwischen ,Regionalität‘ und ,Globalität‘. In: Wilhelm Amann, Georg Mein und Rolf Parr (Hg.): Periphere Zentren oder zentrale Peripherien? Kulturen und Regionen Europas zwischen Globalisierung und Regionalität. Heidelberg 2008, S. 193-208.

Koller (2008). Margot Koller: Otto Eberhard (1875-1960). In: Thomas Hochradner (Hg.): Volksmusik in Salzburg. Lieder und Schnaderhüpfl um 1900 aus dem Sammelgut des „Arbeitsausschusses für das Volkslied in Salzburg“. Wien, Köln, Weimar 2008 (Corpus Musicae Popularis Austriacae, Bd. 19), S. 139-166. 
Kormann (1992). Eva Kormann: Das neue kritische Volksstück. Ein neuer Blick auf eine nicht mehr ganz neue Dramatik. In: Ursula Hassel und Herbert Herzmann (Hg.): Das zeitgenössische deutschsprachige Volksstück. Akten des internationalen Symposions, University College Dublin, 28. Februar-2. März 1991. Tübingen 1992 (Stauffenburg Colloquium, Bd. 23), S. 101-106.

Korotin (2016). Ilse Korotin (Hg.): biografiA. Lexikon österreichischer Frauen. Band 3: P-Z. Wien, Köln, Weimar 2016.

Kos und Rapp (2004). Wolfgang Kos und Christian Rapp (Hg.): Alt-Wien. Die Stadt, die niemals war. [Ausstellungskatalog]. Wien 2004.

Koselleck (1992). Reinhart Koselleck: Volk, Nation, Nationalismus, Masse. In: Otto Brunner, Werner Conze und Reinhart Koselleck (Hg.): Geschichtliche Grundbegriffe. Historisches Lexikon zur politisch-sozialen Sprache in Deutschland. Band 7. Stuttgart 1992, S. 141-431.

Kössinger, Krotz, Müller und Rychterová (2018). Norbert Kössinger, Elke Krotz, Stephan Müller und Pavlína Rychterová (Hg.): Anfangsgeschichten. Origin Stories. Der Beginn volkssprachiger Schriftlichkeit in komparatistischer Perspektive. The Rise of Vernacular Literacy in a Comparative Perspective. Paderborn 2018 (Mittelalterstudien, Bd. 31).

Kralik (1895). Richard Kralik: Das Volksschauspiel vom Doctor Faust. Wien 1895.

Kraus (1899). Karl Kraus: [O.T., Incipit:] Von der Qual der „Schlierseer“. In: Die Fackel 1 (1899), H. 9 , S. 19-21.

Kraus (1900). Karl Kraus: Secessionsbühne. In: Die Fackel 2 (1900), H. 48, S. 7-16.

Kraus (1975). Karl Kraus: Nestroy und die Nachwelt. Zum 50. Todestage [1912]. In: Karl Kraus: Nestroy und die Nachwelt. Mit einem Nachwort von Hans Mayer. Frankfurt am Main 1975 (Bibliothek Suhrkamp, Bd. 387), S. 5-32.

Kreissl (2013). Eva Kreissl (Hg.): Kulturtechnik Aberglaube. Zwischen Aufklärung und Spiritualität. Strategien zur Rationalisierung des Zufalls. Bielefeld 2013 (Edition Kulturwissenschaft, Bd. 19). Kriechbaumer (2013). Robert Kriechbaumer: Zwischen Österreich und Großdeutschland. Eine politische Geschichte der Salzburger Festspiele 1933-1944. Wien, Köln, Weimar 2013 (Schriftenreihe des Forschungsinstituts für politisch-historische Studien der Dr.-Wilfried-Haslauer-Bibliothek, Bd. 46).

Krieger (1990). Dorette Krieger: Die mittelalterlichen deutschsprachigen Spiele und Spielszenen des Weihnachtsstoffkreises. (Zugl. phil. Diss., Univ. Bochum 1989). Frankfurt am Main u.a. 1990 (Bochumer Schriften zur deutschen Literatur, Bd. 15).

Kroetz (1991). Franz Xaver Kroetz: Bauerntheater. Frankfurt am Main 1991.

Kroke (2010). Claudia Kroke: Johann Friedrich Blumenbach. Bibliographie seiner Schriften. Göttingen 2010 (Schriften zur Göttinger Universitätsgeschichte, Bd. 2).

Krünitz (1825). Johann Georg Krünitz: Ökonomisch-technologische Encyklopädie, oder allgemeines System der Staats-, Stadt-, Haus- und Landwirthschaft, und der Kunstgeschichte in alphabetischer Ordnung. Früher fortgesetzt von Friedrich Jakob und Heinrich Gustav Floerke, und jetzt von Johann Wilhelm David Korth. Hundert und ein und vierzigster Theil, welcher die Artikel Schauspiel bis Scheintod enthält. Nebst 12 Kupfertafel auf 3 Bogen und einem Portrait. Berlin 1825.

Krünitz (1855a). Johann Georg Krünitz: Ökonomisch-technologische Encyklopädie, oder allgemeines System der Staats-, Stadt-, Haus- und Landwirthschaft, und der Kunstgeschichte, in alphabetischer Ordnung. Früher fortgesetzt von Friedrich Jakob und Heinrich Gustav Floerke und Johann Wilhelm David Korth, jetzt von C[arl] O[tto] Hoffmann. Zweihundert und dreißigster Theil, welcher die Artikel Volksschule bis Volkstheater enthält. Berlin 1855.

Krünitz (1855b). Johann Georg Krünitz: Ökonomisch-technologische Encyklopädie, oder allgemeines System der Staats-, Stadt-, Haus- und Landwirthschaft, und der Kunstgeschichte, in alphabetischer Ordnung. Früher fortgesetzt von Friedrich Jakob und Heinrich Gustav Floerke und Johann 
Wilhelm David Korth, jetzt von C[arl] O[tto] Hoffmann. Zweihundert und einunddreißigster Theil, welcher die Artikel Volkstheater bis Waadt enthält. Berlin 1855.

Krünitz (1855c). Johann Georg Krünitz: Ökonomisch-technologische Encyklopädie, oder allgemeines System der Staats-, Stadt-, Haus- und Landwirthschaft, und der Kunstgeschichte, in alphabetischer Ordnung. Früher fortgesetzt von Friedrich Jakob und Heinrich Gustav Floerke und Johann Wilhelm David Korth, jetzt von C[arl] O[tto] Hoffmann. Zweihundert achtundzwanzigster Theil, welcher die Artikel Völkerrecht bis Volksredner enthält. Berlin 1855.

Kucher (2016). Primus-Heinz Kucher (Hg.): Verdrängte Moderne - vergessene Avantgarde. Diskurskonstellationen zwischen Literatur, Theater, Kunst und Musik in Österreich 1918-1938. Mit 21 Abbildungen. Göttingen 2016.

Kühebacher (1976). Egon Kühebacher (Hg.): Tiroler Volksschauspiel. Beiträge zur Theatergeschichte des Alpenraumes. Im Auftrag des Südtiroler Kulturinstitutes und des Bundes Südtiroler Volksbühnen. Bozen 1976 (Schriftenreihe des Südtiroler Kulturinstitutes, Bd. 3).

Kühn und Troschitz (2017). Thomas Kühn und Robert Troschitz: Populärkultur. Perspektiven und Analysen. Bielefeld 2017 (Edition Kulturwissenschaft, Bd. 144).

Kühr (2006). Angela Kühr: Als Kadmos nach Boiotien kam. Polis und Ethnos im Spiegel thebanischer Gründungsmythen. (Zugl. Diss., Univ. Köln 2005). Stuttgart 2006 (Hermes Einzelschriften, Bd. 98).

Kummer (1882). Karl Ferdinand Kummer: Erlauer Spiele. Sechs altdeutsche Mysterien nach einer Handschrift des XV. Jahrhunderts. Zum erstenmale herausgegeben und erläutert. Wien 1882.

Kupferblum (2013). Markus Kupferblum: Die Geburt der Neugier aus dem Geist der Revolution. Die Commedia dell'Arte als politisches Volkstheater. Mit Zeichnungen von Linde Waber. Wien 2013.

Küpper (2013). Joachim Küpper (Hg.): Approaches to World Literature. Berlin 2013 (Weltliteraturen, World Literatures, Bd. 1).

Küpper (2016). Joachim Küpper: Das frühneuzeitliche europäische Drama und das Konzept der Nationalliteratur. In: Andreas Kablitz (Hg.): Europas Sprachenvielfalt und die Einheit seiner Literatur. Freiburg im Breisgau, Berlin, Wien 2016 (Politisches Projekt und kulturelle Tradition. Schriftenreihe des Arbeitskreises Europa der Fritz Thyssen Stiftung, Bd. 1), S. 29-49.

Küpper (2017). Joachim Küpper: Rhetoric and the Cultural Net. Transnational Agencies of Culture. In: D. S. Mayfield (Hg.): Rhetoric and Drama. Berlin, Boston 2017, S. 151-175.

Küpper (2018a). Joachim Küpper: ,National Literatures‘? In: Toni Bernhart, Jaša Drnovšek, Sven Thorsten Kilian, Joachim Küpper und Jan Mosch (Hg.): Poetics and Politics. Net Structures and Agencies in Early Modern Drama. Berlin 2018, S. 19-35.

Küpper (2018b). Joachim Küpper: The Cultural Net. Early Modern Drama as a Paradigm. Berlin 2018. Kuprian und Reitterer (1999). H[ermann] Kuprian und H[ubert] Reitterer: Schuler Johann(es). In: ÖBL. Bd. 11 (1999), S. 318-319.

Kürschner (1879). Joseph Kürschner: Hagemann, Friedrich Gustav. In: ADB. Bd. 10 (1879), S. 327328.

Kwan (2013). Jonathan Kwan: Liberalism and the Habsburg Monarchy, 1861-1895. Basingstoke, New York 2013.

l'Houet (1905). A. l'Houet [d.i. Wilhelm Borée]: Zur Psychologie des Bauerntums. Ein Beitrag. Im Anschluß an synodale Verhandlungen, sowie in Verbindung mit dem „Ausschuß für Wohlfahrtspflege auf dem Lande“. Tübingen 1905.

Lacheny (2006). Marc Lacheny: La réception de l'œuvre de Johann Nestroy par Karl Kraus. Mécanismes et enjeux. Thèse de doctorat, Paris III 2006.

Lacheny (2016). Marc Lacheny: Littérature „d'en haut“, littérature „d'en bas“? La dramaturgie canonique allemande et le théâtre populaire viennois de Stranitzky à Nestroy. Mit einer umfangreichen Zusammenfassung in deutscher Sprache. Berlin 2016 (Forum Österreich, Bd. 2). 
Lammel und Schütt (1975). Inge Lammel und Ilse Schütt (Hg.): Hundert proletarische Balladen 1842-1945. Berlin 1975.

Lamping (2009a). Dieter Lamping: Einführung. In: Dieter Lamping (Hg.): Handbuch der literarischen Gattungen. In Zusammenarbeit mit Sandra Poppe, Sascha Seiler und Frank Zipfel. Stuttgart 2009, S. XV-XXVI.

Lamping (2009b). Dieter Lamping (Hg.): Handbuch der literarischen Gattungen. In Zusammenarbeit mit Sandra Poppe, Sascha Seiler und Frank Zipfel. Stuttgart 2009.

Landesgeschichtliches Informationssystem Hessen (2018). Landesgeschichtliches Informationssystem Hessen: Gründung des Bühnenvolksbundes in Frankfurt am Main, 8. April 1919. In: Zeitgeschichte in Hessen. Daten, Fakten, Hintergründe. http://www.lagis-hessen.de/de/subjects/ idrec/sn/edb/id/2101 (3.2.2019).

Landtag von Baden-Württemberg (2011). Landtag von Baden-Württemberg: Stellungnahme des Ministeriums für Wissenschaft, Forschung und Kunst. Landespreis für Volkstheaterstücke. Drucksache $15 / 859$ vom 10.11.2011. https://www.landtag-bw.de/files/live/sites/LTBW/files/ dokumente/WP15/Drucksachen/0000/15_0859_D.pdf (18.1.2019).

Lazarowicz und Balme (2012). Klaus Lazarowicz und Christopher Balme (Hg.): Texte zur Theorie des Theaters. Stuttgart 2012.

Lazarus (2003). Moritz Lazarus: Ueber den Begriff und die Möglichkeit einer Völkerpsychologie [1851]. In: Moritz Lazarus: Grundzüge der Völkerpsychologie und Kulturwissenschaft. Hg. von Klaus Christian Köhnke. Hamburg 2003 (Philosophische Bibliothek, Bd. 551), S. 3-25.

Lechleitner (1890). Franz Lechleitner: Tiroler Bauernspiele. I. Joseph Speckbacher, der Schützenmajor von Rinn, oder: Der Franzosenkrieg von Anno 1809. Ein Tiroler Nationalspiel in 5 Akten. II. Sunnwendgluten. Eine Tiroler Bauerntragödie in 4 Akten. III. Die Schlangenburg auf Frankenstein. Eine Tiroler Bauern-Ritterkomödie in 9 Bildern. Eisenach 1890 (Deutscher Bücherschatz, Bd. 6).

Leggewie und Meyer (2017). Claus Leggewie und Erik Meyer (Hg.): Global Pop. Das Buch zur Weltmusik. Stuttgart 2017.

Leitzmann (1927). Briefwechsel der Brüder Jacob und Wilhelm Grimm mit Karl Lachmann. Mit einer Einleitung von Konrad Burdach. 2 Bände. Hg. von Albert Leitzmann. Jena 1927.

Lentner (1893). Ferdinand Lentner: Deutsche Volkskomödie und Salzburgisches Hanswurstspiel. Studie über den Entwicklungs- und Rechtsgang des Bühnenwesens in Österreich. Innsbruck 1893.

Lenz (1774). Jakob Michael Reinhold Lenz: Anmerkungen übers Theater nebst angehängten übersetzten Stück Shakespears. Leipzig 1774.

Lenz (1987a). Jakob Michael Reinhold Lenz: Anmerkungen übers Theater. In: Jakob Michael Reinhold Lenz: Werke und Briefe in drei Bänden, Band 2. Hg. von Sigrid Damm. Leipzig 1987, S. 641671.

Lenz (1987b). Jakob Michael Reinhold Lenz: Nur ein Wort über Herders Philosophie der Geschichte. In: Jakob Michael Reinhold Lenz: Werke und Briefe in drei Bänden, Band 2. Hg. von Sigrid Damm. Leipzig 1987, S. 671-672.

Lenz (1987c). Jakob Michael Reinhold Lenz: Über Götz von Berlichingen. In: Jakob Michael Reinhold Lenz: Werke und Briefe in drei Bänden, Band 2. Hg. von Sigrid Damm. Leipzig 1987, S. 637641.

Lenz (1987d). Jakob Michael Reinhold Lenz: Von Shakespeares Hamlet. In: Jakob Michael Reinhold Lenz: Werke und Briefe in drei Bänden, Band 2. Hg. von Sigrid Damm. Leipzig 1987, S. 737744.

Lenz (1987e). Jakob Michael Reinhold Lenz: Werke und Briefe in drei Bänden, Band 2. Hg. von Sigrid Damm. Leipzig 1987.

Lewald (1831-1833). August Lewald: Novellen. 3 Bände. Hamburg 1831-1833. 
Lewald (1833). August Lewald: Die Stumme von Portici, auf dem hiesigen Hoftheater gegeben, den 19. März, mit veränderter Besetzung, und zum Vortheile der Mad. Spitzeder. In: Unterhaltungen für das Theater-Publikum (1833), H. 1, S. 13-16.

Lewald (1838). August Lewald: Tirol vom Glockner zum Orteles und vom Garda- zum Bodensee. Mit vier Stahlstichen, einer Postkarte von Tirol, einer vergleichenden Höhenkarte und einigen musikalischen Beigaben. Zweite durchgesehene Ausgabe in einem Bande. München 1838.

Lewald (1841). August Lewald: Theater-Roman. Mit Federzeichnungen von E[mil] Hochdanz. Stuttgart 1841.

Lewald (1844-1846). August Lewald: August Lewald's gesammelte Schriften. In einer Auswahl. 12 Bände. Leipzig 1844-1846.

Lewald (1844a). August Lewald: Biographisches über Ignaz Jeitteles. In: Ignaz Jeitteles: Eine Reise nach Rom. Mit einer biographischen Skizze desselben von August Lewald. Siegen und Wiesbaden 1844 , S. V-XXX.

Lewald (1844b). August Lewald: Theater in Büchsenhausen. In: August Lewald: August Lewald's gesammelte Schriften. In einer Auswahl. Fünfter Band. Leipzig 1844, S. 20-28.

Lewald (1845a). August Lewald: Deutsche Volks-Sagen. Für die erwachsene Jugend bearbeitet. Mit zwölf Stahlstichen. Stuttgart 1845.

Lewald (1845b). August Lewald: Die Geheimnisse des Theaters. Mit Federzeichnungen von E[mil] Hochdanz. Stuttgart 1845.

Lewald (1846). August Lewald: Entwurf zu einer praktischen Schauspielerschule. Wien 1846.

Lexer (1862). Matthias Lexer: Kärntisches Wörterbuch. Mit einem Anhange: Weihnacht-Spiele und Lieder aus Kärnten. Leipzig 1862.

Lexer (1872-1878). Matthias Lexer: Mittelhochdeutsches Handwörterbuch. 3 Bände. Leipzig 18721878.

Linden (1936). Walther Linden (Hg.): Naturalismus. Leipzig 1936 (Deutsche Literatur. Sammlung literarischer Kunst- und Kulturdenkmäler in Entwicklungsreihen, Reihe Vom Naturalismus zur neuen Volksdichtung, Bd. 1).

Linden (1940). Walther Linden (Hg.): Eindrucks- und Symbolkunst. Leipzig 1940 (Deutsche Literatur. Sammlung literarischer Kunst- und Kulturdenkmäler in Entwicklungsreihen, Reihe Vom Naturalismus zur neuen Volksdichtung, Bd. 2).

Lindner (1845). Heinrich Lindner: Karl der Zwölfte vor Friedrichshall. Eine Haupt- und Staatsaction in vier Actus, nebst einem Epilogus. Mit einem Vorwort herausgegeben. Dessau 1845.

Linke (1976). Hansjürgen Linke: Ist das Tiroler Schauspiel des Mittelalters Volksschauspiel? In: Egon Kühebacher (Hg.): Tiroler Volksschauspiel. Beiträge zur Theatergeschichte des Alpenraumes. Im Auftrag des Südtiroler Kulturinstitutes und des Bundes Südtiroler Volksbühnen. Bozen 1976 (Schriftenreihe des Südtiroler Kulturinstitutes, Bd. 3), S. 88-109.

Linke (2001). Hansjürgen Linke: Unstimmige Opposition. „Geistlich“ und „weltlich“ als Ordnungskategorien der mittelalterlichen Dramatik. In: Leuvense Bijdragen. Leuven Contributions in Linguistics and Philology 90 (2001), S. 75-126.

Linke (2002). Hansjürgen Linke (Hg.): Die deutschen Weltgerichtspiele des späten Mittelalters. Synoptische Gesamtausgabe. Tübingen, Basel 2002.

Lipphardt und Roloff (1980-1996). Walther Lipphardt und Hans-Gert Roloff (Hg.): Die geistlichen Spiele des Sterzinger Spielarchivs. 6 Bände. Bern, Frankfurt am Main, New York 1980-1996 (Mittlere deutsche Literatur in Neu- und Nachdrucken, Bd. 14-19).

Lugowski (1985). Clemens Lugowski: Der junge Herder und das Volkslied. Eine Interpretation [1938]. In: Manfred Wacker (Hg.): Sturm und Drang. Darmstadt 1985 (Wege der Forschung, Bd. 559), S. $215-233$. 
Lukács (1973). Georg Lukács: Es geht um den Realismus [1938]. In: Hans-Jürgen Schmitt (Hg.): Die Expressionismusdebatte. Materialien zu einer marxistischen Realismuskonzeption. Frankfurt am Main 1973, S. 192-230.

Lundell (1901-1909). J[ohan] A[ugust] Lundell: Skandinavische Volkspoesie. In: Hermann Paul (Hg.): Grundriß der germanischen Philologie, Band II, 1. Abt. 2., verbesserte und vermehrte Aufl. Straßburg 1901-1909, S. 1135-1177.

Luther (1545). Martin Luther: Biblia: das ist: Die gantze Heilige Schrifft: Deudsch. Auffs new zugericht. Wittenberg 1545 .

Maier (1782). [Jacob] Maier: Fust von Stromberg. Ein Schauspiel in fünf Aufzügen. Mit den Sitten[,] Gebräuchen und Rechten seines Jahrhunderts. Auf der Nationalschaubühne in Mannheim zum erstenmal aufgeführt den 5. Nov. 1782. Mannheim 1782.

Malzacher (2015). Florian Malzacher (Hg.): Not just a mirror. Looking for the political theatre of today. Berlin 2015 (Performing urgency, Bd. 1).

Margetts (1982). John Margetts (Hg.): Neidhartspiele. Graz 1982 (Wiener Neudrucke, Bd. 7).

Margetts (1986). John Margetts (Hg.): Die mittelalterlichen Neidhart-Spiele. In Abbildungen der Handschriften herausgegeben. Göppingen 1986 (Litterae, Göppinger Beiträge zur Textgeschichte, Bd. 73).

Marschall (2010). Brigitte Marschall: Politisches Theater nach 1950. Unter Mitarbeit von Martin Fichter. Wien, Köln, Weimar 2010 (UTB, Bd. 3403).

Martens (1981). Wolfgang Martens: Obrigkeitliche Sicht. Das Bühnenwesen in den Lehrbüchern der Policey und Cameralistik des 18. Jahrhunderts. In: Internationales Archiv für Sozialgeschichte der deutschen Literatur 6 (1981), S. 19-51.

Martin (2003). Dieter Martin: Horn, Franz Christoph. In: IGL, S. 807-809.

Martini (1985). Fritz Martini: Die Einheit der Konzeption in J.M.R. Lenz' ,Anmerkungen übers Theater [1970]. In: Manfred Wacker (Hg.): Sturm und Drang. Darmstadt 1985 (Wege der Forschung, Bd. 559), S. 250-278.

Martus (2015). Steffen Martus: Die Brüder Grimm. Eine Biographie. 2. Aufl. Reinbek bei Hamburg 2015 [2009].

Oče Romuald (2009). Oče Romuald [d.i. Lovrenc Marusič]: Škofjeloški pasijon. Znanstvenokritična izdaja. Hg. von Matija Ogrin. Celje, Ljubljana 2009.

Marx (2008). Peter W. Marx: Ein theatralisches Zeitalter. Bürgerliche Selbstinszenierungen um 1900. Tübingen, Basel 2008.

Mauelshagen (2013). Franz Mauelshagen: Emil Ottokar Weller. In: Historisches Lexikon der Schweiz. http://www.hls-dhs-dss.ch/textes/d/D46665.php (28.5.2019).

Mautner (1974). Franz M. Mautner: Nestroy. Heidelberg 1974.

Mautz (2003). Susanne Mautz: Al decoro dell'opera ed al gusto dell'auditore. Intermedien im italienischen Theater der ersten Hälfte des 17. Jahrhunderts. (Zugl. Diss., Univ. Karlsruhe 2001). Berlin 2003.

May (1975). Erich Joachim May: Wiener Volkskomödie und Vormärz. Berlin 1975.

Mayer (1975). Hans Mayer: Nachwort. In: Karl Kraus: Nestroy und die Nachwelt. Mit einem Nachwort von Hans Mayer. Frankfurt am Main 1975 (Bibliothek Suhrkamp, Bd. 387), S. 209-216.

Mayer und Koberg (2006). Verena Mayer und Roland Koberg: Elfriede Jelinek. Ein Porträt. Reinbek bei Hamburg 2006.

Meier (1901-1909). John Meier: Deutsche und niederländische Volkspoesie. In: Hermann Paul (Hg.): Grundriß der germanischen Philologie, Band II, 1. Abt. 2., verbesserte und vermehrte Aufl. Straßburg 1901-1909, S. 1178-1297.

Meier (1935a). John Meier (Hg.): Balladen. Erster Teil. Leipzig 1935 (Deutsche Literatur. Sammlung literarischer Kunst- und Kulturdenkmäler in Entwicklungsreihen, Reihe Das deutsche Volkslied, Bd. 1). 
Meier (1935b). John Meier (Hg.): Deutsche Volkslieder. Balladen. Erster Teil. Unter Mithilfe von Harry Schewe und Erich Seemann gemeinsam mit Wilhelm Heiske und Fred Quellmalz. Berlin, Leipzig 1935 (Deutsche Volkslieder mit ihren Melodien, Bd. 1).

Meier (1936). John Meier (Hg.): Balladen. Zweiter Teil. Leipzig 1936 (Deutsche Literatur. Sammlung literarischer Kunst- und Kulturdenkmäler in Entwicklungsreihen, Reihe Das deutsche Volkslied, Bd. 2).

Meier (1939). John Meier (Hg.): Deutsche Volkslieder. Balladen. Zweiter Teil. Unter Mithilfe von Bruno Maerker gemeinsam mit Gerhard Heilfurth, Wilhelm Heiske, Fred Quellmalz, Erich Seemann, Richard Volk, Sascha Wingenroth und Walter Wiora. Berlin 1939 (Deutsche Volkslieder mit ihren Melodien, Bd. 2).

Meier (1954). John Meier (Hg.): Deutsche Volkslieder. Balladen. Dritter Teil. Unter Mithilfe mehrerer Fachgenossen gemeinsam mit Erich Seemann und Walter Wiora. Berlin 1954 (Deutsche Volkslieder mit ihren Melodien, Bd. 3).

Meinert (1817). Joseph George Meinert: Alte teutsche Volkslieder in der Mundart des Kuhländchens. Herausgegeben und erläutert. Erster Band [mehr nicht erschienen]. Wien, Hamburg 1817.

Meister (1912). Hermann Meister: Das Bauerntheater. In: Der Merker. Österreichische Zeitschrift für Musik und Theater 3 (1912), H. 15, S. 577-579.

Menghin (1910). Oswald Menghin: Ein Weihnachtszeltenspiel aus Tirol. In: Zeitschrift des Vereins für Volkskunde 20 (1910), S. 387-394.

Merbach (1922). Paul [Alfred] Merbach: Das deutsche Volksstück. Augsburg 1922 (Dichter und Bühne, Reihe 1: Wesen und Art des Dramas, Bd. 11).

Mercier (1784). Louis-Sébastien Mercier: Montesquieu à Marseille. Piece en Trois Actes. Lausanne 1784.

Metz (2002). Bernhard Metz: „Bei deinen Feiertagen Germania, wo du Priesterin bist“. Germanistische Literaturwissenschaft in der Zeit des Nationalsozialismus. Master Thesis, Universität Konstanz 2002. http://nbn-resolving.de/urn:nbn:de:bsz:352-opus-9765 (22.3.2019).

Meves (2000). Uwe Meves: Karl Lachmann (1793-1851). In: Christoph König, Hans-Harald Müller und Werner Röcke (Hg.): Wissenschaftsgeschichte der Germanistik in Porträts. Berlin, New York 2000, S. 20-32.

Meyer (1986-2011). Reinhart Meyer: Bibliographia dramatica et dramaticorum. Kommentierte Bibliographie der im ehemaligen deutschen Reichsgebiet gedruckten und gespielten Dramen des 18. Jahrhunderts nebst deren Bearbeitungen und Übersetzungen und ihrer Rezeption bis in die Gegenwart. Tübingen, Berlin 1986-2011.

Meyer (1990). Reinhart Meyer: Hanswurst und Harlekin, oder: Der Narr als Gattungsschöpfer. Versuch einer Analyse des komischen Spiels in den Staatsaktionen des Musik- und Sprechtheaters im 17. und 18. Jahrhundert. In: Roland Krebs und Jean-Marie Valentin (Hg.): Théâtre, nation \& société en Allemagne au XVIIle siècle. Études rassemblées. Nancy 1990, S. 13-39.

Michler (2015). Werner Michler: Kulturen der Gattung. Poetik im Kontext, 1750-1950. Göttingen 2015.

Mohr (2018). Jan Mohr: Wege nach innen. Die Reise zum Oberammergauer Passionsspiel seit dem 19. Jahrhundert. In: Uta Schaffers, Stefan Neuhaus und Hajo Diekmannshenke (Hg.): (Off) The Beaten Track? Normierungen und Kanonisierungen des Reisens. Würzburg 2018, S. 97-116. Möller (1936). Eberhard Wolfgang Möller: Das Frankenburger Würfelspiel. Berlin 1936.

Mosen (1856). Gustav Mosen: Die Anfänge der Tragödie bei den Griechen und die Keime einer christlichen Tagödie der Zukunft. In: Gymnasium zu Zwickau. Jahresbericht über das Schuljahr 1855-1856 (1856), S. 3-40.

Mosen (1861). Gustav Mosen: Die Weihnachtsspiele im sächsischen Erzgebirge. Zwickau 1861. 
Mosen (1884). Gustav Mosen: Was ein Morgensonnenstrahl hervorgerufen hat. Eine beglückende Weltanschauung, gegründet auf sichere naturwissenschaftliche Tatsachen und alltägliche Erfahrungen. Zwickau 1884.

Mosen (1888). Gustav Mosen: In Dämmerlicht und Sonnenschein. Gedichte. Zwickau 1888.

Mosen (1894). Gustav Mosen: Christi Geburt. Weihnachtsfestspiel in sieben Handlungen für Vereine und Schulen. Durchgesehen und mit einer Notenbeilage. Hg. von Alfred Müller. 2. Aufl. Annaberg 1894.

Moser (1929). Hans Moser: Das Volksschauspiel zu Kiefersfelden. Ein Beitrag zur Kulturgeschichte Altbayerns. (Zugl. Diss., Univ. München 1927, Teildruck). In: Oberbayerisches Archiv für vaterländische Geschichte 66 (1929), S. 117-208.

Moser (1935a). Hans Moser: Das Volksschauspiel [1934]. In: Adolf Spamer (Hg.): Die Deutsche Volkskunde. Band 1: Textband. 2., verbesserte und vermehrte Aufl. Leipzig, Berlin 1935 (Das deutsche Volk, Bd. 3), S. 349-387.

Moser (1935b). Hans Moser: Volksschauspiel im Auslanddeutschtum. In: Dichtung und Volkstum 36 (1935), S. 88-107.

Moser (1962). Hans Moser: Vom Folklorismus in unserer Zeit. In: Zeitschrift für Volkskunde 58 (1962), H. 2, S. 177-209.

Moser (1984). Dietz-Rüdiger Moser: Volksschauspiel. In: Klaus Kanzog und Achim Masser (Hg.): Reallexikon der deutschen Literaturgeschichte. Begründet von Paul Merker und Wolfgang Stammler. Band 4. 2. Aufl. Berlin 1984, S. 772-786.

Moser (1987). Gerhard Moser: Vom Pöbel zur Volksgemeinschaft. Die Beliebigkeit des Begriffs „Volk“. In: Erwin Kisser und Reinhard Auer (Hg.): Konflikttheater - Theaterkonflikte. Zur Phänomenologie nicht-illusionistischer Theaterformen. Wien 1987 (Korrespondenz fortschrittlicher Hochschullehrer und Wissenschaftler), S. 25-33.

Moser (1991). Hans Moser: Volksschauspiel im Spiegel von Archivalien. Ein Beitrag zur Kulturgeschichte Altbayerns. Hg. von Edgar Harvolk und Hans Schuhladen. München 1991 (Bayerische Schriften zur Volkskunde, Bd. 3).

Moser und Zoder (1938). Hans Moser und Raimund Zoder: Deutsches Volkstum in Volksschauspiel und Volkstanz. Mit 24 Tafeln. Berlin 1938 (Deutsches Volkstum, Bd. 3).

Müllenhoff (1845). Karl Müllenhoff (Hg.): Sagen, Märchen und Lieder der Herzogthümer Schleswig, Holstein und Lauenburg. Kiel 1845.

Müller ([um 1775]). Johann Heinrich Friedrich Müller: Gräfinn Tarnow. Ein Originaldrama, in fünf Aufzügen verfertiget. Zum erstenmale aufgeführt den 15ten Oct. 1771. [Wien] [um 1775].

Müller (1985). Jan-Dirk Müller: Volksbuch/Prosaroman im 15./16. Jahrhundert - Perspektiven der Forschung. In: Internationales Archiv für Sozialgeschichte der deutschen Literatur, Sonderheft Forschungsreferate 1 (1985), S. 1-128.

Müller (1990). Jan-Dirk Müller (Hg.): Romane des 15. und 16. Jahrhunderts. Nach den Erstdrucken mit sämtlichen Holzschnitten. Frankfurt am Main 1990 (Bibliothek der Frühen Neuzeit, Bd. 1).

Müller (2003). Jan-Dirk Müller (Hg.): Reallexikon der deutschen Literaturwissenschaft. Neubearbeitung des Reallexikons der deutschen Literaturgeschichte, gemeinsam mit Georg Braungart, Harald Fricke, Klaus Grubmüller, Friedrich Vollhardt und Klaus Weimar. Band III. Berlin, New York 2003.

Müller (2003b). Jan-Dirk Müller: Volksbuch. In: Jan-Dirk Müller (Hg.): Reallexikon der deutschen Literaturwissenschaft. Neubearbeitung des Reallexikons der deutschen Literaturgeschichte gemeinsam mit Georg Braungart, Harald Fricke, Klaus Grubmüller, Friedrich Vollhardt und Klaus Weimar. Band III. Berlin, New York 2003, S. 789-791.

Müller (2014). Jan-Dirk Müller: Volksbuch. In: Rolf Wilhelm Brednich (Hg.): Enzyklopädie des Märchens. Handwörterbuch zur historischen und vergleichenden Erzählforschung. Begründet von Kurt Ranke. Band 14. Berlin, Boston 2014, Sp. 309-324. 
Müller (2007). Karl Müller: Eine Zeit „ohne Ordnungsbegriffe“? Die literarische Antimoderne nach 1918 - ein Fallbeispiel: Hugo von Hofmannsthals Programmstück der Salzburger Festspiele und die „Konservative Revolution“. In: Primus-Heinz Kucher (Hg.): Literatur und Kultur im Österreich der Zwanziger Jahre. Vorschläge zu einem transdisziplinären Epochenprofil. Bielefeld 2007, S. 21-46.

Müller-Kampel (2003). Beatrix Müller-Kampel: Hanswurst, Bernardon, Kasperl. Spaßtheater im 18. Jahrhundert. Paderborn 2003.

Münkler (2010). Marina Münkler: „durch unverdrossene tüchtige Arbiet“. Karl Lachmann (17931851) als Philologe. In: Zeitschrift für Germanistik 20 (2010), H. 1, S. 104-122.

Müry (2014). Andres Müry: Jedermann darf nicht sterben. Geschichte eines Salzburger Kults. Völlig neu bearbeitete Aufl. Salzburg 2014 [2001].

Musäus (1782-1786). Johann August Musäus: Volksmährchen der Deutschen. 5 Bände. Gotha 17821786.

[Nachtigal] (1800). [Johann Karl Christoph Nachtigal]: Volcks-Sagen. Nacherzählt von Otmar. Bremen 1800.

Nadler (1912). Josef Nadler: Literaturgeschichte der deutschen Stämme und Landschaften. Band 1: Die Altstämme (800-1600). Regensburg 1912.

Nadler (1918). Josef Nadler: Literaturgeschichte der deutschen Stämme und Landschaften. Band 3: Hochblüte der Altstämme bis 1805 und der Neustämme bis 1800. Regensburg 1918.

Nadler ([1921]). Josef Nadler: Das österreichische Volksstück. Literatur- und Musikgeschichte in Einzelheften für Theaterbesucher. Hg. vom Bühnen-Volksbund in Frankfurt/Main. Augsburg, Stuttgart [1921].

Nadler (1934a). Josef Nadler: Das stammhafte Gefüge des deutschen Volkes. München 1934.

Nadler (1934b). Josef Nadler: Rassenkunde, Volkskunde, Stammeskunde. In: Dichtung und Volkstum. Neue Folge des Euphorion 35 (1934), S. 1-18.

[Naubert] (1789-1792). [Benedikte Naubert]: Neue Volksmährchen der Deutschen. 4 Bände. Leipzig 1789-1792.

Naubert (2001). Benedikte Naubert: Neue Volksmärchen der Deutschen. Erster Band [1789]. Hg. von Marianne Henn, Paola Mayer und Anita Runge. Göttingen 2001.

Naumann (1921). Hans Naumann: Primitive Gemeinschaftskultur. Beiträge zur Volkskunde und Mythologie. Jena 1921.

Naumann und Naumann (1923). Hans Naumann und Ida Naumann (Hg.): Isländische Volksmärchen. Übersetzt von Hans und Ida Naumann. Jena 1923 (Die Märchen der Weltliteratur).

NDB. Neue Deutsche Biographie. Hg. von der Historischen Kommission bei der Bayerischen Akademie der Wissenschaften. Berlin 1953-.

Nebrig (2014). Alexander Nebrig: Die Welt als Lied. Der globale Anspruch von Herders Volksliedern. In: Christian Moser und Linda Simonis (Hg.): Figuren des Globalen. Weltbezug und Welterzeugung in Literatur, Kunst und Medien. Mit 21 Abbildungen. Bonn 2014 (Global Poetics, Bd. 1), S. 315-325.

Neckel (1935-1936). Gustav Neckel (Hg.): Deutsche Sagen. Band 1: Sagen aus dem germanischen Altertum. Band 2: Vom Altertum zum Mittelalter. Band 3: Vermischte Sagen. Leipzig 1935-1936 (Deutsche Literatur. Sammlung literarischer Kunst- und Kulturdenkmäler in Entwicklungsreihen, Reihe Deutsche Sagen, Bd. 1-3).

Nelissen Haken (1935). Bruno Nelissen Haken: Das Volks- und Thingspiel. In: Hochschule und Ausland. Monatsschrift für Kulturpolitik und zwischenvölkische geistige Zusammenarbeit 13 (1935), H. 8, S. 55-65.

Nestroy (1890-1891). Johann Nestroy: Gesammelte Werke. 12 Bände. Hg. von Vincenz Chiavacci und Ludwig Ganghofer. Stuttgart 1890-1891. 
Nestroy (1977-2012). Johann Nestroy: Sämtliche Werke. Historisch-kritische Ausgabe. Hg. von Jürgen Hein, Johann Hüttner, Walter Obermaier und W. Edgar Yates. Wien, München 19772012.

Neuber (1987). Wolfgang Neuber: Nestroys Rhetorik. Wirkungspoetik und Altwiener Volkskomödie im 19. Jahrhundert. (Zugl. phil. Diss., Univ. Wien 1980). Bonn 1987 (Abhandlungen zur Kunst-, Musik- und Literaturwissenschaft, Bd. 373).

Neuert (1886). Hans Neuert: Almenrausch und Edelweiß. Oberbayerisches Charaktergememälde mit Gesang und Tanz in fünf Aufzügen mit theilweiser Benützung der Erzählung des Dr. Herman von Schmid. Augsburg 1886.

Neuhuber (2002). Christian Neuhuber: Otto Rommel. In: Ingeborg Fiala-Fürst und Jörg Krappmann (Hg.): Lexikon deutschmährischer Autoren. [Loseblattsammlung]. Olomouc 2002 (Beiträge zur mährischen deutschsprachigen Literatur, Bd. 5), S. 1-5.

Neumann (1979). Bernd Neumann: Zeugnisse mittelalterlicher Aufführungen im deutschen Sprachraum. Eine Dokumentation zum volkssprachigen geistlichen Schauspiel. 2 Teile. (Zugl. Diss., Univ. Köln 1977). Köln 1979.

Neumann und Obermair (2011). Bernd Neumann und Hannes Obermair: Tiroler Spiele. In: Wilhelm KühImann (Hg.): Killy Literaturlexikon. Autoren und Werke des deutschsprachigen Kulturraumes. In Verbindung mit Achim Aurnhammer, Jürgen Egyptien, Karina Kellermann, Steffen Martus, Reimund B. Sdzuj. 2. Aufl. Berlin, Boston 2011 (Bd. 11), S. 546-548.

[Nicolai] (1775). [Friedrich Nicolai]: Freuden des jungen Werthers. Leiden und Freuden Werthers des Mannes. Voran und zuletzt ein Gespräch. Berlin 1775.

[Nicolai] (1777). [Friedrich Nicolai]: Eyn feyner kleyner Almanach vol schönerr echterr liblicherr Volckslieder, lustigerr Reyen vnndt kleglicherr Mordgeschichte, gesungen von Gabriel Wunderlich weyl. Benkelsengernn zu Dessaw, herausgegeben von Daniel Seuberlich, Schusternn tzu Ritzmück ann der Elbe. Erster Jahrgang. Berlynn vnndt Stettynn 1777 [eigentlich 1776].

[Nicolai] (1778). [Friedrich Nicolai]: Eyn feyner kleyner Almanach vol schönerr echterr ljblicherr Volcksljder, lustigerr Reyen vnndt kleglicherr Mordgeschichten, gesungenn von Gabryel Wunderlich weyl. Benkelsengernn tzu Dessaw, heraußgegebenn von Danyel Seuberlich, Schusternn tzu Ritzmück ann der Elbe. Zweyter Jargang. Berlynn vnndt Stettynn 1778.

Nicolai (1784). Friedrich Nicolai: Beschreibung einer Reise durch Deutschland und die Schweiz, im Jahre 1781. Nebst Bemerkungen über Gelehrsamkeit, Industrie, Religion und Sitten. Vierter Band. Berlin, Stettin 1784.

Nicolai (1987). Friedrich Nicolai: „Kritik ist überall, zumal in Deutschland, nötig“. Satiren und Schriften zur Literatur. Mit 20 zeitgenössischen Abbildungen. Hg. von Wolfgang Albrecht. München 1987 (Bibliothek des 18. Jahrhunderts).

Nicolai (2015). Friedrich Nicolai: Eyn feyner kleyner Almanach (Erster und zweyter Jahrgang). In: Friedrich Nicolai: Sämtliche Werke - Briefe - Dokumente. Kritische Ausgabe mit Kommentar. Literarische Schriften I, Band 1,2: Freuden des jungen Werthers, Eyn feyner kleiner Almanach, Anhang zu Friedrich Schillers Musen-Almanach für das Jahr 1797. Bearbeitet von Hans-Gert Roloff. Hg. von Rainer Falk, István Gombocz, Hans-Gert Roloff und Jutta Weber. Stuttgart-Bad Cannstatt 2015, S. 37-236.

Nied (1986). Ernst Georg Nied: Almenrausch und Jägerblut. Die Anfänge des berufsmäßigen oberbayerischen Bauerntheaters vor dem Ersten Weltkrieg. München 1986 (Münchner Beiträge zur Theaterwissenschaft, Bd. 17).

Nies (1989). Fritz Nies: Für die stärkere Ausdifferenzierung eines pragmatisch konzipierten Gattungssystems. In: Christian Wagenknecht (Hg.): Zur Terminologie der Literaturwissenschaft. Akten des IX. Germanistischen Symposions der Deutschen Forschungsgemeinschaft Würzburg 1986. Stuttgart 1989 (Germanistische Symposien, Berichtsbände, Bd. 9), S. 326-336. 
Nishani (1936). Trandafile Omer Nishani [d.i. Roswitha von Woller]: Albanien, das Wunschland Mussolinis. 2. Aufl. Halle (Saale) 1936.

Niven (2000). William Niven: The Birth of Nazi Drama? Thing Plays. In: John London (Hg.): Theatre under the Nazis. Manchester 2000, S. 54-95.

Noa (2013). Miriam Noa: Volkstümlichkeit und Nationbuilding. Zum Einfluss der Musik auf den Einigungsprozess der deutschen Nation im 19. Jahrhundert. (Zugl. Diss., Humboldt-Univ. zu Berlin 2012). Münster u.a. 2013 (Populäre Kultur und Musik, Bd. 8).

Nowotnick (2018). Michaela Nowotnick: „... die geistige Verbindung mit dem Mutterlande aufrecht zu erhalten“. Ostland. Vom geistigen Leben der Auslanddeutschen und die Bemühungen um Kontakte zum literarischen Leben in Deutschland. In: Enikő Dácz (Hg.): Räumliche Semantisierungen. Raumkonstruktionen in den deutschsprachigen Literaturen aus Zentral- und Südosteuropa im 20.-21. Jahrhundert. Regensburg 2018 (Veröffentlichungen des Instituts für deutsche Kultur und Geschichte Südosteuropas, Bd. 135), S. 179-198.

Noyes (2015). John K. Noyes: Herder. Aesthetics against Imperialism. Toronto, Buffalo, London 2015. Nußbaumer (2001). Thomas Nußbaumer: Alfred Quellmalz und seine Südtiroler Feldforschungen (1940-42). Eine Studie zur musikalischen Volkskunde unter dem Nationalsozialismus. Innsbruck u.a. 2001 (Bibliotheca Musicologica, Bd. 6).

Nyssen (1984). Ute Nyssen: Nachwort. In: Elfriede Jelinek: Theaterstücke. Clara S., Was geschah, nachdem Nora ihren Mann verlassen hatte, Burgtheater. Hg. und mit einem Nachwort von Ute Nyssen. Köln 1984, S. 151-162.

Oberst (2010). Manuela Oberst: Exercitium, Propaganda und Repräsentation. Die Dramen-, Periochen- und Librettosammlung der Prämonstratenserreichsabtei Marchtal (1657 bis 1778). Stuttgart 2010 (Veröffentlichungen der Kommission für Geschichtliche Landeskunde in BadenWürttemberg, Reihe B, Bd. 179).

ÖBL. Österreichisches Biographisches Lexikon 1815-1950. Hg. von der Österreichischen Akademie der Wissenschaften. Graz, Köln, Wien 1954-.

Oppel (1994). Margarete Oppel: Kunst-Ideal und Sammlungstätigkeit. In: Sabine Schulze (Hg.): Goethe und die Kunst. Ostfildern-Ruit 1994, S. 60-61.

Ospovat (2016). Kirill Ospovat: Terror and Pity. Aleksandr Sumarokov and the Theater of Power in Elizabethan Russia. Boston, MA 2016 (Imperial encounters in Russian history).

Pailler (1883). Wilhelm Pailler: Weihnachtslieder und Krippenspiele aus Oberösterreich und Tirol. Band 2: Krippenspiele aus Oberösterreich und Tirol. Innsbruck 1883.

Palmetshofer (2009). Ewald Palmetshofer: sauschneidn. Grazer Fassung. [Bühnenmanuskript]. Frankfurt am Main 2009.

Palomba (1798). Giuseppe Palomba: La Pianella persa. Farsa giocosa per musica d'un solo atto. Da rappresentarsi nel Teatro della Magnifica Accademia Filarmonica di Verona. La musica è tutta nuova del maestro Francesco Gardi. Verona 1798.

Pan (2009). David Pan: Developing a Theater of the Collective. Brecht's „Lehrstücke“ and the Nazi „Thingspiele“. In: Colloquia Germanica 42 (2009), H. 4, S. 307-326.

Pappalardo (2013). Ferdinando Pappalardo: „Genericità“. Il discorso sui generi letterari nella cultura europea. Bari 2013.

Paul (1901-1909). Hermann Paul (Hg.): Grundriß der germanischen Philologie, Band II, 1. Abt. 2., verbesserte und vermehrte Aufl. Straßburg 1901-1909.

Pauli (1986). Manfred Pauli: Stücke für und über das Volk. Zum Volksstück in der Dramen- und Theatergeschichte des deutschen Sprachraums. Von den realen Wirkungsmöglichkeiten volkstümlicher Dramatik. Diss., Universität Leipzig 1986.

Pauli (1992). Manfred Pauli: Spurensuche. Wirkungen von Brechts Volksstück-Konzept auf Stückeschreiber und Theater in der DDR. In: Ursula Hassel und Herbert Herzmann (Hg.): Das zeitgenössische deutschsprachige Volksstück. Akten des internationalen Symposions, University 
College Dublin, 28. Februar-2. März 1991. Tübingen 1992 (Stauffenburg Colloquium, Bd. 23), S. 65-74.

Pauli (2015). Manfred Pauli: Dem Volk aufs Maul geschaut. Dramaturgische Studien zu einem Prinzip Volksstück in der deutschsprachigen Dramatik. 2 Bände. Schkeuditz 2015.

Payer von Thurn (1908-1910). Rudolf Payer von Thurn (Hg.): Wiener Haupt- und Staatsaktionen. Eingeleitet und herausgegeben. 2 Bände. Wien 1908-1910 (Schriften des Literarischen Vereins in Wien, Bd. 10).

Peter (1865). Anton Peter: Volksthümliches aus Österreichisch-Schlesien. Gesammelt und herausgegeben. Band 1: Kinderlieder und Kinderspiele, Volkslieder und Volksschauspiele, Sprichworte. Troppau 1865.

Peter (1867). Anton Peter: Volksthümliches aus Österreichisch-Schlesien. Gesammelt und herausgegeben. Band 2: Sagen und Märchen, Bräuche und Volksaberglauben. Troppau 1867.

Peter (1873). Anton Peter: Volksthümliches aus Österreichisch-Schlesien. Gesammelt und herausgegeben. Band 3: Leben der Oppaländer in Vergangenheit und Gegenwart. Mit colorierten Trachtenbildern. Troppau 1873.

Peters (2003). Jelko Peters: Weinhold, Karl Gotthold Jakob. In: IGL, S. 1999-2001.

Petersen und Pongs (1934). Julius Petersen und Hermann Pongs: An unsere Leser! In: Dichtung und Volkstum. Neue Folge des Euphorion 35 (1934), S. III-IV.

Pichler (1850). Adolph Pichler: Ueber das Drama des Mittelalters in Tirol. Innsbruck 1850.

Pichler (1854a). Adolph Pichler: Ueber Bauernspiele in Tirol. Ein Beitrag zur Geschichte deutscher Volksdichtung. In: Österreichische Blätter für Literatur und Kunst, Beilage zur ÖsterreichischKaiserlichen Wiener Zeitung (1854), H. 32, S. 209-210.

Pichler (1854b). Adolph Pichler: Ueber Bauernspiele in Tirol. Ein Beitrag zur Geschichte deutscher Volksdichtung (Fortsetzung). In: Österreichische Blätter für Literatur und Kunst, Beilage zur Österreichisch-Kaiserlichen Wiener Zeitung (1854), H. 34, S. 221-224.

Pichler (1854c). Adolph Pichler: Ueber Bauernspiele in Tirol. Ein Beitrag zur Geschichte deutscher Volksdichtung (Schluß). In: Österreichische Blätter für Literatur und Kunst, Beilage zur Österreichisch-Kaiserlichen Wiener Zeitung (1854), H. 36, S. 234-238.

Pichler (1905-1909). Adolf Pichler: Gesammelte Werke. Vom Verfasser für den Druck vorbereitet. 17 Bände. München, Leipzig 1905-1909.

Piech (2016). Janina Piech: Anekdotisierung von Zensur - Nestroy im Zensurarchiv Houben. In: Nestroyana 36 (2016), H. 3/4, S. 159-168.

Pindar (1986). Pindar: Oden. Griechisch/Deutsch. Übersetzt und hg. von Eugen Dönt. Stuttgart 1986.

Planard (1833). Eugène de Planard: Der Zweikampf, Oper in drei Aufzügen. Nach dem Französischen des Planard: „Le Pré aux Clercs“. Zur beibehaltenen Musik von Herold, für die deutsche Bühne bearbeitet von dem Freiherrn von Lichtenstein. Mainz 1833.

Plattner (1999). Irmgard Plattner: Kultur und Kulturpolitik. In: Michael Gehler (Hg.): Tirol. „Land im Gebirge“. Zwischen Tradition und Moderne. Wien, Köln, Weimar 1999 (Geschichte der österreichischen Bundesländer seit 1945, Bd. 3), S. 223-312.

Pohle (2010). Frank Pohle: Glaube und Beredsamkeit. Katholisches Schultheater in Jülich-Berg, Ravenstein und Aachen (1601-1817). (Zugl. phil. Diss., RWTH Aachen 2005). Münster 2010 (Symbolische Kommunikation und gesellschaftliche Wertesysteme, Bd. 29).

Polheim (1916). Karl Polheim: [Bericht über die mit Unterstützung der kais. Akademie unternommenen Vorarbeiten zur Herausgabe steirischer Volksschauspiele]. In: Anzeiger, Kaiserliche Akademie der Wissenschaften in Wien, Philosophisch-historische Klasse 53 (1916), S. 90-102.

Polheim (1918). Karl Polheim: [Zweiter Bericht über die mit Unterstützung der Akademie unternommenen Vorarbeiten zur Herausgabe steirischer Volksschauspiele]. In: Anzeiger, Akademie der Wissenschaften in Wien, Philosophisch-historische Klasse 55 (1918), S. 128-134. 
Polheim (1986). Karl Konrad Polheim: Das verkannte Volksschauspiel. Eine mißachtete Erkenntnisquelle des mittelalterlichen Dramas. In: Klaus Grubmüller und Günter Hess (Hg.): Bildungsexklusivität und volkssprachliche Literatur. Literatur vor Lessing - nur für Experten? Tübingen 1986 (Kontroversen, alte und neue, Bd. 7), S. 86-104.

Polheim (1992). Karl Konrad Polheim: Katalog der Volksschauspiele aus Steiermark und Kärnten. Nebst Analekten aus Bayern, West- und Ostösterreich. Tübingen 1992.

Polheim (2000). Karl Konrad Polheim: Vorwort. In: Karl Konrad Polheim und Stefan Schröder (Hg.): Volksschauspiele. Band I: Passionsspiele. Erster Teil. Paderborn u.a. 2000, S. VII-X.

Polheim (2002a). Karl Konrad Polheim: Volksschauspiel und mittelalterliches Drama. Am Beispiel der Passionsspiele aus Tirol, Kärnten und der Steiermark [1976]. In: Karl Konrad Polheim und Stefan Schröder (Hg.): Volksschauspiele. Band V: Studien zum Volksschauspiel und mittelalterlichen Drama, mit einer Fotodokumentation. Paderborn u.a. 2002, S. 11-36.

Polheim (2002b). Karl Konrad Polheim: Vorwort. In: Karl Konrad Polheim und Stefan Schröder (Hg.): Volksschauspiele. Band V: Studien zum Volksschauspiel und mittelalterlichen Drama, mit einer Fotodokumentation. Paderborn u.a. 2002, S. 5-6.

Polheim und Schröder (2000-2004). Karl Konrad Polheim und Stefan Schröder (Hg.): Volksschauspiele. 5 Bände. Paderborn u.a. 2000-2004.

Polheim und Schröder (2002). Karl Konrad Polheim und Stefan Schröder (Hg.): Volksschauspiele. Band V: Studien zum Volksschauspiel und mittelalterlichen Drama, mit einer Fotodokumentation. Paderborn u.a. 2002.

Pörnbacher (2005). Hans Pörnbacher: Sailer, Sebastian. In: NDB. Bd. 22 (2005), S. 357-358.

Porra und Wedekind (2017). Véronique Porra und Gregor Wedekind: Orient - Zur (De-)konstruktion eines Phantasmas. Bielefeld 2017 (Mainzer Historische Kulturwissenschaften, Bd. 32).

Prem (1922). S[imon] M[arian] Prem: Geschichte der neueren deutschen Literatur in Tirol. 1. Abteilung: Vom Beginn des 17. bis zur Mitte des 19. Jahrhunderts. Mit einem Textanhang. Innsbruck 1922.

Pröhle (1851). Heinrich Pröhle: Aus dem Harze. Skizzen und Sagen. Leipzig 1851.

Pröhle (1852). Heinrich Pröhle (Hg.): Hausbüchlein für das Volk und seine Freunde. Eine Sammlung von Erzählungen, Märchen und Schilderungen aus dem Leben des Volks. Mit einer Einleitung über die volksthümliche Literatur in Deutschland. Ausgewählt und herausgegeben. 2 Bände. Leipzig 1852.

Pröhle (1853). Heinrich Pröhle: Kinder- und Volksmärchen. Leipzig 1853.

Pröhle (1854a). Heinrich Pröhle: Harzsagen. Gesammelt auf dem Oberharz und in der übrigen Gegend von Harzeburg und Goslar bis zur Grafschaft Hohenstein und bis Nordhausen. Leipzig 1854.

Pröhle (1854). Heinrich Pröhle: Ueber die Sage und das Märchen und ihre Benutzung in deutschen Dichtungen, insbesondere Gottfried August Bürgers. In: Allgemeine Monatsschrift für Wissenschaft und Literatur (1854), S. 521-547.

Pröhle (1855a). Henricus Pröhle: De Bructeri nominibus et de fabulis quae ad eum montem pertinent. Dissertatio inauguralis. Werningerode 1855.

Pröhle (1855b). Heinrich Pröhle: Friedrich Ludwig Jahn's Leben. Nebst Mittheilungen aus seinem literarischen Nachlasse. Berlin 1855.

Pröhle (1855c). Heinrich Pröhle: Weltliche und geistliche Volkslieder und Volksschauspiele. Mit einer Musikbeilage. Aschersleben 1855.

Pröhle (1856a). Heinrich Pröhle: Aus dem Tagebuche eines deutschen Sammlers I. In: Deutsches Museum. Zeitschrift für Literatur, Kunst und öffentliches Leben 6 (1856), H. 15, S. 540-552.

Pröhle (1856b). Heinrich Pröhle: Aus dem Tagebuche eines deutschen Sammlers II. In: Deutsches Museum. Zeitschrift für Literatur, Kunst und öffentliches Leben 6 (1856), H. 18, S. 641-651. 
Pröhle (1856c). Heinrich Pröhle: Gottfried August Bürger. Sein Leben und seine Dichtungen. Leipzig 1856.

Pröhle (1856d). Heinrich Pröhle: Unterharzische Sagen. Mit Anmerkungen und Abhandlungen. Aschersleben 1856.

Pröhle (1857a). Heinrich Pröhle: Kriegsdichter des siebenjährigen Krieges und der Freiheitskriege. Ein Vortrag. Leipzig 1857.

Pröhle (1857b). Heinrich Pröhle: Zusätze und Berichtigungen zu meiner Schrift „Gottfried August Bürger. Sein Leben und seine Dichtungen. Leipzig, 1856“. In: Archiv für das Studium der neueren Sprachen und Literaturen 12 (1857), H. 21, S. 169-179.

Pröhle (1858). Heinrich Pröhle: Die Fremdherrschaft. Mittheilungen aus der Geschichte des ehemaligen Königreichs Westphalen. Vorgelesen am 13. Februar 1858 im Verein für wissenschaftliche Vorträge zu Berlin. Leipzig 1858.

Pröhle (1863). Heinrich Pröhle: Deutsche Sagen. Mit Illustrationen. Berlin 1863.

Pröhle (1877). Heinrich Pröhle: Lessing, Wieland, Heinse. Nach den handschriftlichen Quellen in Gleims Nachlasse dargestellt. Berlin 1877.

Pröhle ([1886]). Heinrich Pröhle: Rheinlands schönste Sagen und Geschichten. Für die Jugend bearbeitet. Mit sechs Lichtdruckbildern nach Originalen von Louis H.E. Schmidt. Berlin [1886].

Pröhle (1889). Heinrich Pröhle: Abhandlungen über Goethe, Schiller, Bürger und einige ihrer Freunde. Mit Knesebeck's Briefen an Gleim als Seitenstück zu Goethe's Campagne in Frankreich. Potsdam 1889.

Proß (1984). Wolfgang Proß: Anmerkungen. In: Johann Gottfried Herder: Werke. Band I: Herder und der Sturm und Drang 1764-1774. Nachwort von Pierre Pénisson. Hg. von Wolfgang Proß. München, Wien 1984, S. 693-863.

Proß (1986). Wolfgang Proß: Das Konzept des Populären in Italien und sein Einfluß auf das deutschsprachige Theater des 18. Jahrhunderts. In: Jean-Marie Valentin (Hg.): Volk - Volksstück Volkstheater im deutschen Sprachraum des 18.-20. Jahrhunderts. Akten des mit Unterstützung des Centre National de la Recherche Scientifique veranstalteten Kolloquiums, Nancy, 12.-13. November 1982. Bern, Frankfurt am Main, New York 1986 (Jahrbuch für Internationale Germanistik, Reihe A, Bd. 15), S. 24-40.

Proß (1988). Wolfgang Proß: Herders Shakespeare-Interpretation. Von der Dramaturgie zur Geschichtsphilosophie. In: Roger Bauer (Hg.): Das Shakespeare-Bild in Europa zwischen Aufklärung und Romantik. In Verbindung mit Michael de Graat und Jürgen Wertheimer. Bern u.a. 1988 (Jahrbuch für Internationale Germanistik, Reihe A, Bd. 22), S. 162-181.

Prosser-Schell (2015). Michael Prosser-Schell: Forschungen und Forschungsmöglichkeiten mit dem Nachlass Karasek im IVDE Freiburg. Neuere Ergebnisse und Befunde. In: Hans-Werner Retterath (Hg.): Zugänge. Volkskundliche Archiv-Forschung zu den Deutschen im und aus dem östlichen Europa. Münster, New York 2015 (Schriftenreihe des Instituts für Volkskunde der Deutschen des östlichen Europa, Bd. 16), S. 159-193.

Puchner (2009). Walter Puchner: Studien zur Volkskunde Südosteuropas und des mediterranen Raums. Wien, Köln, Weimar 2009.

Puchner (2014). Walter Puchner: Volksschauspiel. In: Rolf Wilhelm Brednich (Hg.): Enzyklopädie des Märchens. Handwörterbuch zur historischen und vergleichenden Erzählforschung. Begründet von Kurt Ranke. Bd. 14. Berlin, Boston 2014, Sp. 350-360.

Quellmalz (1968-1976). Alfred Quellmalz (Hg.): Südtiroler Volkslieder. Gesammelt und herausgegeben. Im Auftrag des Staatlichen Instituts für Musikforschung, Preussischer Kulturbesitz Berlin. 3 Bände. Kassel u.a. 1968-1976.

Raber (1886). Vigil Raber: Sterzinger Spiele. Nach Aufzeichnungen des Vigil Raber. 2 Bände. Hg. von Oswald Zingerle. Wien 1886. 
Raber (1982). Vigil Raber: Sterzinger Spiele. Die weltlichen Spiele des Sterzinger Spielarchivs nach den Originalhandschriften (1510-1535) von Vigil Raber und nach der Ausgabe Oswald Zingerles (1886). Hg. von Werner M. Bauer. Wien 1982 (Wiener Neudrucke, Bd. 6).

Ranzmaier (2008). Irene Ranzmaier: Stamm und Landschaft. Josef Nadlers Konzeption der deutschen Literaturgeschichte. Berlin, New York 2008 (Quellen und Forschungen zur Literatur- und Kulturgeschichte, Bd. 48).

Rauchenegger (1890). Benno Rauchenegger: Jägerblut. Volksstück in vier Akten (6 Bildern). Musik von Josef Krägel. Als Manuskript gedruckt. München 1890.

Razum (1935). Hannes Razum: Salz und Brot. Ein Bauernspiel. München 1935 (Münchener Laienspiele, Bd. 129).

Red[aktion] (2003). Red[aktion]: Rommel, Otto. In: IGL, S. 1511-1513.

Reichl (1988). Johannes M. Reichl: Das Thingspiel. Über den Versuch eines nationalsozialistischen Lehrstück-Theaters (Euringer - Heynicke - Möller). Mit einem Anhang über Bert Brecht. Frankfurt am Main 1988.

Reimann (1982). Horst Reimann: Siziliens kleines Volkstheater Opera dei pupi. Mit Lichtbildern und Federzeichnungen von Helga Reimann. Bochum 1982 (Puppenspielkundliche Quellen und Forschungen, Bd. 7).

Reinsberg-Düringsfeld (1874). O[tto] v[von] Reinsberg-Düringsfeld: Culturhistorische Studien aus Meran. Sprache - Literatur - Volksgebräuche - Zunftwesen - mit vielen ungedruckten Documenten. Leipzig 1874.

Renk (2007). Herta-Elisabeth Renk: Volksstück. In: Dieter Burdorf, Christoph Fasbender und Burkhard Moennighoff (Hg.): Metzler Lexikon Literatur. Begründet von Günther und Irmgard Schweikle. 3. Aufl. Stuttgart 2007, S. 815-816.

Reuschel (1922). Karl Theodor Reuschel (Hg.): Das deutsche Volksschauspiel. Eine Auswahl. Bielefeld, Leipzig 1922 (Deutsche Schulausgaben, Bd. 194).

Riccabona, Sauter und Unterkircher (2017). Christine Riccabona, Sebastian von Sauter und Anton Unterkircher: Anna Reithmayr, in: Lexikon Literatur in Tirol. https://orawww.uibk.ac.at/apex/uprod/f?p=20090202:2:0::NO::P2_ID,P2_TYP_ID:1229 (25.3.2019).

Richter (2010). Sandra Richter: A History of Poetics. German Scholarly Aesthetics and Poetics in International Context, 1770-1960. With Bibliographies by Anja Zenk, Jasmin Azazmah, Eva Jost, Sandra Richter. Berlin, New York 2010.

Richter (2017). Sandra Richter: Eine Weltgeschichte der deutschsprachigen Literatur. München 2017.

Richter, Sandra (2018). Sandra Richter: Cross-Cultural Inventions in Drama on the Basis of the Novel in Prose, or World Literature before World Literature. The Case of Fortunatus. In: Toni Bernhart, Jaša Drnovšek, Sven Thorsten Kilian, Joachim Küpper und Jan Mosch (Hg.): Poetics and Politics. Net Structures and Agencies in Early Modern Drama. Berlin 2018, S. 53-68.

Richter, Falk (2018). Falk Richter: Disconnected. Theater, Tanz, Politik. Saarbrücker Poetikdozentur für Dramatik. Mit einem Nachwort hg. von Johannes Birgfeld. Berlin 2018.

Rieck (1935). Friedrich Rieck: Johann Friedrich Schütze und die Volkskunde. Ein Beitrag zur Geschichte der niederdeutschen Volkskunde des ausgehenden 18. Jahrhunderts. (Zugl. Diss., Univ. Hamburg, 1934). Kellinghusen bei Hamburg 1935.

Rieder (1974). Hans Rieder: Jeit(t)eles (Geitler), Ignaz. In: NDB. Bd. 10 (1974), S. 388.

Rieder (2000). Claus Rieder: Fernseh-Volkstheater. Theaterware im Fernsehsystem. Wiesbaden 2000.

Riedmann (2003). Bettina Riedmann: Feifalik, Julius. In: IGL, S. 481-482.

Rohrer (1796). Joseph Rohrer: Uiber die Tiroler. Ein Beytrag zur Oesterreichischen Völkerkunde. Wien 1796. 
Rölleke (1985). Heinz Rölleke: Die Märchen der Brüder Grimm. Eine Einführung. München, Zürich 1985 (Artemis Einführungen, Bd. 18).

Rölleke (1993). Heinz Rölleke (Hg.): Das Volksliederbuch. Über 300 Lieder, ihre Melodien und Geschichten. Hg. und mit Erläuterungen versehen. Musikalische Betreuung von Tilo Medek. Köln 1993.

Rölleke (1998). Heinz Rölleke: Grimms Märchen und ihre Quellen. Die literarischen Vorlagen der Grimmschen Märchen synoptisch vorgestellt und kommentiert. Trier 1998 (Schriftenreihe Literaturwissenschaft, Bd. 35).

Rölleke (2000). Heinz Rölleke: Die Märchen der Brüder Grimm. Quellen und Studien. Gesammelte Aufsätze. Trier 2000 (Schriftenreihe Literaturwissenschaft, Bd. 50).

Rölleke und Schindehütte (2011). Heinz Rölleke und Albert Schindehütte (Hg.): Es war einmal. Die wahren Märchen der Brüder Grimm und wer sie ihnen erzählte. Frankfurt am Main 2011 (Die andere Bibliothek, Sonderband).

Roloff (2005). Hans-Gert Roloff: Volksschauspiele [Rez. zu Polheim und Schröder (2000-2004)]. In: Editionen in der Kritik 1 (2005), S. 171-176.

Rommel (1906). Otto Rommel: Der Wiener Musenalmanach. Eine literaturhistorische Untersuchung. Leipzig, Wien 1906 (Euphorion Ergänzungsheft, Bd. 6).

Rommel ([1912]). Otto Rommel: Die politische Lyrik des Vormärz und des Sturmjahres. Auswahl. Wien, Teschen, Leipzig [1912] (Deutsch-Österreichische Klassiker-Bibliothek, Bd. 33).

Rommel (1930). Otto Rommel: Johann Nestroy. Ein Beitrag zur Geschichte der Wiener Volkskomik. Wien 1930 (Johann Nestroy, Sämtliche Werke, Bd. 15).

Rommel (1931). Otto Rommel: Der österreichische Vormärz 1816-1847. Leipzig 1931 (Deutsche Literatur. Sammlung literarischer Kunst- und Kulturdenkmäler in Entwicklungsreihen, Reihe Politische Dichtung, Bd. 4).

Rommel (1935). Otto Rommel (Hg.): Die Maschinenkomödie. Leipzig 1935 (Deutsche Literatur. Sammlung literarischer Kunst- und Kulturdenkmäler in Entwicklungsreihen, Reihe Barock: Barocktradition im österreichisch-bayrischen Volkstheater, Bd. 1).

Rommel (1944). Otto Rommel: Der Wienerische Hanswurst als Dramatiker. In: Jahrbuch der Gesellschaft für Wiener Theaterforschung [1] (1944), S. 105-131.

Rommel (1947). Otto Rommel (Hg.): Wiener Renaissance. Wien, Zürich 1947 (Klassiker der Wiener Kultur, Bd. 1).

Rommel (1952). Otto Rommel: Die Alt-Wiener Volkskomödie. Ihre Geschichte vom Barocken WeltTheater bis zum Tode Nestroys. Mit 250 Abbildungen, 4 davon farbig. Wien 1952.

Rommel (1957). Otto Rommel: Mein Weg zur Volkstheater-Forschung. In: Maske und Kothurn. Vierteljahrsschrift für Theaterwissenschaft 3 (1957), H. 3, S. 280-283.

Rommel (1965). Otto Rommel: Spittelers „Olympischer Frühling“ und seine epische Form. Bern, München 1965.

Rössler (1981). Helmut Rössler: Karl Kraus und Nestroy. Kritik und Verarbeitung. (Zugl. Diss., Univ. Stuttgart 1980). Stuttgart 1981 (Stuttgarter Arbeiten zur Germanistik, Bd. 90).

Rousseau (1978). Jean-Jacques Rousseau: Brief an Herrn d’Alembert über seinen Artikel „Genf“ im VII. Band der Enzyklopädie und insbesondere über den Plan, ein Schauspielhaus in dieser Stadt zu errichten [Deutsch von Dietrich Feldhausen] [1758]. In: Jean-Jacques Rousseau: Schriften, Band 1. Hg. von Henning Ritter. München, Wien 1978, S. 333-474.

Rousseau (1995). Jean-Jacques Rousseau: J.J. Rousseau citoyen de Genève, à M. d’Alembert [1758]. In: Jean-Jacques Rousseau: CEuvres complètes V: Écrits sur la musique, la langue et le théâtre. Hg. von Bernard Gagnebin und Marcel Raymond. [Paris] 1995 (Bibliothèque de la Pléiade, Bd. 416), S. 9-125.

Rudin (2013). Bärbel Rudin: Banise als Haupt- und Staatsaktion. Zum erfolgreichsten Lückenbüßer der deutschen Verspätung im Drama. In: Dieter Martin und Karin Vorderstemann (Hg.): Die eu- 
ropäische Banise. Rezeption und Übersetzung eines barocken Bestsellers. Berlin, Boston 2013 (Frühe Neuzeit, Bd. 175), S. 67-90.

Rüegg (2019). Madeline Rüegg: The Patient Griselda Myth. Looking at Late Medieval and Early Modern European Literature. (Zugl. Diss., Freie Univ. Berlin 2017). Berlin 2019.

Rühmkorf (1967). Peter Rühmkorf: Über das Volksvermögen. Exkurse in den literarischen Untergrund. Reinbek bei Hamburg 1967.

Saage-Maaß (2007). Miriam Saage-Maaß: Die Göttinger Sieben - demokratische Vorkämpfer oder nationale Helden? Zum Verhältnis von Geschichtsschreibung und Erinnerungskultur in der Rezeption des Hannoverschen Verfassungskonfliktes. (Zugl. Diss., Univ. Frankfurt am Main 2006). Göttingen 2007.

Sailer (1766). Sebastian Sailer: Des ehrwürdigen P. Sebastian Sailer Chorherrn von Prämonstrat, und des unmittelbaren freyen Reichsstifts Marchtall an der Donau in Schwaben Capitularen Geistliche Reden, bey mancherley Gelegenheiten und über zerschiedene Materien gesprochen. Erster Band. Augsburg 1766.

Sailer (1768). Sebastian Sailer: Des ehrwürdigen P. Sebastian Sailer Chorherrn von Prämonstrat, und des unmittelbaren freyen Reichsstifts Marchtall an der Donau in Schwaben Capitularen Geistliche Reden, bey mancherley Gelegenheiten und über zerschiedene Materien gesprochen. Zweyter Band. Augsburg 1768.

Sailer (1774). Sebastian Sailer: P. Sebastian Sailers Chorherrn von Prämonstrat, und des unmittelbaren freyen Reichsstifts Marchtall an der Donau Kapitularen, der Zeit Pfarrverwesern zu Dietrichskirch. Geistliche Schaubühne des Leidens Jesu Christi, in gesungenen Oratorien aufgeführt. Augsburg 1774.

[Sailer] (1783). [Sebastian Sailer]: Adams und Evens Erschaffung, und ihr Sündenfall. Ein geistlich Fastnachtspiel mit Sang und Klang: aus dem Schwäbischen in's Oesterreichische versetzt. 0.0. 1783.

[Sailer] (1784). [Sebastian Sailer]: Melodrama Adam und Eva im Paradeiß. Ein musikalisches Bauernspiel vom Jahre 1250 in vier Aufzügen, verfasset von Sebastian Relies O.S.B., verbessert und vermehret von M.H. und A.M. zur privat Unterhaltung, musikalischer Dilettanten, aus dem Schwäbischen in die Oesterreicher Bauernsprache übersetzet. 0.0.1784.

Sailer (1969). Sebastian Sailer: Die Schöpfung. Hg. von Martin Stern. Stuttgart 1969.

Sailer (1977). Sebastian Sailer: Adams und Evens Erschaffung und ihr Sündenfall. Ein geistlich Fastnachtspiel mit Sang und Klang: aus dem Schwäbischen in's Österreichische versetzt. Faksimileausgabe der ersten gedruckten, posthum erschienenen Fassung der Komödie „Die schwäbische Schöpfung“von Pater Sebastian Sailer, aus Anlaß des 200. Todestages des Dichters. Nachwort von [Stefan] Ott. Biberach an der Riß 1977.

Sailer (2004). Sebastian Sailer: Die Schwäbische Schöpfung. Verschiedene Fassungen. Hg. von Walter Frei und Wolfgang Schürle in Verbindung mit dem Förderverein Schwäbischer Dialekt e.V. Konstanz 2004 (Bibliotheca suevica, Bd. 11).

Sailer (2012). Sebastian Sailer: Geistliche Reden. Eine Auswahl. Neu hg. und kommentiert von Konstantin Maier. Konstanz 2012 (Bibliotheca suevica, Bd. 32).

Sangmeister (2011). Dirk Sangmeister: Von Blumenlesen und Geheimbünden. Die Jahre von Johann Friedrich Ernst Albrecht als Verleger in Reval und Erfurt. In: Heinrich Bosse, Otto-Heinrich Elias und Thomas Taterka (Hg.): Baltische Literaturen in der Goethezeit. Würzburg 2011, S. 411-487.

Santi (2007). Cesare Santi: Toscano. In: Historisches Lexikon der Schweiz. http://www.hls-dhs-dss.ch/textes/d/D24911.php (3.5.2019).

Saphir (1835). M[oritz] G[ottlieb] Saphir: Ad vocem Nestroy’s: „Ebener Erde und erster Stock“. In: Allgemeine Theaterzeitung und Originalblatt für Kunst, Literatur, Musik, Mode und geselliges Leben vom 30.9.1835, S. 778-779. 
Saphir (1839). M[oritz] G[ottlieb] Saphir: Nestroy und die Wiener Lokalposse. In: Der Humorist vom 17.4.1839, S. 303-304.

Sauder (1997). Gerhard Sauder: Lenz’ eigenwillige Anmerkungen über das Theater. In: Etudes Germaniques 52 (1997), H. 1, S. 49-64.

Scheichl (1994). S[igurd] P[aul] Scheichl: Schmalz Josef. In: ÖBL. Bd. 10 (1994), S. 227.

Schellenberg (2012). Renata Schellenberg: The Self and Other Things. Goethe the Collector. In: Publications of the English Goethe Society (PEGS) 81 (2012), H. 3, S. 166-177.

Schennach (2003). Martin P. Schennach: Geschichte des bäuerlichen Besitz- und Erbrechts in Tirol - ein Überblick. In: Hofgeschichten der 2002 und 2003 verliehenen Erbhöfe. Mit einem Überblick über die Geschichte des bäuerlichen Besitz- und Erbrechtes in Tirol. Innsbruck 2003 (Tiroler Erbhöfe, Bd. 21), S. 9-30.

Scherpe (1985). Klaus R. Scherpe: Dichterische Erkenntnis und „Projektmacherei“. Widersprüche im Werk von J.M.R. Lenz [1977]. In: Manfred Wacker (Hg.): Sturm und Drang. Darmstadt 1985 (Wege der Forschung, Bd. 559), S. 279-314.

Schiller (1992). Friedrich Schiller: Was kann eine gute stehende Schaubühne eigentlich wirken? [Die Schaubühne als eine moralische Anstalt betrachtet] [1784]. In: Friedrich Schiller: Werke und Briefe in zwölf Bänden. Band 8: Theoretische Schriften. Hg. von Rolf-Peter Janz unter Mitarbeit von Hans Richard Brittnacher, Gerd Kleiner und Fabian Strömer. Frankfurt am Main 1992, S. $185-200$.

Schindler (1970). Otto G. Schindler: Wandertruppen in Niederösterreich im 18. Jahrhundert. In: Jahrbuch der Gesellschaft für Wiener Theaterforschung 17 (1970), S. 1-80.

Schindler (2007). Otto G. Schindler: Volkstheater. http://www.musiklexikon.ac.at/ml/musik_V/Volkstheater.xml (28.5.2019).

Schlaffer (1987). Heinz Schlaffer: Lugowski, Clemens. In: NDB. Bd. 15 (1987), S. 497-498.

Schlegel (1884). A[ugust] W[ilhelm] Schlegel: Vorlesungen über schöne Litteratur und Kunst. Dritter Teil (1803-1804): Geschichte der romantischen Litteratur (nebst Personenregister zu den drei Teilen). Heilbronn 1884 (Deutsche Litteraturdenkmale des 18. und 19. Jahrhunderts in Neudrucken, Bd. 19).

Schlehe und Sandkühler (2014). Judith Schlehe und Evamaria Sandkühler (Hg.): Religion, Tradition and the Popular. Transcultural Views from Asia and Europe. Bielefeld 2014 (History in Popular Cultures, Bd. 12).

Schlossar (1881). Anton Schlossar: Deutsche Volkslieder aus Steiermark. Zugleich Beiträge zur Kenntniß der Mundart und der Volkspoesie auf bairisch-österreichischem Sprachgebiete. Mit Einleitung, Anmerkungen und ausgewählten Melodien herausgegeben. Innsbruck 1881.

Schlossar (1891). Anton Schlossar: Deutsche Volksschauspiele. In Steiermark gesammelt. Mit Anmerkungen und Erläuterungen, nebst einem Anhange: das Leiden Christi-Spiel aus dem Gurkthale in Kärnten. 2 Bände. Halle 1891.

Schmalz (2018). Ferdinand Schmalz: jedermann (stirbt). In: Uwe B. Carstensen, Friederike Emmerling, Stefanie von Lieven, Barbara Neu und Bettina Walther (Hg.): Theater Theater. Anthologie. Frankfurt am Main 2018 (Aktuelle Stücke, Bd. 29), S. 483-532.

Schmeller (1837). Andreas Schmeller: Bayerisches Wörterbuch. Sammlung von Wörtern und Ausdrücken, die in den lebenden Mundarten sowohl, als in der ältern und ältesten ProvincialLitteratur des Königreichs Bayern, besonders seiner ältern Lande, vorkommen, und in der heutigen allgemein-deutschen Schriftsprache entweder gar nicht, oder nicht in denselben Bedeutungen üblich sind, mit urkundlichen Belegen, nach den Stammsylben etymologischalphabetisch geordnet. Vierter Theil. Stuttgart, Tübingen 1837.

Schmid (1864). Herman Schmid: Almenrausch und Edelweiß. Erzählung aus dem Beirischen Hochgebirge. Berlin 1864. 
Schmidt (1932). Leopold Schmidt: Neue Volksschauspielforschung. In: Deutsch-ungarische Heimatsblätter. Vierteljahrschrift für Kunde des Deutschtums in Ungarn und für deutsche und ungarische Beziehungen 4 (1932), H. 4, S. 338-345.

Schmidt (1934). Leopold Schmidt: Der Oberuferer Spielkreis. In: Sudetendeutsche Zeitschrift für Volkskunde 7 (1934), S. 145-157.

Schmidt (1935). Leopold Schmidt: Stammheitlichkeitsfragen in der deutschen Volksschauspielschichtung in Ungarn. In: Deutsch-ungarische Heimatsblätter. Vierteljahrschrift für Kunde des Deutschtums in Ungarn und für deutsche und ungarische Beziehungen 7 (1935), H. 1, S. 68-71.

Schmidt (1937). Leopold Schmidt: Formprobleme der deutschen Weihnachtsspiele. (Zugl. Diss., Univ. Wien 1934). Emsdetten 1937 (Die Schaubühne, Bd. 20).

Schmidt (1951). Leopold Schmidt: Die burgenländischen Sebastianispiele im Rahmen der barocken Sebastiansverehrung und der Volksschauspiele vom hl. Sebastian. Eisenstadt 1951 (Burgenländische Forschungen, Bd. 16).

Schmidt (1954). Leopold Schmidt: Das deutsche Volksschauspiel in zeitgenössischen Zeugnissen vom Humanismus bis zur Gegenwart. Berlin 1954 (Veröffentlichungen des Instituts für Deutsche Volkskunde, Bd. 7).

Schmidt (1962). Leopold Schmidt: Das deutsche Volksschauspiel. Ein Handbuch. Mit 6 Karten im Text und 18 Abbildungen auf Tafeln. Berlin 1962.

Schmidt (1965). Léopold Schmidt (Hg.): Le théâtre populaire européen. Édité en collaboration avec Gianfranco D’Aronco, Georgios Megas, Hans Moser, Georges-Henri Rivière, Achmed Tecer et Hans Trümpy. La traduction française des textes originaux et du manuscrit allemand des commentaires, établie par Michèle Ramzeyer et Pierre Robinet, a été coordonnée par Klaus Beitl. Paris 1965 (Folklore européen, Bd. 3).

Schmidt (1980). Leopold Schmidt: Das alte Volksschauspiel des Burgenlandes. Mit 6 Karten im Text, 14 Abbildungen auf Tafeln und einer Farbtafel. Wien 1980 (Theatergeschichte Österreichs, Bd. 8: Burgenland, H. 1).

Schmidt (2010). R[obin] Schmidt: Steiner Rudolf Joseph Lorenz. In: ÖBL. Bd. 13 (2010), S. 176-177. Schmidt (2016). Sarah Schmidt (Hg.): Sprachen des Sammelns. Literatur als Medium und Reflexionsform des Sammelns. Paderborn 2016.

Schmidt (2017). Laura Schmidt: Weihnachtliches Theater. Zur Entstehung und Geschichte einer bürgerlichen Fest- und Theaterkultur. Bielefeld 2017 (Theater).

Schmidt-Dengler (1981). Wendelin Schmidt-Dengler: Bedürfnis nach Geschichte. In: Franz Kadrnoska (Hg.): Aufbruch und Untergang. Österreichische Kultur zwischen 1918 und 1938. Wien, München, Zürich 1981, S. 393-407.

Schmidt-Dengler (1986). Wendelin Schmidt-Dengler: Rustikalität. Zur Funktion des ländlichen Lebensraumes bei Carl Morre und Franz Schönherr [sic; gemeint ist Karl Schönherr, Anm. T.B.]. In: Jean-Marie Valentin (Hg.): Volk - Volksstück - Volkstheater im deutschen Sprachraum des 18.-20. Jahrhunderts. Akten des mit Unterstützung des Centre National de la Recherche Scientifique veranstalteten Kolloquiums, Nancy, 12.-13. November 1982. Bern, Frankfurt am Main, New York 1986 (Jahrbuch für Internationale Germanistik, Reihe A, Bd. 15), S. 173-185.

Schmidt-Dengler (1996). Wendelin Schmidt-Dengler: Nadler und die Folgen. Germanistik in Wien 1945 bis 1957. In: Wilfried Barner und Christoph König (Hg.): Zeitenwechsel. Germanistische Literaturwissenschaft vor und nach 1945. Frankfurt am Main 1996, S. 35-46.

Schmidt-Dengler (2001). Wendelin Schmidt-Dengler: Nestroy. Die Launen des Glücks. Wien 2001. Schmitz (1990). Thomas Schmitz: Das Volksstück. Stuttgart 1990 (Sammlung Metzler, Bd. 257).

Schmook (1993). Reinhard Schmook: „Gesunkenes Kulturgut - primitive Gemeinschaft“. Der Germanist Hans Naumann (1886-1951) in seiner Bedeutung für die Volkskunde. (Zugl. Diss., Humboldt-Univ. zu Berlin 1988). Wien 1993 (Beiträge zur Volkskunde und Kulturanalyse, Bd. 7). 
Scholz (1990). Friedrich Scholz: Die Literaturen des Baltikums. Ihre Entstehung und Entwicklung. Opladen 1990 (Abhandlungen der Rheinisch-Westfälischen Akademie der Wissenschaften, Bd. 80).

Scholz (1995). Friedrich Scholz: Herders Auffassung des Volkslieds und der Dichtung und die lettischen Volksliedersammlungen des 19. Jahrhunderts. In: Zeitschrift für OstmitteleuropaForschung 44 (1995), H. 4, S. 564-577.

Schöne (1993). Albrecht Schöne: Emblematik und Drama im Zeitalter des Barock. 3. Aufl. München 1993 [1964].

Schönwiese und Schuhladen (1976). Ekkehard Schönwiese und Hans Schuhladen: Beiträge zu den neuaufgetauchten Volksschauspielhandschriften aus den Nachlässen Ludwig v. Hörmanns und Leopold Pirkls. In: Egon Kühebacher (Hg.): Tiroler Volksschauspiel. Beiträge zur Theatergeschichte des Alpenraumes. Im Auftrag des Südtiroler Kulturinstitutes und des Bundes Südtiroler Volksbühnen. Bozen 1976 (Schriftenreihe des Südtiroler Kulturinstitutes, Bd. 3), S. 301318.

Schöpel (1965). Brigitte Schöpel: „Naturtheater“. Studien zum Theater unter freiem Himmel in Südwestdeutschland. (Zugl. Diss., Univ. Tübingen 1965). Tübingen 1965 (Volksleben, Bd. 9).

Schöppner (1852-1853). Alexander Schöppner: Sagenbuch der Bayerischen Lande. Aus dem Munde des Volkes, der Chronik und der Dichter. 3 Bände. München 1852-1853.

Schöttker (1989). Detlev Schöttker: Bertolt Brechts Ästhetik des Naiven. Stuttgart 1989.

[Schreiber] (1788a). [Alois Wilhelm Schreiber] (Hg.): Tagebuch der Mainzer Schaubühne. Mainz 1788.

[Schreiber] (1788b). [Alois Wilhelm Schreiber]: An das Publikum. In: Dramaturgische Blätter. Erstes Stück (1788), S. 5-8.

[Schreiber] (1788c). [Alois Wilhelm Schreiber]: Ueber Volksschauspiele. In: Dramaturgische Blätter. Erstes Stück (1788), S. 9-14.

Schreiber (1809). Aloys Schreiber: Lehrbuch der Aesthetik. Heidelberg 1809.

Schröder (1992). Jürgen Schröder: Auf der Suche nach dem Volk. In: Ursula Hassel und Herbert Herzmann (Hg.): Das zeitgenössische deutschsprachige Volksstück. Akten des internationalen Symposions, University College Dublin, 28. Februar-2. März 1991. Tübingen 1992 (Stauffenburg Colloquium, Bd. 23), S. 75-84.

Schröder (2006a). Jürgen Schröder: Das „dramatische“ Jahrzehnt der Bundesrepublik. In: Wilfried Barner (Hg.): Geschichte der deutschen Literatur von 1945 bis zur Gegenwart. 2., aktualisierte und erweiterte Aufl. München 2006, S. 463-501.

Schröder (2006b). Jürgen Schröder: „Postdramatisches Theater“ oder „neuer Realismus“? Drama und Theater der neunziger Jahre. In: Wilfried Barner (Hg.): Geschichte der deutschen Literatur von 1945 bis zur Gegenwart. 2., aktualisierte und erweiterte Aufl. München 2006, S. 10801120.

Schröer (1855a). K[arl] J[ulius] Schröer: Beitrag zur deutschen Mythologie und Sittenkunde aus dem Volksleben der Deutschen in Ungern. Als Aufmunterung zu gröszeren Sammlungen in den deutschen Gegenden Ungerns. Presburg 1855.

Schröer (1855b). K[arl] J[ulius] Schröer: Ein Weihnachtspiel aus Ungern. Nach der Handschrift der Sternspielbruderschaft zu Kremnitz. In: Weimarisches Jahrbuch für deutsche Sprache, Litteratur und Kunst 3 (1855), S. 391-419.

Schröer (1857). Karl Julius Schröer: Ein Bruchstück des Gedichtes Laurin oder Der kleine Rosengarten. Aus dem siebenten Jahresprogramme der Presburger Oberrealschule besonders abgedruckt. Presburg 1857.

Schröer (1858a). Karl Julius Schröer: Beitrag zu einem Wörterbuche der deutschen Mundarten des ungarischen Berglandes. Aus dem Novemberhefte des Jahrganges 1857 der Sitzungsberichte 
der philos.-histor. Classe der kais. Akademie der Wissenschaften [XXV. Bd., S. 213] besonders abgedruckt. Erste Abtheilung A bis H. Wien 1858.

Schröer (1858b). Karl Julius Schröer: Beitrag zu einem Wörterbuche der deutschen Mundarten des ungarischen Berglandes. Aus dem Aprilhefte des Jahrganges 1858 der Sitzungsberichte der philos.-historischen Classe der kais. Akademie der Wissenschaften [Bd. XXVII, S. 174] besonders abgedruckt. Zweite Abtheilung I bis Z. Wien 1858.

Schröer (1858c). Karl Julius Schröer: Deutsche Weihnachtspiele aus Ungern. Geschildert und mitgeteilt. Wien 1858.

Schröer (1858d). Karl Julius Schröer: Nachtrag zu den deutschen Weihnachtspielen aus Ungern. Presburg 1858.

Schröer (1859). Karl Julius Schröer: Nachtrag zum Wörterbuche der deutschen Mundarten des ungarischen Berglandes. Aus dem Mai-Hefte des Jahrganges 1859 der Sitzungsberichte der phil.hist. Classe der k. Akademie der Wissenschaften [XXXI. Band, S. 245] besonders abgedruckt. Wien 1859.

Schröer (1862). Karl Julius Schröer: Deutsche Weihnachtspiele aus Ungern. Geschildert und mitgetheilt. Neue Ausgabe. Wien 1862.

Schröer (1870). Karl Julius Schröer: Wörterbuch der Mundart von Gottschee. I. Ausflug nach Gottschee, II. Weitere Mittheilungen über die Mundart von Gottschee. Aus dem Octoberhefte des Jahrganges 1868 der Sitzungsberichte der philos.-hist. Cl. der kais. Akademie der Wissenschaften [LX. Bd., S. 165] und aus dem Maihefte des Jahrganges 1870 der Sitzungsberichte der philos.-histor. Cl. der kais. Akademie der Wissenschaften [LXV. Bd., S. 391] besonders abgedruckt. Wien 1870.

Schröer (1879a). Karl Julius Schröer: Die Deutschen in Oesterreich-Ungarn und ihre Bedeutung für die Monarchie. Vortrag, gehalten im deutschen Verein in Wien den 16. Januar 1879. Berlin 1879.

Sch[röer] (1879b). [Karl Julius] Sch[röer]: Ein Ritterschauspiel in Tirol. In: Neue Freie Presse vom 24.8.1879, S. 6-7.

Schröer (1917). K[arl] J[ulius] Schröer: Spiel vom Sündenfall. Paradeisspiel aus Oberufer bei Preßburg. 14. Jahrhundert. Leipzig 1917 (Deutsche Volksspiele des Mittelalters, Bd. 1).

Schröer (1918). K[arl] J[ulius] Schröer: Christgeburtspiel aus Oberufer bei Preßburg. Leipzig 1918 (Deutsche Volksspiele des Mittelalters, Bd. 3).

Schubert (1986). Karl Schubert: Erinnerungen an die Weihnachtspiele [1948]. In: Rudolf Steiner: Ansprachen zu den Weihnachtspielen aus altem Volkstum, gehalten in Dornach 1915 bis 1924 und ein Aufsatz Weihnachten 1922. Hg. von Edwin Froböse. 2. Aufl. Dornach 1986, S. 107-110.

Schuller (1859). Johann Karl Schuller: Herodes. Ein deutsches Weihnachtsspiel aus Siebenbürgen. Mit einleitenden Bemerkungen über Festbräuche der Sachsen in Siebenbürgen. Sylvestergabe für Gönner und Freunde. Hermannstadt 1859.

Schulz (1797a). Friedrich Schulz: Neue Reise durch Italien. Erster Band. Erstes Heft. Berlin 1797.

Schulz (1797b). Friedrich Schulz: Reise eines Liefländers durch Italien. Siebentes Heft. Enthaltend die Reise von Botzen über Trient, Roveredo, Verona, Mantua und Kremona, bis nach Mailand. Berlin 1797.

Schulze (2012). Ursula Schulze: Geistliche Spiele im Mittelalter und in der Frühen Neuzeit. Von der liturgischen Feier zum Schauspiel. Eine Einführung. Berlin 2012.

Schütze (1794). Johann Friedrich Schütze: Hamburgische Theater-Geschichte. Hamburg 1794.

Schütze (1800-1806). Johann Friedrich Schütze: Holsteinisches Idiotikon, ein Beitrag zur Volkssittengeschichte; oder Sammlung plattdeutscher, alter und neugebildeter Worte, Wortformen, Redensarten, Volkswitzes, Sprichwörter, Spruchreime, Wiegenlieder, Anekdoten und aus dem 
Sprachschatze erklärter Sitten, Gebräuche, Spiele, Feste der alten und neuen Holsteiner. Mit Holzschnitten. 4 Bände. Hamburg 1800-1806.

Schütze (1800). Johann Friedrich Schütze: Satyrisch-ästhetisches Hand- und Taschen-Wörterbuch für Schauspieler und Theaterfreunde beiden Geschlechts. Nebst einem lehr- und scherzreichen Anhange. Hamburg 1800.

Scribe (1830). Eugène Scribe: Arien und Gesänge der großen Oper „Die Stumme von Portici“, in fünf Abtheilungen, mit Tanz. Nach dem Französischen „La Muette de Portici“, des Scribe, zur beibehaltenen Musik von Auber für die deutsche Bühne bearbeitet vom Freiherrn von Lichtenstein. Dessau 1830.

Seelbach (1994). Susanne Seelbach: Proletarisch-Revolutionäres Theater in Düsseldorf 1930-1933. Die Bühne als politisches Medium. (Zugl. Diss., Univ. Düsseldorf 1992). Frankfurt am Main u.a. 1994 (Europäische Hochschulschriften, Reihe 30: Theater-, Film- und Fernsehwissenschaften, Bd. 55).

Seemann und Wiora (1959). Erich Seemann und Walter Wiora (Hg.): Deutsche Volkslieder. Balladen. Vierter Teil. Unter Mithilfe von Hinrich Siuts. Berlin 1959 (Deutsche Volkslieder mit ihren Melodien, Bd. 4).

Seeßlen (1993). Georg Seeßlen: Volks Tümlichkeit. Über Volksmusik, Biertrinken, Bauerntheater und andere Erscheinungen gnadenloser Gemütlichkeit im neuen Deutschland. Greiz 1993.

Seidl ([1840]). Joh[ann] Gabr[iel] Seidl: Wanderungen durch Tyrol und Steyermark. Erster Band. Wanderungen durch Tyrol. Mit 30 Stahlstichen. Leipzig [1840] (Das malerische und romantische Deutschland. In zehn Sektionen, Bd. VII).

Selbmann (1985). Rolf Selbmann: Lewald, August. In: NDB. Bd. 14 (1985), S. 408-409.

Sengle (1980). Friedrich Sengle: Biedermeierzeit. Deutsche Literatur im Spannungsfeld zwischen Restauration und Revolution 1815-1848. Band III: Die Dichter. Stuttgart 1980.

Shakespeare (1975). William Shakespeare: Twelfth Night. Hg. von J.M Lothian und T. W. Craik. London 1975 (The Arden Edition of the Works of William Shakespeare).

Shakespeare (2001). William Shakespeare: Love's Labour's Lost. Hg. von H. R. Woudhuysen. London 2001 (The Arden Shakespeare).

[Shakespeare] (2016). [William Shakespeare]: The Norton Shakespeare. Hg. von Stephen Greenblatt, Walter Cohen, Suzanne Gossett, Jean E. Howard, Katharine Eisaman Maus und Gordon McMullan. 3. Aufl. New York, London 2016.

Shapiro (2000). James Shapiro: Oberammergau. The Troubling Story of the World's Most Famous Passion Play. New York 2000.

Sikora (1905a). Adalbert Sikora: Das Verbot der Volksschauspiele (1751) und seine Folgen. Ein Beitrag zur Kulturgeschichte des tirolischen Volkes. In: Forschungen und Mitteilungen zur Geschichte Tirols und Vorarlbergs 2 (1905), S. 199-209.

Sikora (1905b). Adalbert Sikora: Zur Geschichte der Volksschauspiele in Tirol. In: Archiv für Theatergeschichte 2 (1905), S. 3-55.

Sikora (1906). Adalbert Sikora: Zur Geschichte der Volksschauspiele in Tirol. In: Zeitschrift des Ferdinandeums für Tirol und Vorarlberg 50 (1906), H. 3, S. 339-372.

Simek (1992). Ursula Simek: Das Berufstheater in Innsbruck im 18. Jahrhundert. Theater im Zeichen der Aufklärung in Tirol. Wien 1992 (Theatergeschichte Österreichs, Bd. 2,4).

Simon (2003). Eckehard Simon: Die Anfänge des weltlichen deutschen Schauspiels 1370-1530. Untersuchung und Dokumentation. Tübingen 2003 (Münchener Texte und Untersuchungen zur deutschen Literatur des Mittelalters, Bd. 124).

Simon (2007). Eckehard Simon: Geistliche Fastnachtspiele. Zum Grenzbereich zwischen geistlichem und weltlichem Spiel. In: Ingrid Kasten und Erika Fischer-Lichte (Hg.): Transformationen des Religiösen. Performativität und Textualität im geistlichen Spiel. Berlin, New York 2007, S. 18-45. 
Simrock (1845). Karl Simrock: Heinrich der Löwe. Die schöne Magelone. Reineke Fuchs. Genovefa. Frankfurt am Main 1845 (Die deutschen Volksbücher. Gesammelt und in ihrer ursprünglichen Echtheit wiederhergestellt von Karl Simrock, Bd. 1).

Simrock ([1846]). Karl Simrock: Faust. Das Volksbuch und das Puppenspiel. Frankfurt am Main [1846].

Singer (2006). Rüdiger Singer: „Nachgesang“. Ein Konzept Herders, entwickelt an Ossian, der popular ballad und der frühen Kunstballade. (Zugl. Diss., Freie Univ. Berlin 2004). Würzburg 2006 (Epistemata, Reihe Literaturwissenschaft, Bd. 548).

Soden (1797). Julius Soden: Doktor Faust. Volks-Schauspiel in fünf Akten. Mit einem Kupfer. Augsburg 1797.

Solbach (2015). Andreas Solbach: Ironische Kontamination. Funktionen der Komik in den Hauptund Staatsaktionen von J.A. Stranitzky. In: Carsten Jakobi und Christine Waldschmidt (Hg.): Witz und Wirklichkeit. Komik als Form ästhetischer Weltaneignung. Bielefeld 2015 (Mainzer Historische Kulturwissenschaften, Bd. 23), S. 19-40.

Sommer (1999). Manfred Sommer: Sammeln. Ein philosophischer Versuch. Frankfurt am Main 1999. Sommer-Mathis (2009). Andrea Sommer-Mathis: „Von den Lustbarkeiten des Hofs und den privatErgötzlichkeiten der Regenten“. Zu Begriff und Funktion höfischer Unterhaltung (am Beispiel von Sachsen-Weißenfels). In: Franz M. Eybl und Irmgard M. Wirtz (Hg.): Delectatio. Unterhaltung und Vergnügen zwischen Grimmelshausen und Schnabel. Bern u.a. 2009 (Beihefte zu Simpliciana, Bd. 4), S. 51-64.

Sommervogel (1890-1900). Carlos Sommervogel: Bibliothèque de la Compagnie de Jésus par les Pères Augustin et Aloys de Backer. Nouvelle édition. 10 Bände. Paris, Brüssel 1890-1900.

Sonnleitner (1996a). Johann Sonnleitner: Hanswurst, Bernardon, Kasperl und Staberl. In: Johann Sonnleitner (Hg.): Hanswurstiaden. Ein Jahrhundert Wiener Komödie. Joseph Anton Stranitzky, Joseph Felix Kurz, Philipp Hafner, Joachim Perinet, Adolf Bäuerle. Salzburg 1996 (Eine österreichische Bibliothek), S. 331-389.

Sonnleitner (1996b). Johann Sonnleitner (Hg.): Hanswurstiaden. Ein Jahrhundert Wiener Komödie. Joseph Anton Stranitzky, Joseph Felix Kurz, Philipp Hafner, Joachim Perinet, Adolf Bäuerle. Salzburg 1996 (Eine österreichische Bibliothek).

Sonnleitner (2006). Johann Sonnleitner: „Raimund schau oba“. Zu Elfriede Jelineks Burgtheater. In: Hubert Christian Ehalt und Jürgen Hein (Hg.): „, besser schön lokal reden als schlecht hochdeutsch“. Ferdinand Raimund in neuer Sicht. Beiträge zum Raimund-Symposium im Rahmen der Wiener Vorlesungen, 4.-5. Oktober 2004. Wien 2006 (Wiener Vorlesungen, Konversatorien und Studien, Bd. 18), S. 95-108.

Spoerhase (2018). Carlos Spoerhase: Das Format der Literatur. Praktiken materieller Textualität zwischen 1740 und 1830. (Zugl. Habil., Humboldt-Univ. zu Berlin 2016). Göttingen 2018.

Sprengel (1991). Peter Sprengel: Moritz Gottlieb Saphir in Berlin. Journalismus und Biedermeierkultur. In: Günter Blamberger, Manfred Engel und Monika Ritzer (Hg.): Studien zur Literatur des Frührealismus. Frankfurt am Main u.a. 1991, S. 243-275.

Springenschmid (1954). Karl Springenschmid: Das Jahreszeitenspiel. Ein schlichtes volkstümliches Bauernspiel für unsere Schuljugend. München 1954 (Spiele des bunten Wagens, Bd. 105).

Staffler (1848). Johann Jakob Staffler: Tirol und Vorarlberg, statistisch, mit geschichtlichen Bemerkungen. Neue unveränderte Ausgabe. Innsbruck 1848 [1847].

Standún (2013). Regina Standún: Das österreichische und irische ländliche Volksstück des 20. Jahrhunderts als Ausdruck nationaler Selbstdarstellung auf der Bühne. Ein Vergleich. (Zugl. Diss., Univ. Maynooth 2008). Konstanz 2013 (Germanistik in Ireland, Bd. 2).

Staudenmaier (2012). Peter Staudenmaier: Der deutsche Geist am Scheideweg. Anthroposophen in Auseinandersetzung mit völkischer Bewegung und Nationalsozialismus. In: Uwe Puschner und Clemens Vollnhals (Hg.): Die völkisch-religiöse Bewegung im Nationalsozialismus. Eine Bezie- 
hungs- und Konfliktgeschichte. Göttingen 2012 (Schriften des Hannah-Arendt-Instituts für Totalitarismusforschung, Bd. 47), S. 473-490.

Staudenmaier (2014). Peter Staudenmaier: Between Occultism and Nazism. Anthroposophy and the Politics of Race in the Fascist Era. Leiden, Boston 2014 (Aries Book Series. Texts and Studies in Western Esotericism, Bd. 17).

Steinberg (2000). Michael P. Steinberg: Austria as Theater and Ideology. The Meaning of the Salzburg Festival. With a New Preface. Ithaca N.Y., London 2000 [1990].

Steiner ([1910]). Rudolf Steiner: Das Weihnachtsfest im Wandel der Zeiten. Vortrag gehalten in Berlin am 22. Dezember 1910. Als Manuskript gedruckt. Nach einer vom Vortragenden nicht durchgesehenen Nachschrift. O.O. [1910].

Steiner (1922a). Rudolf Steiner: Von den volkstümlichen Weihnachtsspielen. Eine Christfest-Erinnerung. In: Das Goetheanum. Internationale Wochenschrift für Anthroposophie und Dreigliederung 2 (1922), H. 18/19, S. 137-138.

Steiner (1922b). Rudolf Steiner: Zur Aufführung unserer volkstümlichen Weihnachtspiele. In: Das Goetheanum. Internationale Wochenschrift für Anthroposophie und Dreigliederung 2 (1922), H. 20/21, S. 153-154.

Steiner (1935). Rudolf Steiner: Vier Mysteriendramen. Die Pforte der Einweihung, Die Prüfung der Seele, Der Hüter der Schwelle, Der Seelen Erwachen. Dornach 1935.

Steiner, Marie (1937). Marie Steiner: [o.T., Incipit:] Was Rudolf Steiner durch Karl Julius Schröer so aufnahm. In: Rudolf Steiner: Weihnachtspiele aus altem Volkstum. Eine Christfest-Erinnerung. Dornach 1937, S. 9-12.

Steiner (1937a). Rudolf Steiner: Dr. Rudolf Steiner begrüßt in Dornach am 4. Januar 1917 anläßlich einer Aufführung des Paradeis-Spiels und des Christgeburt-Spiels die deutschen Internierten aus Basel und Bern. In: Rudolf Steiner: Weihnachtspiele aus altem Volkstum. Eine ChristfestErinnerung. Dornach 1937, S. 13-17.

Steiner (1937b). Rudolf Steiner: Weihnachtspiele aus altem Volkstum. Eine Christfest-Erinnerung. Dornach 1937.

Steiner, Marie ([1938]). Marie Steiner: Zum Geleit. In: [Rudolf Steiner]: Weihnachtspiele aus altem Volkstum. Die Oberuferer Spiele. Mit einer Ansprache von Rudolf Steiner und einem Gedenkwort. Hg. von Marie Steiner. Dornach [1938], S. 10-12.

[Steiner] ([1938a]). [Rudolf Steiner]: Das Dreikönigspiel. In: [Rudolf Steiner]: Weihnachtspiele aus altem Volkstum. Die Oberuferer Spiele. Mit einer Ansprache von Rudolf Steiner und einem Gedenkwort. Hg. von Marie Steiner. Dornach [1938], S. 51-76.

[Steiner] ([1938b]). [Rudolf Steiner]: Das Oberuferer Christi-Geburt-Spiel. In: [Rudolf Steiner]: Weihnachtspiele aus altem Volkstum. Die Oberuferer Spiele. Mit einer Ansprache von Rudolf Steiner und einem Gedenkwort. Hg. von Marie Steiner. Dornach [1938], S. 28-50.

[Steiner] ([1938c]). [Rudolf Steiner]: Das Oberuferer Paradeis-Spiel. In: [Rudolf Steiner]: Weihnachtspiele aus altem Volkstum. Die Oberuferer Spiele. Mit einer Ansprache von Rudolf Steiner und einem Gedenkwort. Hg. von Marie Steiner. Dornach [1938], S. 13-27.

[Steiner] ([1938d]). [Rudolf Steiner]: Weihnachtspiele aus altem Volkstum. Die Oberuferer Spiele. Mit einer Ansprache von Rudolf Steiner und einem Gedenkwort. Hg. von Marie Steiner. Dornach [1938].

Steiner (1957). Rudolf Steiner: Weihnachtspiele aus altem Volkstum. Die Oberuferer Spiele. Mitgeteilt von Karl Julius Schröer. Szenisch eingerichtet von Rudolf Steiner. 2., neu durchgesehene und erweiterte Aufl. Dornach 1957.

Steiner (1986). Rudolf Steiner: Ansprachen zu den Weihnachtspielen aus altem Volkstum, gehalten in Dornach 1915 bis 1924 und ein Aufsatz Weihnachten 1922. Hg. von Edwin Froböse. 2. Aufl. Dornach 1986. 
[Steiner] (1991). [Rudolf Steiner]: Weihnachtspiele aus altem Volkstum. Die Oberuferer Spiele. Mitgeteilt von Karl Julius Schröer. Szenisch eingerichtet von Rudolf Steiner. Ausgabe mit zusätzlichen Regieangaben nach der Dornacher Inszenierung. Dornach 1991.

[Steiner] (1997). [Rudolf Steiner]: Die Oberuferer Weihnachtspiele nach Karl Julius Schröer und Rudolf Steiner. Anhand alter Quellen revidierte und ergänzte Fassung. Hg. und kommentiert von Reiner Marks. Dornach 1997.

Steiner (1998). Rudolf Steiner: Vier Mysteriendramen. Die Pforte der Einweihung, Die Prüfung der Seele, Der Hüter der Schwelle, Der Seelen Erwachen. Hg. von der Rudolf Steiner-Nachlaßverwaltung. 5. Aufl. Dornach 1998.

Steiner und Schröer (1998). Rudolf Steiner und Karl Julius Schröer: Von den Oberuferer Weihnachtsspielen und ihrem geistigen Hintergrund. Wortlaute aus Vorträgen und Aufsätze von Rudolf Steiner, Texte von Karl Julius Schröer zu den Oberuferer Spielen, Berichte zu ihrer Aufführungspraxis und weitere Materialien. Ergänzungsband zur Textausgabe der Oberuferer Weihnachtsspiele. Hg. von Reiner Marks. Dornach 1998.

Steinig (2006). Martina Steinig: „Wo man singt, da lass’ dich ruhig nieder ...“. Lied- und Gedichteinlagen im Roman der Romantik. Eine exemplarische Analyse von Novalis' Heinrich von Ofterdingen und Joseph von Eichendorffs Ahnung und Gegenwart. Mit Anmerkungen zu Achim von Arnims Armut, Reichtum, Schuld und Buße der Gräfin Dolores. (Zugl. Diss., Univ. Passau 2005). Berlin 2006 (Literaturwissenschaft, Bd. 3).

Steinsberg (1783). K[arl Franz Guolfinger] von Steinsberg: Otto von Wittelsbach. Trauerspiel in fünf Aufzügen. Mit einem Titelkupfer. Berlin 1783.

Stenzel (im Druck). Julia Stenzel: A Rabbi's Passion, a Hajj's Play. Oberammergau and its Passion Play between Performed History and Histrionic Place. In: Julia Stenzel (Hg.): Re-Enacting Religion. Vom Wiedererzählen und Wiederaufführen ,religiöser‘ Performanzen. (Forum Modernes Theater 29/1, Sonderheft) im Druck.

Stephani (1568). Clemens Stephani: Ein kurtze vnd fast lustige Satyra/ oder Bawrenspil/ mit fünff Personen/ von einer Mülnerin vnd jren Pfarrherr/ Reymen weiß gestellet/ Vnd inn Fünff Actus (Der ein jeglicher nur zwo Scenas hat.) Durch/Clementem Stephanum/ von Buchaw/ vnnd Jnnwoner zu Eger. Nürnberg 1568.

Stern (1965). Martin Stern: Sebastian Sailers „Schöpfung“. Ein Vorspiel zu Goethes Farcen. In: Jahrbuch der Deutschen Schillergesellschaft 9 (1965), S. 131-166.

Stern (1969). Martin Stern: Nachwort. In: Sebastian Sailer: Die Schöpfung. Hg. von Martin Stern. Stuttgart 1969, S. 57-71.

Stern (1986). Martin Stern: Das Festspiel des 19. Jahrhunderts in der Schweiz. In: Jean-Marie Valentin (Hg.): Volk - Volksstück - Volkstheater im deutschen Sprachraum des 18.-20. Jahrhunderts. Akten des mit Unterstützung des Centre National de la Recherche Scientifique veranstalteten Kolloquiums, Nancy, 12.-13. November 1982. Bern, Frankfurt am Main, New York 1986 (Jahrbuch für Internationale Germanistik, Reihe A, Bd. 15), S. 186-208.

Stern (2003). Martin Stern: Konfessionalisierung und Politisierung im Bibeldrama der frühen Neuzeit. In: Colloquium Helveticum. Schweizer Hefte für allgemeine und vergleichende Literaturwissenschaft 34 (2003), S. 81-96.

Stern (2006). Martin Stern: Die Raimund- und Nestroy-Rezeption Hofmannsthals mit einem Seitenblick auf Josef Nadler, Heinz Kindermann und Herbert Cysarz. In: Hofmannsthal-Jahrbuch. Zur europäischen Moderne 14 (2006), S. 369-381.

Sternschutz ([1772]). Johann von Sternschutz: Karl der fünfte in Afrika, ein heroisches Trauerspiel, in fünf Aufzügen. Aufgeführt auf der kaiserlich-königlichen Schaubühne 1772. [Wien] [1772].

Steub (1846). Ludwig Steub: Drei Sommer in Tirol. München 1846.

Stollberg und Böker (2013). Jochen Stollberg und Wolfgang Böker (Hg.): „,... die Kunst zu sehn“. Arthur Schopenhauers Mitschriften der Vorlesungen Johann Friedrich Blumenbachs (1809- 
1811). Mit einer Einführung von Marco Segala. Göttingen 2013 (Schriften zur Göttinger Universitätsgeschichte, Bd. 3).

Stommer (1985). Rainer Stommer: Die inszenierte Volksgemeinschaft. Die „Thing-Bewegung“ im Dritten Reich. (Zugl. Diss., Univ. Bochum 1980). Marburg 1985.

Storch (1794). Heinrich Storch: Gemählde von St. Petersburg. Zweiter Theil. Riga 1794.

Straeter (2001). Michael Straeter: Die ,volkstümliche“ Gestaltung deutscher volkssprachlicher Weihnachtsspiele des Mittelalters. In: Leuvense Bijdragen - Leuven Contributions in Linguistics and Philology 90 (2001), S. 263-295.

Streitfeld (2003). Erwin Streitfeld: Schröer, Karl Julius. In: IGL, S. 1667-1670.

Strohschneider (2016). Peter Strohschneider: Das neue Alte. Museum und Archiv, Sammeln und Forschen. In: Jahrbuch der Deutschen Schillergesellschaft 60 (2016), S. 635-651.

Stumme (1957). Gerhard Stumme: Meine Faust-Sammlung. Bearbeitet von Hans Henning. Weimar 1957 (Jahresgabe der Nationalen Forschungs- und Gedenkstätten der klassischen deutschen Literatur in Weimar).

Stumpfl (1930). Robert Stumpfl: Schauspielmasken des Mittelalters und der Renaissancezeit und ihr Fortbestehen im Volksschauspiel. Mit 10 Abbildungen. In: Neues Archiv für Theatergeschichte 2 (1930), S. 1-78.

Stumpfl (1933). Robert Stumpfl: Das alte Schultheater in Steyr im Zeitalter der Reformation und Gegenreformation. Ein Beitrag zur Literatur- und Theatergeschichte Oesterreichs. Linz 1933.

Stumpfl (1934). Robert Stumpfl: Der Ursprung des Fastnachtspiels und die kultischen Männerbünde der Germanen. In: Zeitschrift für Deutschkunde 48 (1934), S. 286-297.

Stumpfl (1936). Robert Stumpfl: Kultspiele der Germanen als Ursprung des mittelalterlichen Dramas. Berlin 1936.

Stumpfl (1937). Robert Stumpfl: Das Fortleben germanischer Kultspiele im Volksbrauch. Das Dreikönigs- oder Sternsingen. In: Zeitschrift für Deutschkunde 51 (1937), S. 253-266.

Sulzer (1775). Johann George Sulzer: Allgemeine Theorie der Schönen Künste in einzeln, nach alphabetischer Ordnung der Kunstwörter auf einander folgenden, Artikeln abgehandelt. Zweyter Theil. Leipzig 1775.

Sulzer (1780). Johann George Sulzer: Tagebuch einer von Berlin nach den mittäglichen Ländern von Europa in den Jahren 1775 und 1776 gethanen Reise und Rückreise. Leipzig 1780.

Sulzer (1794). Johann George Sulzer: Allgemeine Theorie der Schönen Künste in einzeln, nach alphabetischer Ordnung der Kunstwörter auf einander folgenden, Artikeln abgehandelt. Vierter Theil. Neue vermehrte zweyte Auflage. Leipzig 1794 [1774].

Suppan (1978). Wolfgang Suppan: Volkslied. Seine Sammlung und Erforschung. 2., durchgesehene und ergänzte Aufl. Stuttgart 1978 (Sammlung Metzler, Abteilung E: Poetik, Bd. 52).

Suttner (1997). Sabine Suttner: Die Darstellung der Bayern im ,Komödienstadel'. Germanistische, volkskundliche und psychologische Untersuchung eines Fernseh-Bauerntheaters. (Zugl. Diss., Univ. Regensburg 1996). Frankfurt am Main u.a. 1997 (Regensburger Beiträge zur deutschen Sprach- und Literaturwissenschaft, Reihe B, Bd. 66).

Szarota (1979-1987). Elida Maria Szarota: Das Jesuitendrama im deutschen Sprachgebiet. Eine Periochenedition. Texte und Kommentare. 4 Bände. München 1979-1987.

Taube (1995). Gerd Taube: Puppenspiel als kulturhistorisches Phänomen. Vorstudien zu einer „Sozial- und Kulturgeschichte des Puppenspiels“. (Zugl. Diss., Humboldt-Univ. zu Berlin 1993). Tübingen 1995 (Theatron, Bd. 14).

Temme (1839). J[odocus] D[onatus] H[ubertus] Temme: Die Volkssagen der Altmark. Mit einem Anhange von Sagen aus den übrigen Marken und aus dem Magdeburgischen. Berlin 1839.

Temme (1840). J[odocus] D[onatus] H[ubertus] Temme: Die Volkssagen von Pommern und Rügen. Berlin 1840. 
Thurnher (1976). Eugen Thurnher: Möglichkeiten und Aufgaben des Volksschauspieles in Vergangenheit und Gegenwart. In: Egon Kühebacher (Hg.): Tiroler Volksschauspiel. Beiträge zur Theatergeschichte des Alpenraumes. Im Auftrag des Südtiroler Kulturinstitutes und des Bundes Südtiroler Volksbühnen. Bozen 1976 (Schriftenreihe des Südtiroler Kulturinstitutes, Bd. 3), S. 21-34.

[Tieck] (1797). [Ludwig Tieck]: Volksmährchen herausgegeben von Peter Leberecht. 3 Bände. Berlin 1797.

Tieck (1817). Ludwig Tieck (Hg.): Deutsches Theater. 2 Bände. Berlin 1817.

Tigges, Pewny und Deutsch-Schreiner (2010). Stefan Tigges, Katharina Pewny und Evelyn DeutschSchreiner (Hg.): Zwischenspiele. Neue Texte, Wahrnehmungs- und Fiktionsräume in Theater, Tanz und Performance. Bielefeld 2010.

Tilg (2008). Stefan Tilg: Die Entwicklung des Jesuitendramas vom 16. bis zum 18. Jahrhundert. Eine Fallstudie am Beispiel Innsbruck. In: Reinhold F. Glei und Robert Seidel (Hg.): Das lateinische Drama der Frühen Neuzeit. Exemplarische Einsichten in Praxis und Theorie. Tübingen 2008 (Frühe Neuzeit, Bd. 129), S. 183-199.

Tille ([1890]). Alexander Tille: Doktor Johann Faust. Volksschauspiel vom Plagwitzer Sommertheater. Nach der Bühnenhandschrift der J. Dreßlerschen Truppe herausgegeben und mit den übrigen Volksschauspielen von Faust verglichen. Oldenburg, Leipzig [1890] (Deutsche Puppenkomödien, Ergänzung der Engel'schen Sammlung, Bd. 10).

Toscano Del Banner (1849). Jos[eph] G[eorg] Toscano Del Banner: Die deutsche Nationalliteratur der gesammten Länder (sowohl der heutigen wie der jeweilig dazu gehörigen) der österreichischen Monarchie von den ältesten Zeiten bis zur Gegenwart, historisch-chronologisch dargestellt. Erster Band: Das Mittelalter. Wien 1849.

Trabusch und Zipfel (2009). Markus Trabusch und Frank Zipfel: Volksstück. In: Dieter Lamping (Hg.): Handbuch der literarischen Gattungen. In Zusammenarbeit mit Sandra Poppe, Sascha Seiler und Frank Zipfel. Stuttgart 2009, S. 751-761.

Trappen (2001). Stefan Trappen: Gattungspoetik. Studien zur Poetik des 16. bis 19. Jahrhunderts und zur Geschichte der triadischen Gattungslehre. (Zugl. Habil., Univ. Mainz 1998). Heidelberg 2001 (Beihefte zum Euphorion, Bd. 40).

Tröge (1934a). Walther Tröge: Bauernland in Flammen. Freilichtspiel aus der Zeit des Bauernaufstandes 1525 in 4 Bildern. Weimar 1934 (Veröffentlichungen der Landesbauernschaft Thüringen, Hauptabteilung 1$)$.

Tröge (1934b). Walther Tröge: D'r schwarze Hans vun Kerspleben. Bauernspiel in Thüringer Mundart aus der Zeit der Bauernerhebung 1525 in 3 Bildern. Weimar 1934.

Tschackert (1894). P[aul] Tschackert: Teller, Wilhelm Abraham. In: ADB. Bd. 37 (1894), S. 556-558.

Turk (1992). Horst Turk: Von der Volkskomödie zum sozialen Drama. Ein Problem der Übersetzung. In: Ursula Hassel und Herbert Herzmann (Hg.): Das zeitgenössische deutschsprachige Volksstück. Akten des internationalen Symposions, University College Dublin, 28. Februar-2. März 1991. Tübingen 1992 (Stauffenburg Colloquium, Bd. 23), S. 35-64.

Tvrdík (2010). Milan Tvrdík: Das Wiener Volksstück und die tschechische Dramatik vor 1848. In: Daniel Fulda, Antje Roeben und Norbert Wichard (Hg.): „Kann man denn auch nicht lachend sehr ernsthaft sein?" Sprachen und Spiele des Lachens in der Literatur. Berlin, New York 2010, S. 105-114.

Uhland (1844-1845). Johann Ludwig Uhland: Alte hoch- und niederdeutsche Volkslieder mit Abhandlung und Anmerkungen herausgegeben. 2 Abteilungen. Stuttgart, Tübingen 1844-1845.

Unger (1995). Thorsten Unger: Omnia vincit Amor zum Mitlachen. Funktionen der Komik in frühen Übersetzungen von Love's Labour's Lost (Lenz, Eschenburg). In: Thorsten Unger, Brigitte Schultze und Horst Turk (Hg.): Differente Lachkulturen? Fremde Komik und ihre Übersetzung. Tübingen 1995 (Forum Modernes Theater, Bd. 18), S. 209-242. 
Urbach (1973). Reinhard Urbach: Die Wiener Komödie und ihr Publikum. Stranitzky und die Folgen. Wien, München 1973.

Valentin (1986). Jean-Marie Valentin (Hg.): Volk - Volksstück - Volkstheater im deutschen Sprachraum des 18.-20. Jahrhunderts. Akten des mit Unterstützung des Centre National de la Recherche Scientifique veranstalteten Kolloquiums, Nancy, 12.-13. November 1982. Bern, Frankfurt am Main, New York 1986 (Jahrbuch für Internationale Germanistik, Reihe A, Bd. 15).

Valentin (1988). Jean-Marie Valentin: Theatralische Paradigmen und Konventionen im österreichischen Volkstheater (Anfang des 18.-Ende des 19. Jahrhunderts). Eine provisorische Bilanz. In: Jean-Marie Valentin (Hg.): Das österreichische Volkstheater im europäischen Zusammenhang 1830-1880. Akten des vom Centre de Recherches Germaniques (R.C.P. 666, Paris, des Centre National de la Recherche Scientifique) veranstalteten Kolloquiums, Dezember 1984. Bern u.a. 1988 (Contacts 1, Theatrica, Bd. 5), S. 5-12.

van der Pals (1986). Leopold van der Pals: Erinnerungen eines Musikers aus den Anfängen der Weihnachtspiele [1948]. In: Rudolf Steiner: Ansprachen zu den Weihnachtspielen aus altem Volkstum, gehalten in Dornach 1915 bis 1924 und ein Aufsatz Weihnachten 1922. Hg. von Edwin Froböse. 2. Aufl. Dornach 1986, S. 110-112.

van der Zande (1998). Johan van der Zande: Johann Georg Sulzer’s Allgemeine Theorie der Schönen Künste. In: Das achtzehnte Jahrhundert 22 (1998), H. 1, S. 87-101.

van Eyck (1935). Herbert Adam van Eyck: Deutsches Bauernspiel. Leipzig 1935 (Bausteine für Fest und Feier der deutschen Jugend, Bd. 5).

Vancsa (1972). Kurt Vancsa: Hoffmann, Leopold Alois. In: NDB. Bd. 9 (1972), S. 433-434.

Venzl (2019). Tilman Venzl: „Itzt kommen die Soldaten“. Studien zum deutschsprachigen Militärdrama des 18. Jahrhunderts. (Zugl. Diss., Univ. Stuttgart 2016). Frankfurt am Main 2019 (Das Abendland, N.F., Bd. 43).

Vermeiren (2016). Jan Vermeiren: The First World War and German National Identity. The Dual Alliance at War. Cambridge 2016 (Studies in the social and cultural history of modern warfare). Vischer (1867). Wilhelm Vischer: Die Sage von der Befreiung der Waldstädte nach ihrer allmälichen Ausbildung. Nebst einer Beilage: Das älteste Tellenschauspiel. Leipzig 1867.

Volke (1974). Werner Volke: Hugo von Hofmannsthal und Josef Nadler in Briefen. In: Jahrbuch der Deutschen Schillergesellschaft 18 (1974), S. 37-88.

Voßkamp (1985). Wilhelm Voßkamp: Kontinuität und Diskontinuität. Zur deutschen Literaturwissenschaft im Dritten Reich. In: Peter Lundgreen (Hg.): Wissenschaft im Dritten Reich. Frankfurt am Main 1985, S. 140-162.

Wacker (1985). Manfred Wacker (Hg.): Sturm und Drang. Darmstadt 1985 (Wege der Forschung, Bd. 559).

Wackernell (1887). J[oseph] E[duard] Wackernell: Die ältesten Passionsspiele in Tirol. Wien 1887 (Wiener Beiträge zur deutschen und englischen Philologie, Bd. 2).

Wackernell (1897). J[oseph] E[duard] Wackernell: Altdeutsche Passionsspiele aus Tirol mit Abhandlungen über ihre Entwicklung, Composition, Quellen, Aufführungen und litterarhistorische Stellung. Graz 1897 (Quellen und Forschungen zur Geschichte, Litteratur und Sprache Österreichs und seiner Kronländer, Bd. 1).

Wagenknecht (1989). Christian Wagenknecht (Hg.): Zur Terminologie der Literaturwissenschaft. Akten des IX. Germanistischen Symposions der Deutschen Forschungsgemeinschaft Würzburg 1986. Stuttgart 1989 (Germanistische Symposien, Berichtsbände, Bd. 9).

Wagner (1873). Hermann Wagner: Der Unterricht im Deutschen mit Rücksicht auf die österreichische Mundart. Ein Versuch. (Aus dem Jahresberichte der Kommunal-Oberrealschule Rossau in Wien). Wien 1873.

Wagner (1882a). Hermann F. Wagner: Das Volksschauspiel in Salzburg. Salzburg 1882.

Wagner (1882b). H[ermann] F. Wagner: Die Volksdichtung in Salzburg. Salzburg 1882. 
Wagner (1890). Hermann F. Wagner: Das Schuldrama in Salzburg. Salzburg 1890.

Wagner (1908). Hermann Wagner: Die mundartliche Dichtung in Salzburg. Salzburg 1908.

Warstat (2005). Matthias Warstat: Theatrale Gemeinschaften. Zur Festkultur der Arbeiterbewegung 1918-33. (Zugl. Diss., Freie Univ. Berlin 2002). Tübingen, Basel 2005 (Theatralität, Bd. 9).

Wąsik (2015). Monika Wąsik: Rückkehr des Volksstücks? Das neueste deutschsprachige Drama in Gegenüberstellung mit der Tradition des Volksstücks. In: Katarzyna Grzywka-Kolago, Lech Kolago, Maciej Jędrzejewski und Robert Małecki (Hg.): Karły na ramionach olbrzymów? Kultura niemieckiego obszaru językowego w dialogu z tradycją. Band 1. Warschau 2015, S. 91-101.

Wedel-Wolff (1982). Annegret von Wedel-Wolff: Geschichte der Sammlung und Erforschung des deutschsprachigen Volkskinderliedes und Volkskinderreimes im 19. Jahrhundert. (Zugl. phil. Diss., Univ. Freiburg im Breisgau 1981). Göppingen 1982 (Göppinger Arbeiten zur Germanistik, Bd. 339).

Weech (1891). [Friedrich] von Weech: Schreiber, Alois Wilhelm. In: ADB. Bd. 32 (1891), S. 471.

Weigel (1989). Harald Weigel: „Nur was du nie gesehn wird ewig dauern“. Carl Lachmann und die Entstehung der wissenschaftlichen Edition. (Zugl. Diss., Univ. Freiburg im Breisgau 1986). Freiburg im Breisgau 1989 (Rombach Wissenschaft, Reihe Litterae).

Weinhold (1853). Karl Weinhold: Weihnacht-Spiele und Lieder auß Süddeutschland und Schlesien. Mit Einleitungen und Erläuterungen. Mit einer Musikbeilage. [Graz] 1853.

Weinhold (1870). Karl Weinhold: Weihnacht-Spiele und Lieder aus Süddeutschland und Schlesien. Mit Einleitungen und Erläuterungen. Mit einer Musikbeilage. Neue Ausgabe. Graz 1870.

Weinhold (1875). Karl Weinhold: Weihnacht-Spiele und Lieder aus Süddeutschland und Schlesien. Mit Einleitungen und Erläuterungen. Mit einer Musikbeilage. Neue Ausgabe. Wien 1875.

Weinhold (1967). Karl Weinhold: Weihnacht-Spiele und Lieder aus Süddeutschland und Schlesien. [Nachdruck der Ausgabe 1875]. Wiesbaden 1967.

Weiß (2008). Wolfgang Weiß: Shakespeare in Bayern - und auf Bairisch. Passau 2008.

Weiß (2017). Volker Weiß: Die autoritäre Revolte. Die Neue Rechte und der Untergang des Abendlandes. Stuttgart 2017.

Weissert (1966). Gottfried Weissert: Das Mildheimische Liederbuch. Studien zur volkspädagogischen Literatur der Aufklärung. Tübingen 1966 (Volksleben, Bd. 15).

Weller (1854). Emil Weller: Neue Original-Poesieen Johann Fischarts. Hg. und mit einer literarhistorischen Einleitung und neuen Aufschlüssen über J. Fischart versehen. Halle 1854.

Weller (1858). Emil Weller: Die Lieder des Dreissigjährigen Krieges nach den Originalen abgedruckt. Zum ersten Male gesammelt. Mit einer Einleitung von W[ilhelm] Wackernagel. 2. Aufl. Basel 1858 [1855].

Weller (1858-1861). Emil Weller: Die falschen und fingierten Druckorte. Repertorium der seit Erfindung der Buchdruckerkunst unter falscher Firma erschienenen Schriften. 3 Bände. Leipzig 1858-1861.

Weller (1862-1864). Emil Weller: Annalen der Poetischen National-Literatur der Deutschen im XVI. und XVII. Jahrhundert. Nach den Quellen bearbeitet. 2 Bände. Freiburg im Breisgau 1862-1864.

Weller (1863). Emil Weller: Das alte Volks-Theater der Schweiz. Nach den Quellen der Schweizer und süddeutschen Bibliotheken bearbeitet von Emil Weller. Frauenfeld 1863.

Weller (1867). Emil Weller: Index Pseudonymorum. Wörterbuch der Pseudonymen oder Verzeichniss aller Autoren, die sich falscher Namen bedienten. 3. Aufl. Glauchau, Leipzig 1867 [1855].

Werle (2014). Dirk Werle: Ruhm und Moderne. Eine Ideengeschichte (1750-1930). (Zugl. Habil., Univ. Leipzig 2012). Frankfurt am Main 2014 (Das Abendland, N.F., Bd. 38).

Werner (1891). Richard Maria Werner: Der Laufner Don Juan. Ein Beitrag zur Geschichte des Volksschauspiels. Hamburg, Leipzig 1891 (Theatergeschichtliche Forschungen, Bd. 3).

Werner (1999). Uwe Werner: Anthroposophen in der Zeit des Nationalsozialismus (1933-1945). Unter Mitwirkung von Christoph Lindenberg. München 1999. 
Wertheimer (1920). Paul Wertheimer (Hg.): Alt-Wiener Theater. Schilderungen von Zeitgenossen. Wien 1920.

Wetmore (2017). Kevin J. Wetmore, Jr. (Hg.): The Oberammergau Passion Play. Essays on the 2010 Performance and the Centuries-Long Tradition. Jefferson, NC 2017.

Wetzels (1990). Walter D. Wetzels: The Herder-Nicolai Controversy. In: Wulf Koepke (Hg.): Johann Gottfried Herder. Language, History, and the Enlightenment. Columbia, SC 1990 (Studies in German Literature, Linguistics, and Culture, Bd. 52), S. 87-97.

[Wickart] (1746). [Michael Wickart]: Bullarium Ordinis FF. Minorum S.P. Francisci Capucinorum seu Collectio Bullarum, Brevium, Decretorum, Rescriptorum, \& Oraculorum \&c. quae à S. Sede Apostolica pro Ordine Capucino emanârunt [...] Variis Notis \& Scholiis elucubrata A P.F. Michaele a Tugio in Helvetia. Tomus Quartus. Romae 1746.

Wieland (1883-1887). Christoph Martin Wieland: Wielands Werke. 6 Bände. Hg. von Heinrich Pröhle. Berlin, Stuttgart 1883-1887 (Deutsche National-Litteratur, historisch kritische Ausgabe, Bd. 51-56).

Wietschorke und Schmidt-Lauber (2016). Jens Wietschorke und Brigitta Schmidt-Lauber (Hg.): „Volkskultur“ 2.0. Themenheft der Österreichischen Zeitschrift für Geschichtswissenschaften 27 (2016), H. 2.

Wild (2012). Gabriele Wild: 30 Jahre Theater für das „Volk“?! Die Tiroler Volksschauspiele Telfs im Spiegel der Medien und eine Suche nach dem Begriff des Volksschauspiels. In: Mitteilungen aus dem Brenner-Archiv 31 (2012), S. 201-218.

Wildt (2017). Michael Wildt: Volk, Volksgemeinschaft, AfD. Hamburg 2017.

Wirthensohn (2016). Simon Wirthensohn: Anton Claus. Leben und Werk. Studie zum späten Jesuitentheater. Innsbruck: Universität Innsbruck 2016. http://diglib.uibk.ac.at/urn:nbn:at:at-ubi:1-4559 (26.3.2019).

Woesler (1989). Winfried Woesler: Die Idee der deutschen Nationalliteratur in der zweiten Hälfte des 18. Jahrhunderts. In: Klaus Garber (Hg.): Nation und Literatur im Europa der Frühen Neuzeit. Akten des I. Internationalen Osnabrücker Kongresses zur Kulturgeschichte der Frühen Neuzeit. Tübingen 1989 (Frühe Neuzeit, Bd. 1), S. 716-733.

Wolf (2011). Norbert Christian Wolf: Ordnungsutopie oder Welttheaterschwindel? Hofmannsthals Salzburger Festspielkonzepte in ihrem kultur- und ideologiegeschichtlichen Kontext. In: Hofmannsthal-Jahrbuch 19 (2011), S. 217-254.

Wolf (2014). Norbert Christian Wolf: Eine Triumphpforte österreichischer Kunst. Hugo von Hofmannsthals Gründung der Salzburger Festspiele. Salzburg, Wien 2014.

Wolf (2016). Norbert Christian Wolf: ,In seiner Kitschigkeit und Verlogenheit nicht mehr zu überbieten“. Zum Österreich-Kitsch in Elfriede Jelineks Posse Burgtheater. In: Kathrin Ackermann und Christopher F. Laferl (Hg.): Kitsch und Nation. Zur kulturellen Modellierung eines polemischen Begriffs. Bielefeld 2016 (Edition Kulturwissenschaft, Bd. 60), S. 65-97.

Wolfram (1933). Richard Wolfram: Ernst Moritz Arndt und Schweden. Zur Geschichte der deutschen Nordsehnsucht. (Zugl. Diss., Univ. Wien 1926). Weimar 1933 (Forschungen zur neueren Literaturgeschichte, Bd. 65).

Wolfram (1987). Richard Wolfram: Südtiroler Volksschauspiele und Spielbräuche. Wien 1987 (Österreichische Akademie der Wissenschaften, Philosophisch-Historische Klasse, Bd. 480).

Wolfram (2010). Ilse Wolfram: 200 Jahre Volksheld Andreas Hofer auf der Bühne und im Film. (Zugl. Diss., Univ. München 2009). München 2010 (Münchener Universitätsschriften Theaterwissenschaft, Bd. 16).

Woller (1936). Roswitha von Woller: Im Namen Gottes. Ein Bauernspiel aus dem Dreißigjährigen Krieg in sieben Bildern. Halle (Saale) 1936. 
Wyss (1995). Ulrich Wyss: Literaturlandschaft und Literaturgeschichte. Am Beispiel Rudolf

Borchardts und Josef Nadlers. In: Hartmut Kugler (Hg.): Interregionalität der deutschen Literatur im europäischen Mittelalter. Berlin, New York 1995, S. 45-63.

Wyss (1997). Ulrich Wyss: Rudolf Borchardt und Josef Nadler. In: Ernst Osterkamp (Hg.): Rudolf Borchardt und seine Zeitgenossen. Berlin, New York 1997 (Quellen und Forschungen zur Literatur- und Kulturgeschichte, Bd. 10), S. 113-131.

Yates (2008). W. Edgar Yates: Karl Kraus, Otto Rommel, and editing Nestroy. In: Germanistik in Ireland, Yearbook of the Association of Third-Level Teachers of German in Ireland (GiL) 3 (2008), S. 121-129.

Yates und Tanzer (2006). W. Edgar Yates und Ulrike Tanzer: Theater und Gesellschaft im Wien des 19. Jahrhunderts. Zur Einführung. In: W. Edgar Yates und Ulrike Tanzer (Hg.): Theater und Gesellschaft im Wien des 19. Jahrhunderts. Ausgewählte Aufsätze zum 25-jährigen Bestehen der Zeitschrift Nestroyana. Wien 2006 (Quodlibet. Publikationen der Internationalen NestroyGesellschaft, Bd. 8), S. 7-18.

Young (1920). Karl Young: The Dramatic Associations of the Easter Sepulchre. Madison 1920 (University of Wisconsin Studies in Language and Literatrure, Bd. 10).

Young (1933). Karl Young: The Drama of the Medieval Church. 2 Bände. Oxford 1933.

Zeman (1986). Herbert Zeman: Die Alt-Wiener Volkskomödie des 18. und frühen 19. Jahrhunderts ein gattungsgeschichtlicher Versuch. In: Herbert Zeman (Hg.): Die österreichische Literatur. Ihr Profil von den Anfängen im Mittelalter bis ins 18. Jahrhundert (1050-1750). Unter Mitwirkung von Fritz Peter Knapp. Teil 2. Graz 1986, S. 1299-1333.

Zille (1908). Heinrich Zille: Kinder der Straße. 100 Berliner Blätter. Berlin 1908.

[Zille] (1913a). [Heinrich Zille]: Hurengespräche. Gehört, geschrieben und gezeichnet von W. Pfeifer. Berlin 1913.

Zille (1913b). Heinrich Zille: „Mein Milljöh“. Neue Bilder aus dem Berliner Leben. Mit einem Vorwort von Georg Hermann. Berlin 1913.

Zingerle (1877). Ignaz V[inzenz] Zingerle: Bauernspiele in Tirol [1863]. In: Ignaz V[inzenz] Zingerle: Schildereien aus Tirol. Innsbruck 1877, S. 42-71.

Zingerle und Zingerle (1852). [Ignaz] Zingerle und [Joseph] Zingerle: Kinder- und Hausmärchen gesammelt durch die Brüder Zingerle. Innsbruck 1852.

Zingerle und Zingerle (1854). Ignaz Zingerle und Joseph Zingerle: Kinder- und Hausmärchen aus Süddeutschland. Gesammelt und herausgegeben durch die Brüder Ignaz und Joseph Zingerle. Mit einer Einleitung von J[ohann] W[ilhelm] Wolf. Mit einem Titelbilde. Regensburg 1854 (Tirols Volksdichtungen und Volksgebräuche, Bd. 2).

Ziska und Schottky (1819). Franz Ziska und Julius Max Schottky: Oesterreichische Volkslieder mit ihren Singeweisen, gesammelt und herausgegeben. Pesth 1819.

Zittel und Holona (2008). Claus Zittel und Marian Holona (Hg.): Positionen der Jelinek-Forschung. Beiträge zur Polnisch-Deutschen Elfriede Jelinek-Konferenz Olsztyn 2005. Bern u.a. 2008 (Jahrbuch für Internationale Germanistik, Reihe A, Bd. 74).

Zuckmayer (1930). Carl Zuckmayer: Der Hauptmann von Köpenick. Ein deutsches Märchen in drei Akten. Berlin 1930.

Zymner (2003). Rüdiger Zymner: Gattungstheorie. Probleme und Positionen der Literaturwissenschaft. Paderborn 2003.

Zymner (2010). Rüdiger Zymner (Hg.): Handbuch Gattungstheorie. Stuttgart, Weimar 2010. 
